\title{
5
}

\section{US TELECOMMUNICATIONS LAW}

Karen Lee and Jamison Prime

5.1 Introduction

5.2 Regulatory Law and Policy: History and Developments

188

5.3 Overview of Key US Regulatory Bodies and

Procedural Principles

5.4 Federal Bodies

208

5.5 State Bodies

213

5.6 Procedural Principles and Mechanisms: The Administrative Procedure Act and Administrative Law Principles 214

5.7 The Pre-Emption Doctrine and FCC Jurisdiction

5.8 Licensing

5.9 Spectrum Management

5.10 Access, Interconnection, and Related Measures

5.11 Universal Service Obligations (USOs)

5.12 Competition Law

5.13 Communications Privacy 257

5.14 Concluding Remarks 273

\subsection{INTRODUCTION}


This chapter focuses on the regulation of the provision of telecommunication services and the operation of telecommunication networks in the US. It begins by giving a brief history of the American approach to the regulation of switched, cable, wireless, satellite, broadband, and IP networks and services. It then provides an overview of the numerous governmental bodies involved in the regulation of the US telecommunications market. It summarizes the licensing requirements under the Communications Act of 1934, and briefly explains the US approach to certain key regulatory issues: access, interconnection and related measures, including network neutrality, spectrum management, universal service, the application of competition law to the sector, and communications privacy.

\subsection{REGULATORY LAW AND POLICY: HISTORY}

\section{AND DEVELOPMENTS}

The Communications Act of 1934 (1934 Act) established the Federal Communications Commission (FCC), ${ }^{1}$ the primary communications regulatory body in the US, and thus is seen as the starting point of modern federal communications regulation. Since the adoption of the 1934 Act, the FCC has remained a constant. However, the regulatory policies Congress has required the FCC to implement and the initiatives the agency has pursued to achieve them have evolved. Despite a brief period of intensive competition between network operators in the late 1890 s, the provision of telephony service was seen as a natural monopoly when the FCC was created. Telephony service was provided solely by AT\&T, a privately-owned company, using the public switched tele-

\footnotetext{
${ }^{1}$ For a discussion of the FCC's powers, see Section 5.4.1.
} 
phone network (PSTN). However, the development of new microwave technology in the 1960s triggered a period of market liberalization and deregulation which culminated in the adoption of the Telecommunications Act of 1996 (1996 Act). ${ }^{2}$ The FCC now seeks to encourage vigorous competition in all markets for telecommunications services and between all modes of service delivery, including cable, wireless, and satellite. Nevertheless, it continues to regulate networks and services in a technology-specific way, despite the increasing level of convergence of network systems brought about by the invention of IP technology. The purpose of this section is to explain the development and evolution of the regulatory frameworks for switched, cable, wireless and satellite systems and to show how their legacies continue to influence the FCC's approach to broadband and IP.

\subsubsection{Switched networks}

\subsubsection{Pre-Communications Act of 1934}

Evolution of the Bell network Until its patents expired in 1893-4, the Bell Company (Bell) - the company founded by Alexander Graham Bell, the inventor of the telephone, and later known as AT\&T—monopolized the telephony market. Thereafter competition flourished for about a decade. At one stage, independent companies provided up to half of the telephone stations in local areas. However, absent an obligation for Bell to interconnect with the independents, the competition which existed was inefficient. It was not unusual for businesses to subscribe to two or more local telephone networks utilizing separate lines and equipment. Bell,

2 Pub L No 104-104, 110 Stat 56 (8 February 1996) (codified at 47 USC §§251-261, 271-276, 336, 363, 571-573, 549, $613,160-161,660-561,230,232,614$, and at 15 USC $\S 79 z-5 c)$. 
meanwhile, successfully reorganized into a vertically integrated company, making use of its patented technology which significantly improved the sound quality of long-distance calls, and began to acquire independent phone companies at a rapid pace.

Initial federal regulation In response to calls to halt the rise of AT\&T and cease the unnecessary duplication of infrastructure, Congress enacted the Mann-Elkins Act ${ }^{3}$ in 1910, which marked the start of telephony regulation at the federal level. Prior to the Mann-Elkins Act, the states were largely responsible for it. Modelled on the Interstate Commerce Commission Act of 1877 which governed railroads, the Act gave the Interstate Commerce Commission (ICC) the power to regulate telecommunications providers as 'common carriers ${ }^{4}$ which were required to 'provide service on request at just and reasonable rates without unjust discrimination or undue preference'. The ICC had the power to set aside 'unjust and unreasonable' rates of common carriers providing communications services but lacked the authority to require them to file tariffs or interconnect their networks, thus greatly hindering its ability to regulate them effectively.

The Kingsbury Commitment In 1913, in response to the threat of federal anti-trust litigation by the Department of Justice, AT\&T agreed to the Kingsbury Commitment pursuant to which it would interconnect with the independent phone companies and stop buying its competitors. However, the agreement did little to prevent AT\&T's growth. Exploiting loopholes in the agreement, it continued to acquire local phone systems and eliminate competition. In addition to having a monopoly in local and long-distance telephone infrastructure, AT\&T dominated equipment manufacture through its Western Electric unit and communications research via Bell

${ }_{3}^{3}$ Mann-Elkins Act (18 June 1910, ch 309, 36 Stat 539).

${ }^{4}$ See Section 5.8.1 for the meaning of 'common carrier'. 
Telephone Laboratories. By the time of the adoption of the 1934 Act, regulators had concluded that the telephone was a natural monopoly that was best served by a single firm. AT\&T, with its local operating companies and long-distance lines, appeared to be that firm.

\subsubsection{The evolution of competition: 1950-1996}

Long-distance competition For decades after the passage of the 1934 Act, the FCC allowed AT\&T to retain its monopoly on telecommunications in order to secure the goal of securing a 'rapid, efficient, Nation-wide and worldwide . . communication service with adequate facilities at reasonable charges . ..' In turn, AT\&T subsidized the cost of line rentals and free local calls by charging heavy mark-ups on national and international calls. However, in 1969, when the FCC granted a licence to Microwave Communications, Inc (MCI) to install and operate microwave facilities that enabled limited inter-office communications, competition for telephony services began. Two years later, in its Specialized Common Carrier decision (Decision in MCI Telecommunications Corp, 60 FCC 2d 25 (July 13, 1976)), the FCC determined MCI and others could compete with AT\&T for long-distance business customers. Following a 1977 decision of the United States Court of Appeals for the District of Columbia (the DC Circuit Court) overturning an FCC order requiring MCI to cease operation of its Execunet division, competitors were permitted to offer interstate long-distance services to the public (MCI Telecommunications Corp v FCC, 561 F 2d 365 (DC Cir 1977)). In 1978, the same court ruled that new entrants were legally entitled to interconnect with AT\&T (MCI Telecommunications Corp v FCC, 580 F 2d 590 (DC Cir 1978)). Subsequently, the FCC reviewed the charges interstate common carriers paid to local exchange operators to terminate long-distance calls and adopted a number of measures forcing AT\&T to begin rebalancing its tariffs in line with costs to remove the market distortions and artificial arbitrage opportunities which arose as a result of the subsidization of local services. 
Divestiture of AT\&T and the modification of final judgment In 1974, the Department of Justice brought a suit against AT\&T, Western Electric, and Bell Telephone Laboratories, Inc alleging that the monopolies held by the defendants in several telecommunications service areas and equipment manufacturing violated the Sherman Anti-trust Act. ${ }^{5}$ The case was pending for eight years until Judge Harold Greene of the DC Circuit Court entered the Modification of Final Judgment (MFJ), which slightly modified divestiture provisions voluntarily agreed to by the parties (US v AT\&T Corp, 552 F Supp 131 (DC Cir 1982), aff'd sub nom Maryland v US, 460 US 1001 (1983)). The MFJ ordered AT\&T to divest itself of its 22 Regional Bell Operating Companies (RBOCs), which resulted in the separation of local and interexchange (long-distance) markets, and established procedures for the implementation of divestiture.

Under the provisions of the MFJ, the 22 RBOCs, which by 2011 had been consolidated into three main holding companies-AT\&T, CenturyLink, and Verizon—would provide communication in 'exchange areas' (also known as local access and transport areas (LATAs)). Exchange areas referred to a geographic area that encompassed one or more contiguous local exchange areas serving common social, economic, and other purposes. Within these exchange areas, RBOCs could originate and terminate calls but were prohibited from providing interexchange telecommunication services and information services (see Section 5.2.5). The original settlement provisions sought to restrict the manufacture and provision of customer premises equipment but the MFJ allowed RBOCs to market equipment once they divested from AT\&T.

The MFJ also sought to ensure that all interexchange service providers (eg MCI and Sprint) obtained equal access to RBOC services. The judgment imposed a duty on local exchange carriers to provide service on an 'unbundled, tariffed basis' that was equal in quality, type, and cost to that provided to AT\&T and its affiliates. In addition, RBOCs were prohibited from discriminating against other service providers in favour of

\footnotetext{
5 Sherman Anti-trust Act, ch 647, 26 Stat 209, 209-10 (1892) (codified as amended at 15 USC $\S \S 1-7$ ).
} 
AT\&T in the following areas: procurement, establishment and dissemination of technical information, interconnection standards, interconnection, and provision of new services and facilities.

\subsubsection{Competitive carrier rulemaking}

In a series of rulings designed to adapt the regulatory framework to further promote competition among interexchange carriers in the late 1980s, the FCC distinguished between common carriers with market power ('dominant' carriers) and common carriers without market power ('non-dominant' carriers). Dominant carriers were subject to all of the requirements of Title II of the 1934 Act which deals with common carriers, including the need to provide 90 days' notice for new tariffs and to notify decisions to roll out network infrastructure. Such restrictions on non-dominant carriers, on the other hand, were no longer to be applied and enforced by the FCC. However, non-dominant carriers had to ensure that their service charges were not 'unjust or unreasonable'. At this time, AT\&T was declared to be dominant in the markets for interstate, domestic, and interexchange services in the US, including Hawaii, Alaska, and the US territories, but by 1995 the FCC reclassified AT\&T as non-dominant in all service markets (Motion of AT\&T to be Re-classified as a Non-dominant Carrier, 11 FCC Rcd 327 (1995)). The obligations on dominant carriers have been reduced further in light of biennial regulatory reviews mandated by the Telecommunications Act of 1996 (1996 Act) to reflect the state of competition in relevant markets.

\subsubsection{Local-exchange competition and the Telecommunications Act of 1996}

The 1996 Act marked the introduction of full competition in the market for telephony services. It declared invalid all state regulation that prohibited or restricted the entry of competitors into intrastate telecommunications services and overturned the MFJ provisions ${ }^{6}$ which allowed RBOCs to retain monopolies in the lucrative

\footnotetext{
${ }^{6}$ The MFJ was officially terminated on 11 April 1996 following the enactment of the 1996 Act.
} 
local market. It also removed the MFJ's restrictions on the provision of interstate telephony services by RBOCs, provided they comply with a 15-point 'competitive' checklist to the satisfaction of the FCC. ${ }^{7}$ This checklist included a number of resale, access, and interconnection obligations, including the provision of nondiscriminatory access to unbundled network elements, which are discussed in Section 5.10.1. In December 1999, Bell Atlantic was the first RBOC permitted by the FCC to offer interstate telephony services, provided it met certain conditions in the State of New York and complied with other specified safeguards. ${ }^{8}$ By 2003 , all RBOCs had received approval to provide long-distance services in all of their regional areas. Since then, there has been significant consolidation in the sector and a return to vertical integration brought about by declining revenue for long-distance services and high prices for local access. Despite the mergers, RBOCs owned by Verizon, AT\&T, and CenturyLink providing interstate telephony services must continue to comply with the competitive checklist and other requirements. ${ }^{9}$

\subsubsection{Cable}

Since its inception in the 1950 s, cable television has evolved from a simple video transmission service to an important provider of broadband services. The FCC has applied varying degrees of regulation to this medium throughout this evolution, and current regulatory policies affect both cable's new role as a broadband provider and its legacy position as the original multichannel video programming distributor (MVPD).

${ }^{7}$ See 47 USC $\S 271$.

${ }^{8}$ See 47 USC $\$ 272$.

${ }^{9}$ For further discussion of the obligations on RBOCs, see Section 272(f)(1) Sunset of the BOC Separate Affiliate and Related Requirements, Report and Order and Memorandum Opinion and Order, WC Docket No 02-122, CC Docket No 00-175, WC Docket No 06-120, FCC No 07-159, 22 FCC Rcd 16440 (2007). 
Individual cable systems have traditionally been local in nature due to their design, although industry consolidation and regulatory changes have made this characteristic increasingly less important. Typically, a cable 'head end' facility receives terrestrial and satellite broadcast signals via a series of antennae and dishes. These signals are then transmitted via wire throughout the community the cable provider serves, usually on telephone poles or along streets. An individual cable line runs to each subscriber. While cable companies are subject to competition for the delivery of video programming from fibre and satellite providers and are themselves robust competitors in the fixed broadband market, cable companies traditionally have respected each other's exclusive franchise areas with respect to the delivery of video programming.

\subsubsection{The development and regulation of cable}

The first cable systems served as community antenna television (CATV) systems, and allowed households in mountainous regions to view local television stations whose signals would otherwise be unavailable. Later, cable service expanded into metropolitan areas that could receive over-the-air broadcasts. In the late 1970s and throughout the 1980s, cable began to provide video programming unavailable through over-the-air broadcast stations. The availability of specialised news and entertainment channels, as well as premium movie and sporting events, was a key to cable subscriber growth.

Initially, the FCC declined to regulate cable. However, the FCC and state regulators soon became concerned that cable's carriage of free-to-air broadcast signals could fragment audiences and harm local broadcasters' revenue bases. In the 1960s, without specific statutory authority to do so, the FCC began its regulation of cable by adopting policies designed to protect free-to-air broadcasters. Despite the FCC's initial hostility toward cable, the medium continued to grow. By 1980, the FCC had relaxed many of its initial cable regulations and Congress passed the first laws specifically addressing the medium. 
The Cable Communications Policy Act of 1984 (the 1984 Cable Act) ${ }^{10}$ served a dual purpose: while it furthered efforts to deregulate cable, it set forth the first statutory framework for cable regulation. The 1984 Cable Act explicitly gave the FCC authority to regulate cable, but it removed issues such as subscriber rates and programme carriage from its jurisdiction. Similarly, the 1984 Cable Act limited state and local regulation, which at that time was viewed as an impediment to the growth of cable. Cable rates rose rapidly after deregulation, and both the FCC and Congress soon faced public pressure to do something about the situation. Congress acted by passing the Cable Television Consumer Protection and Competition Act of $1992,{ }^{11}$ which repealed many provisions of the 1984 Cable Act. Congress greatly expanded the FCC's role in cable regulation. This legislation was a departure from the previous approach, which emphasised less regulation and greater competition, particularly in rate regulation.

Only a few years later, as part of its broad review of communications law and policy in the Telecommunications Act of 1996 (the 1996 Act), Congress again modified cable regulation. The 1996 Act repealed certain cable-specific regulation, and adopted policies designed to encourage the broad provision of telecommunications services. To that end, the 1996 Act removed restrictions that had limited telephone companies from providing cable services, while concurrently, over a three-year period, phased out many of the cable rate regulations adopted in 1992.

Cable entities traditionally have been required to obtain and periodically renew a local franchise license in order to operate. A franchise benefits the cable provider by permitting access to public rights of way, as well as the local franchise authority, which can set renewal standards and charge the cable operator a fee for the

10 Cable Communications Policy Act of 1984, Pub L No 98-549, 98 Stat 2779 (1984).

11 Pub L No 102-385, 106 Stat 1460 (1992). 
right to operate its system in the designated area. However, the scope of what local authorities can regulate has generally diminished over time. The 1996 Act imposed limitations on local and state regulation of cable, such as the prohibition on grants of exclusive franchises or unreasonably withholding consent for a new service. In addition, some states have allowed cable and telecommunications entities to obtain a single franchise from the state, bypassing the need to negotiate individual local agreements. In 2005, the FCC released a thencontroversial Report and Order, ${ }^{12}$ that found evidence that local authorities had acted unreasonably to delay the entry of new competitors. In the Report and Order, it established rules regulating how local franchise authorities can act by, among other things, setting strict time limits for local governments to act on new applications to provide video services. In 2015, the FCC found that cable companies face 'effective competition' nationwide. ${ }^{13}$ As a result, local cable franchising authorities can no longer regulate the rates of basic cable services and equipment unless they overcome a rebuttable presumption that the particular local market is competitive. Previously, there was a rebuttable presumption that cable operators were not subject to effective competition, which resulted in numerous petitions to the FCC from cable operators (or other interested parties) seeking case-by-case determinations that a particular franchise area contained a sufficient quantity of consumer options to be deemed competitive. ${ }^{14}$

Cable's once dominant role in the bundling and delivery of video content continues to be diminished by new entrants and challenged by new technologies. In response, cable providers have attempted to maintain

12 Implementation of Section 621(a)(1) of the Cable Communications Policy Act of 1984 as amended by the Cable Television Consumer Protection and Competition Act of 1992, Report and Order and Further Notice of Proposed Rulemaking, MB Docket No 05-311, FCC No 06-180, 22 FCC Rcd 5101 (2007) (upheld in Alliance for Community Media v FCC, 529 F 3d 763 (6th Cir 2008)).

${ }^{13}$ Concerning Effective Competition; Implementation of Section 111 of the STELA Reauthorization Act, 80 Fed. Reg. 38001 (2015) (upheld in Nat'l Ass'n of Telecom. Officers and Advisorsv FCC (DC Cir 2017)),

${ }^{14}$ Implementation of Sections of the Cable Television Consumer Protection and Competition Act of 1992 Rate Regulation, Report and Order, 8 FCC Rcd. 5631, 5669-70 (1993). 
their role by, for example, deploying a nationwide network of WiFi hotspots and promoting access to subscription video anywhere from any device. In addition, Comcast, the largest cable operator, entered the video content market directly through its purchase of NBC Universal from General Electric, which was approved in 2011. The industry continues to see consolidation including, most recently, the merger of Time Warner Cable and Bright House Networks with Charter into a single entity that markets itself under the 'Spectrum' brand. Today, MVPDs are a mix of traditional cable operators; Direct Broadcast Satellite (DBS) systems that allow consumers to receive video via pizza box-size dish antennae; fibre-to-the-home services provided by traditional telephone companies; and to a lesser extent, competitive 'overbuilders' such as RCN and new technology companies such as Google. Premium subscription internet video services such that provided by Hulu, Roku, and Apple TV, as well as original content from entities such as Amazon and Netflix, are also challenging the traditional cable model. As the cost of cable programming continues to rise due to increased fees for retransmission, particularly for sports programming, consumers appear to be more and more willing to embrace substitutes and drop their traditional cable television subscriptions. This evolving landscape can be illustrated by the experiences of AT\&T. It had previously operated a traditional cable franchise model through AT\&T Broadband, but sold that division to Comcast in 2002. However, by 2017 it had once again become a major MVPD through a combination of fibre-to-the-home, satellite television (it purchased DirecTV in 2015), and internet television subscription services. It counted 30 million content subscribers in a competitive marketplace, despite the fact that it no longer held any traditional cable assets.

Throughout the evolution of cable, the courts have generally upheld efforts to regulate the medium. In 1968, the Supreme Court acknowledged the FCC's right to regulate cable, concluding that it was 'interstate commerce by wire or radio' subject to the FCC's authority under the broad provisions of the 1934 Act (United States v Southwestern Cable Co, 392 US 157 (1968)). Although cable providers are akin to broadcasters and newspapers, in that they select programming for distribution, they are also similar to common carriers in that 
they mostly transmit, unaltered, content originated by third parties. Courts have been deferential to cable regulation, but have been unwilling to afford the types of First Amendment protection for regulation offered to newspapers and, to a lesser extent, broadcasters.

The FCC continues to have statutory obligations that relate to cable's traditional role as a video provider. Recent regulatory decisions have involved the programme access rules, which are designed to ensure that all MVPDs have access to cable-owned programme networks, and retransmission consent, which relates to how cable providers and television stations negotiate for the carriage of over-the-air broadcast channels. Notwithstanding recent developments in broadband, these and other video issues will likely remain a significant component of the US cable regulatory practice.

\subsubsection{Wireless}

The regulation of radio communications has long been a part of the FCC's mission, and government interest in this area can be traced back to before the agency's founding. Similarly, the development of commercial wireless telephone systems can trace its roots to the development of cellular networks in 1947. Under the cellular concept, the use of geographically small service areas (cells) allows a limited number of frequencies to be reused across a larger geographic area, which in turn increases the capacity of a mobile network to process a large number of telephone calls using relatively few frequencies. At the time the cellular system was envisioned, however, the technology did not exist to deploy widespread wireless networks. From 1947 until 1968 , the FCC sharply limited the number of frequencies available for cellular-type telephone operations, and thus there was little research or development in the area.

\subsubsection{Cellular radiotelecommunication services}


The modern cellular radiotelephone service was authorized in 1981. Cellular systems in each market area were divided into two $20 \mathrm{MHz}$ channel blocks, with one block made available to a local wireline carrier. Block A was limited to non-wireline cellular systems and was issued by comparative hearings for the initial markets, and later, by lottery. This wireline/non-wireline distinction no longer exists. Due to the growth in demand for cellular service, the FCC allocated an additional five MHz of spectrum to each cellular system in 1986, providing a total of $50 \mathrm{MHz}$ for these 'first generation' cellular services.

In 1994, the FCC began the auction of broadband personal communications service (PCS) spectrum, which consists of $120 \mathrm{MHz}$ of spectrum in the $1850-1910 \mathrm{MHz}$ and $1930-1990 \mathrm{MHz}$ bands and is divided into six blocks. The FCC broadly defined PCS as mobile and fixed communications offerings that serve individuals and businesses, and can be integrated with a variety of competing networks. As a practical matter, however, the services that were developed under broadband PCS were essentially marketed as and were widely perceived to be a type of cellular service.

The Specialized Mobile Radio (SMR) service was first established by the FCC in 1979 to provide land mobile communications on a commercial basis and was configured to provide dispatch-like services. Several companies — most notably, Nextel (now Sprint) — used their licences to provide cellular-like services. Modern networks and multi-band phones can use frequencies licensed for the purposes of first generation, PCS and SMR services, and the regulatory distinctions (made in different FCC rule parts) are largely transparent to consumers.

The licensing of PCS in the mid-1990s represented a technological improvement in mobile telephone networks, as these systems incorporated digital technology. PCS deployment also marked a significant evolution in auction and relocation policies. To deploy PCS, it was necessary to relocate incumbent $2 \mathrm{GHz}$ licensees who had employed point-to-point microwave links in their private internal radio networks. The FCC's Emerging Technologies relocation principles, which set forth a negotiation process that consisted of multiple negotiation phases and which provided incentives for incumbent users to quickly vacate the band, were developed at 
this time and have since been used as a model for the relocation of incumbent users from other spectrum bands. ${ }^{15}$ Further evolution of these relocation principles led to the groundbreaking 2016 broadcast incentive auction. There, the FCC successfully used a 'two sided' auction in which incumbent broadcasters indicated the amount of money they would be willing to receive for relinquishing their spectrum rights and prospective new wireless licensees indicated what they would pay for this spectrum. Ultimately, the auction resulted in the repurposing of television channels 38 and above, making available for wireless licensees $70 \mathrm{MHz}$ of spectrum that is highly valued for its superior propagation characteristics. Advances in technology have also made it possible to entertain more complex spectrum scenarios, including those in which radios consult an online database to determine real-time spectrum availability.

Today, a robust, competitive market for mobile telephone services exists in the US. As documented by the FCC's annual reports on the state of mobile service competition, ${ }^{16}$ mobile telephony dramatically and quickly transformed from an expensive service used by a relatively small percentage of the American population to a widely accepted medium that was marked by falling prices, increased service areas, and such innovations as unlimited phone calls and no long-distance charges. Prior to this time, the use of mobile telephone services in the US lagged behind that of many other countries, including much of Europe. The increasing use of data services - whether texts and messages, internet browsing, or streaming media services - has slowed the growth of and reduced the revenues associated with traditional voice-based telephony over wireless networks. These

15 See generally Redevelopment of Spectrum to Encourage Innovation in the Use of New Telecommunications Technologies, ET Docket No 92-9.

${ }^{16}$ These reports are docketed under the caption 'In the matter of Implementation of Section 6002(b) of the Omnibus Budget Reconciliation Act of 1993; Annual Report and Analysis of Competitive Market Conditions With Respect to Commercial Mobile Services' and are maintained on the FCC's website at $<\mathrm{http}$ ://wireless.fcc.gov/index.htm?job=cmrs_reports $>$. 
problems have created new challenges for wireless providers, as they work to upgrade their networks to support the higher data rates necessary for these services. They are particularly challenging for wireless providers serving low population density rural areas who are only just completing initial roll-outs or are transitioning from early-generation technology best suited for voice-based communications.

\subsubsection{Evolution of wireless broadband}

The transition from mobile telephony to mobile broadband began in 2002, when the FCC allocated an additional $130 \mathrm{MHz}$ of spectrum for 'advanced wireless services' (also known as AWS or 3G, for the 'third generation' technologies to follow cellular and PCS deployments). This spectrum consists of the $1710-1755 \mathrm{MHz}$, 1915-1920 MHz, 1995-2000 MHz, 2020-2025 MHz, and 2110-2180 MHz bands. This effort followed work at the World Radiocommunication Conference 2000, which had identified spectrum for 'next generation' technologies under the general label of 'IMT-2000'. 3G was succeeded by 4G, which is characterised by even higher data speeds that can support such features as mobile internet access, video conferencing and advanced gaming. The ITU released the IMT-Advanced standards associated with 4G in 2008. The 4G standards were forward-looking and pushed at the boundaries of existing technologies. Carriers first turned to the LTE - long term evolution -technology standard to upgrade their existing 3G networks. Even though LTE did not meet all of the $4 \mathrm{G}$ requirements, it permitted carriers to begin to achieve data rates nearing those identified by the ITU for 4G. Subsequently approved standards, such as LTE Advanced, were designed to satisfy the criteria for 4G systems. By 2017, wireless carriers were making steady progress in making 4G services available, although the US continued to lag behind many other countries in average speeds.

The need to make more spectrum available for wireless broadband continues to be an important policy issue. For example, the National Broadband Plan, which the FCC was required to submit to Congress in 
$2010,{ }^{17}$ called for the FCC to make 500 additional megahertz of spectrum available for broadband use by 2020. By 2015, US regulators reported that they were more than halfway to the goal, although it is becoming increasingly challenging to find additional suitable frequency bands because of use by incumbents. Some spectrum is being used for vital national security purposes, for example. Another development that has given rise to demands for more spectrum has been the interest in ' $5 \mathrm{G}$ ' networks. Parties have differing views about what constitutes $5 \mathrm{G}$, but there in general agreement that these networks will support increasingly large amounts of data, including that used for machine-to-machine communications as part of the Internet of Things. To this end, spectrum in the bands above $24 \mathrm{GHz}$ has received newfound attention, These frequencies were previously seen as undesirable by the mainstream incumbent wireless carriers due to their short propagation distances and greater susceptibly to disruption. Use of such spectrum is expected to result in the deployment of dense networks consisting of clusters of low-power small cells with advanced beam-forming technologies, especially in urban areas, where such small cells can be readily deployed within buildings and on light poles and other public infrastructure.

Mobile telephone services do not have the long history associated with fixed-line services, and have operated under a relatively simpler regulatory structure. US policy has focused on fostering robust competition in this space, and regulators have relied on vigorous competition among licensees to deliver service improvements and ensure reasonable prices. As a result, there has been relatively limited involvement in setting pricing or service quality standards. Instead, the FCC has focused much of its attention on the amount of spectrum a particular entity controls, and has employed various means to ensure that no particular entity becomes so dominant as to threaten the competitive environment. One notable exception to this rule involves net neutrality.

\footnotetext{
${ }^{17}$ See further Section 5.11.1.
} 
When the FCC adopted net neutrality rules in 2015, it applied the rules equally to fixed and mobile broadband networks despite strong objections from the wireless industry. ${ }^{18}$

As wireless telephony transitions to wireless broadband, services that have not been traditionally considered part of the mobile telephone service are more easily integrated into a broadband network. Spectrum previously set aside for educational broadcast purposes, recovered from television broadcasting, and repurposed from satellite use have all been used to expand mobile broadband networks. Because many of these services have been licensed under different schemes, regulators have revisited existing allocations and service rules to remove impediments to flexible spectrum use. While the mechanisms for reallocating or repurposing spectrum continue to evolve, it has become increasingly difficult to identify users that can be easily relocated and suitable spectrum in which to relocate their services. Accordingly, spectrum policy increasingly focuses on how to promote successful band sharing among different and traditionally incompatible services.

\subsubsection{Satellite}

The provision of domestic and international communications services by satellite in the US has increased dramatically since the 1960s. Historically, domestic satellite services in the US have been provided by private entities; however, international satellite communications services in the US were offered exclusively by the Communications Satellite Corporation (Comsat), a government-controlled entity established under the Communications Satellite Act of 1962 (1962 Act). ${ }^{19}$ Comsat was the US signatory to the International Telecommunications Satellite Organization (Intelsat) and the International Mobile Satellite Organization (Inmarsat) and

\footnotetext{
${ }^{18}$ See further Section 5.2.5.3 below.

19 Pub L No 87-624, 76 Stat 419 (1962).
} 
resold Intelsat's services to US telecommunications carriers. Users and service providers were not permitted to access directly Comsat services. To ensure the economic viability of Inmarsat and Intelsat, the FCC did not authorize the operation of other international satellite systems until 1984 when President Ronald Reagan determined that competing systems were in the national interest. ${ }^{20}$ However, the newly-licensed satellite operators were precluded from interconnecting to the PSTN, so commercial providers focused on broadcasting and international private communications. The FCC gradually lifted the interconnection restrictions and by 1997 they were removed. As a result, there are now multiple satellite providers offering integrated packages of traditional telephony and video programming services to their customers.

The desire to encourage greater competition in the US and other foreign markets for international satellite services and to establish a level playing field for competitors also led to the elimination of state control over Comsat, Intelsat, and Inmarsat. In 2000, the Open-Market Reorganization for the Betterment of International Telecommunications Act ${ }^{21}$ (ORBIT) was enacted by Congress which amended the 1962 Act by mandating that Intelsat and Inmarsat privatize. If they failed to privatize, the FCC was directed to refuse to grant them the authorizations necessary to provide specified mobile and broadcasting services in the US. ${ }^{22}$ ORBIT removed many of the privileges and immunities granted to Comsat and, in particular, the private sector ownership restrictions on Comsat. It also gave customers and service providers direct access to Intelsat services. Although the purpose of ORBIT was to establish a competitive global market for satellite communication services,

${ }^{20}$ Presidential Determination No 85-2.

${ }^{21}$ Pub L No 106-180, 114 Stat 48 (2000).

22 Inmarsat was privatized on 15 April 1999, prior to the enactment of ORBIT; Intelsat was privatized on 18 July 2001. See further Chapter 16, at Section 16.2.1.2. 
ORBIT highlights an inconsistency in the US's current technology-neutral approach to regulation. Section 647 of ORBIT prohibits the FCC from awarding spectrum used for the provision of international satellite services by auction even though wireless carriers have incurred significantly higher costs for their spectrum because it was auctioned.

Satellite providers now offer competition to traditional terrestrial and mobile networks in many fields, including radio programming, television, broadband, and telephony. Satellite communications are increasingly being viewed as vital to the provision of public safety services during times of emergency when terrestrial networks may be unavailable; and the provision of telephony services where traditional communications networks are not present, such as wilderness areas, aboard yachts and other vessels.. Most recently, there has been growing interest in developing and deploying networks that consist of constellations of thousands of satellites that would operate in low-earth orbits. Because such satellites would reside much closer to the surface of the earth than many traditional satellites, these new networks would allow for high bandwidth transmissions with minimal latency. With the advent of smaller satellite form factors that can be produced quickly, relatively inexpensively and in large quantities; increased competitive commercial launch options offered by companies such as SpaceX; and technological improvements in satellite communications, these once audacious plans now appear more practical.

\subsubsection{Broadband and IP}

The deployment of broadband services and the IP technology used to provide them over the last decade has created a number of regulatory difficulties for the FCC. One of the most contentious issues has been whether broadband services should be classified as 'telecommunications services' or 'information services'. If these services are 'telecommunications services' they are, absent a decision of the FCC to forbear from regulation, regulated in accordance with the obligations of Title II of the 1934 Act including tariff notification, access, and 
interconnection. ${ }^{23}$ If they are properly classified as 'information services', they are subject to the rules (if any) adopted by the FCC exercising its 'ancillary jurisdiction' set out in Title I-the power to 'perform any and all acts, make such rules and regulations, and issue such orders, not inconsistent with [the 1934] Act, as may be necessary in the execution of its functions'. The 1996 Act defines the terms 'telecommunications services'the 'offering of telecommunications ${ }^{24}$ for a fee directly to the public, or to such classes of users as to be effectively available directly to the public, regardless of the facilities used' ${ }^{25}$ - and 'information services' - 'the offering of a capability for generating, acquiring, storing, transforming, processing, retrieving, utilizing, or making available information via telecommunications, and includes electronic publishing, but does not include any use of any such capability for the management, control, or operation of a telecommunications system or the management of a telecommunications service' ${ }^{26}$ However, the essence of the two concepts and many of the rules and principles that govern them originated in a series of rulings made by the FCC in 1971, 1980, and 1986 known as the Computer Inquiry cases, which dealt with the regulation of the then nascent data-processing industry and the use of traditional telephony lines by common carriers such as AT\&T to provide data-

${ }^{23}$ See Sections 5.8 and 5.10.

24 'Telecommunications' is defined as 'the transmission, between or among points specified by the user, of information of the user's choosing, without change in the form or content of the information as sent and received'. 47 USC $\S 153(43)$.

2547 USC $§ 153(46)$.

2647 USC $§ 153(20)$. 
processing services. Given these rulings continue to influence the regulatory debate surrounding the classification of broadband and IP services and the regulatory framework that should govern them, it is worth reviewing them in some detail before reviewing how the FCC has classified and regulated broadband services.

\subsubsection{The Computer Inquiry cases}

In Computer Inquiry I (Regulatory Pricing Problems Presented by the Interdependence of Computer and Communication Facilities, Final Decision and Order, 28 FCC 2d 267 (1971)), the FCC declined to regulate the data-processing industry by distinguishing between 'hybrid communications' which were regulated and 'hybrid data processing' which was not. These distinctions, however, caused significant confusion and the FCC was forced to revisit them in Computer Inquiry II (Amendment of $\$ 64.702$ of the Commission's Rules and Regulations, Second Computer Inquiry, Final Decision, 77 FCC 2d 384 (1980)). In that decision, the FCC distinguished between so-called 'basic' and 'enhanced' services. 'Basic' services consisted of the provision of transmission capacity and were regulated by Title II of the 1934 Act. 'Enhanced' services were basic transmission services coupled with computer processing applications and were regulated in accordance with the FCC's ancillary jurisdiction.

It also decided that, with the exception of AT\&T and its affiliates, all common carriers were no longer required to establish a separate subsidiary company if they wished to offer data-processing services. However, all carriers who owned their own transmission facilities and provided enhanced services had to acquire the basic services needed for those enhanced services pursuant to tariff. Moreover, they had to make available basic services to competing enhanced service providers on the same rates, terms, and conditions.

Following the implementation of the MFJ, the FCC issued Computer Inquiry III (Amendment of $\$ 64.702$ of the Commission's Rules and Regulations, Third Computer Inquiry, Report and Order, 104 FCC 2d 958 (1986)). Although AT\&T and RBOCs remained free to offer enhanced services through separate subsidiary 
companies, Computer Inquiry III gave them the flexibility to integrate their basic and enhanced services, provided they comply with specified cost-allocation methods and targeted regulations designed to prevent RBOCs from abusing their market power in basic services. Initially, RBOCs were expected to comply with 'comparably efficient interconnection' (CEI) requirements. In the longer term, RBOCs had to comply with certain Open Network Access (ONA) obligations which required them to unbundle their basic services into 'basic service elements' for purchase by enhanced service providers. In addition, quality, installation, and maintenance reporting requirements were imposed. Like other carriers, RBOCs had to offer the basic services used in their enhanced service offerings pursuant to tariff and on a non-discriminatory basis. Because of procedural errors some aspects of the FCC's decision in Computer Inquiry III were overturned on appeal (People of the State of California v FCC, 905F 2d 1217 (9th Cir 1990)), but CEI requirements and some ONA obligations were eventually imposed.

\subsubsection{The regulatory classification of broadband services}

After the decision of the US Court of Appeals for the Ninth Circuit in AT\&T v City of Portland (216 F 3d 871 (2000)), which held that the conveyance element of cable modem services was a 'telecommunications service', the FCC issued a Declaratory Ruling and Notice of Proposed Rulemaking, ${ }^{27}$ which ignored the court's holding. The FCC determined that cable modem services were not telecommunications services. For the FCC, a cable modem service entailed a single, integrated internet access service which comprised computer processing, the provision of information, computer interactivity, and data transport. While the FCC conceded that cable modem services were provided via 'telecommunications', the conveyance service was not a standalone

27 Inquiry Concerning High-Speed Access to the Internet Over Cable and Other Facilities, Declaratory Ruling and Notice of Proposed Rulemaking, GN Docket No 00-185, CS Docket No 02-52, FCC No 02-77, 17 FCC Rcd 4798 (2002). 
product being offered to the public for a fee. Rather, the conveyance service was seen as integral to and indivisible from other internet services, such as email and access to content, offered by cable operators. As such, the conveyance element of the cable modem service was not a telecommunications service. Instead, cable modem services were classified as 'information services'. However, the FCC found that, as the conveyance element of a cable service was indivisible from the other internet services provided by cable operators, it did not need to be provided to competitors in accordance with the FCC's ruling in Computer Inquiry II. The FCC's interpretation of the term 'telecommunication service' was arguably strained but it was nevertheless upheld by the Supreme Court in National Cable \& Telecommunications Association v Brand X Internet Services, 545 US 967 (2005).

The Supreme Court's decision gave the FCC a legal basis on which to implement a deregulatory approach to broadband services. Shortly after it was made, the FCC determined that 'wireline broadband Internet access services' were 'information services'. ${ }^{28}$ The reasons given for the FCC's decision, which was upheld by the US Court of Appeals for the Third Circuit in Time Warner Telecom v FCC (507 F 3d 205 (3rd Cir 2007)), were similar to those articulated in its cable modem decision. Significantly, the FCC also decided that common carriers offering these services, including BOCs, no longer had to comply with its Computer Inquiry rules. In 2006, the FCC determined that Broadband over Power Line-enabled internet access services were 'information

28 Appropriate Framework for Broadband Access to the Internet over Wireline Facilities, Report and Order and Notice of Proposed Rulemaking, CC Docket Nos 02-33, 01-337, 95-20, 98-10, WC Docket Nos 04-242, 05-271, FCC No 05-150, 20 FCC Rcd 14853 (2005). The FCC's decision was in sharp contrast to its earlier policy. Previously, the FCC had sought to require ILECs providing wireline broadband internet access services using xDSL services to provide access to the high frequency portion of the local loop (or line share) in order to increase the roll-out of broadband services on the basis that the conveyance element was a 'telecommunications service'. See Deployment of Wireline Services Offering Advanced Telecommunications Capability, Third Report and Order in CC Docket No 98-147 and Fourth Report and Order in CC Docket No 96-98, FCC No 99-355, 14 FCC Rcd 20912 (1999). 
services'. In 2007, wireless broadband internet access services were classified as 'information services' ${ }^{29}$ In its wireless declaratory ruling, the FCC found that wireless broadband internet access services were not 'commercial mobile services ${ }^{30}$ on the basis that they do not involve the provision of an 'interconnected service'. ${ }^{31}$ Hence they were not subject to the application of Title II of the 1934 Act.

Importantly, in each regulatory classification decision, the FCC argued that if it needed to regulate broadband services it could rely on its ancillary jurisdiction under Title I of the 1934 Act. However, the April 2010 decision of the US Court of Appeals in Comcast v FCC (600 F 3d 642 (DC Cir 2010)) called into question the FCC's ability to regulate on this basis. The case, discussed further in Section 5.2.5.3, overturned the FCC's 2008 decision that Comcast had breached the Commission's policy on network neutrality, holding that absent a 'statutorily mandated responsibility', such as Title II (common carrier), Title III (spectrum management), and Title VI (cable), the FCC had no authority to regulate Comcast's internet management practices. In its Comcast order, the FCC asserted jurisdiction by relying primarily on two policy statements contained in $\S \S 1$ and 230(b) of the 1934 Act. Section 1 specifies the purpose for which the FCC was created: 'regulating interstate and foreign commerce in communication by wire and radio so as to make available, so far as possible, to all of the people of the United States . . . a rapid, efficient, Nation-wide, and worldwide wire and radio communication service ... at reasonable charges'. Section 230(b) states it is the policy of

${ }^{29}$ Appropriate Regulatory Treatment for Broadband Access to the Internet Over Wireless Networks, Declaratory Ruling, WT Docket No 07-53, FCC No 07-30, 32 FCC Rcd 5901 (2007).

30 These are defined in the 1934 Act, s 332(d)(1) (as amended) as 'any mobile service ... that is provided for profit and makes interconnected services available (A) to the public or (B) to such classes of eligible users as to be effectively available to a substantial portion of the public, as specified by regulation by the Commission'.

3147 USC $\S 332(\mathrm{~d})(2)$ defines the term 'interconnected service' as a 'service that is interconnected with the public switched network ... or service for which a request for interconnection is pending pursuant to subsection (c)(1)(B)'. 
the United States to 'preserve the vibrant and competitive free market that presently exists for the Internet and other interactive computer services, unfettered by Federal or State regulation'. In its judgment, the Court of Appeals left open the possibility that the FCC could regulate internet management practices if it could sustain an argument that such regulation was necessary in order to regulate matters over which it did have express statutory authority.

Shortly after the decision of the Court of Appeals, the FCC launched a notice of inquiry ${ }^{32}$ on the adequacy of the legal framework for broadband internet access services soliciting comments on three options:

- Retaining the current arrangements;

- Classifying the access component of broadband internet services as a 'telecommunications service' and applying all Title II regulation to it; or

- Classifying the access component of broadband internet services as a 'telecommunications service' and 'forbearing' from most provisions of Title II.

The 1996 Act gives the FCC the power not to apply Title II in whole or part to providers of telecommunications services provided specified criteria are met.

Despite quickly launching an inquiry on the matter, the FCC did not reclassify broadband services until the decision of the US Court of Appeals in Verizon v FCC (740 F 3d 623 (DC Cir 2014)). In that decision, the Court of Appeals overturned portions of the FCC's 2010 Open Internet Order that sought to codify the Commission's network neutrality policy. ${ }^{33}$ The FCC's order was grounded primarily in $\$ 706$ of the 1996 - a provision that

${ }^{32}$ Framework for Internet Broadband Service, Notice of Inquiry, GN Docket No 10-127, FCC No 10-114, 25 FCC Rcd 7866 (2010).

\footnotetext{
${ }^{33}$ Preserving the Open Internet, Report and Order, GN Docket No 09-191, WC Docket No 07-52, FCC No 10-201, 25
} FCC Rcd 17905 (2010). 
directs the FCC to encourage the deployment of 'advanced telecommunications capability.' The Court of Appeals held that $\S 706$ empowered the FCC to adopt rules regulating broadband services, including network neutrality provisions. However, the proposed network neutrality provisions regulated broadband providers as if they were common carriers subject to Title II of the 1934 Act, and the FCC was prohibited from relying on its $§ 706$ power to regulate broadband providers in this way, unless the FCC found that broadband services were telecommunications services. Because the FCC had previously concluded that broadband services were information services, the Court of Appeals ruled that, with the exception of the transparency rule (discussed in Section 5.10.11), the network neutrality provisions were invalid. Nevertheless, the Court of Appeals made it clear that had the FCC concluded that broadband services were telecommunications services, it would have upheld the Commission's network neutrality provisions.

In 2015, fifteen months after the Verizon decision, the FCC declared broadband services delivered over any technology platform to be telecommunications services and imposed the network neutrality rules discussed in Section 5.10 .11 below. ${ }^{34}$ Both decisions were upheld on appeal in 2016. ${ }^{35}$ The reclassification of broadband services as telecommunications services meant that broadband providers were common carriers and were regulated in accordance with Title II of the 1934 Act. In addition to the network neutrality rules, broadband providers were required to comply with obligations relating to customer privacy, ${ }^{36}$ disability access, and access to poles,

\footnotetext{
${ }^{34}$ Protecting and Promoting the Open Internet, Report and Order on Remand, Declaratory Ruling, and Order, GN Docket No 14-28, FCC No 15-24, 30 FCC Rcd 5601 (2015).

${ }^{35}$ USTA v FCC, $825 \mathrm{~F} 3 \mathrm{~d} 674$ (DC Cir 2016). En banc review by the DC Circuit Court of Appeals of its 2016 decision was denied on 1 May 2017. See USTA v FCC and USA, No 15-1063 (DC Cir May 1, 2017).

${ }^{36}$ See further Section 5.13 .5 (below).
} 
ducts, conduits and rights of way. However, the FCC elected to forbear from many Title II obligations, including tariffing and interconnection, and did not require broadband providers to pay universal service contributions. ${ }^{37}$

Since Ajit Pai, who was a dissenting commissioner in the FCC's 2015 Open Internet Order, was appointed by President Donald Trump as the new chair of the FCC in January 2017, the FCC's approach to the regulation of broadband services has radically changed. On 23 May 2017, the FCC issued a Notice of Proposed Rulemaking (NPRM) in which it proposed to reclassify all broadband services (fixed and mobile) as information services; $;^{38}$ and on 14 December 2017, a majority of the Commission consisting of the FCC's three Republican members voted in favour of the proposal. The text of the Declaratory Ruling, Report and Order, and Order that the FCC adopted was released on January 4, 2018. ${ }^{39}$ Its content closely followed that of the preliminary draft the Commission had released before the vote, and pointed to new legal analysis and reduced investment by ISPs in network infrastructure following the adoption of the 2015 Open Internet Order as important factors supporting the decision. Even though broadband services will no longer be treated as telecommunications services, providers of broadband services will have to comply with a transparency rule that requires them to disclose accurate information about their network management practices, including blocking, 'throttling', paid priorization and affiliated prioritization. In addition, the FTC will regulate the privacy of broadband customers (see further in Section 5.13.5). Undoubtedly, the Declaratory Ruling, Report and Order, and Order will be subject to legal challenge. More than 22 million submissions were made in response to the NPRM. Most of these submissions were brief comments that expressed a particular point of view as opposed to a detailed legal analysis, with many

\footnotetext{
${ }^{37}$ See further Section 5.11 .3 (below).

${ }^{38}$ Restoring Internet Freedom, Notice of Proposed Rulemaking, WC Docket No 17-108, FCC No 17-60, 32 FCC Rcd 4434 (2017).

${ }^{39}$ Restoring Internet Freedom, Declaratory Ruling, Report and Order, and Order, WC Docket No 17-108, FCC No 17166, 33 FCC Rcd [page number to be added during author query stage] (2018).
} 
calling for the retention of the classification of broadband services as telecommunications services and the more stringent regulatory obligations of the 2015 Open Internet Order.

Since the FCC first started classifying broadband services, entrants other than traditional common carriers have established their role in the broadband market. Cable operators, which began upgrading their systems in the mid-1990s at an estimated cost of US $\$ 172$ billion, are now the market leaders in the delivery of fixed broadband services. They hold the majority of the fixed broadband market, followed by telephone companies that provide residential digital subscriber line (DSL) services and fibre-to-the-home applications (such as Verizon's FiOS and AT\&T's U-verse). Cable operators have been more successful at increasing broadband speeds to meet consumer demand than have telephone providers, who face technological limits with DSL technology and who have been reluctant to incur the capital expense of widespread fibre deployments. In 2015, some 58 per cent of all residential households with broadband service used cable modems, while 22 per cent connected to the internet via DSL and 10 per cent employed fibre. Other competitors, including satellite broadband, fixed wireless, and broadband over power line providers, served the remaining premises.

To date, satellite has only been able to obtain a limited share of the fixed broadband market. Until satellite providers can overcome high system costs, limited bandwidth and latency issues, satellite broadband is likely to remain attractive only to those consumers who have no terrestrial service option.

Over the last decade, the demand for mobile broadband services provided by cellular providers has also grown at a phenomenal rate. In 2015, there were 253 million mobile internet connections. Mobile broadband services have not been considered substitutes for fixed broadband services for several reasons, including that they have not been able to consistently achieve the same speeds as fixed broadband services and that handheld devices cannot support some of the most data intensive applications used with fixed broadband services. However, the advent of faster mobile connections could diminish many of the traditional reasons for this distinction. 
In 2017, as part of its statutory requirement to evaluate annually whether advanced telecommunications capability is being deployed in a reasonable and timely fashion, ${ }^{40}$ the FCC observed that Americans are increasingly using mobile broadband services to achieve advanced telecommunications capability. Notably, it asked whether it should evaluate deployment based on the presence of both fixed and mobile services. Whether and when consumers or policymakers might begin viewing fixed and mobile broadband as substitutes for each other was unclear at the time this chapter was written.

\subsubsection{Network neutrality ${ }^{41}$}

One of the principal reasons for the FCC's decision to classify broadband services as information services early on was its fear that Title II regulation or any other form of direct regulation would hinder their deployment. However, the FCC was also concerned that the underlying technology allowed providers of these services to discriminate against data packets containing particular types of data or sent from application providers which may be competing directly with broadband providers or their affiliates, either by blocking access to them or giving them lower network priority. In 2005, it responded to these concerns by adopting a policy of 'net neutrality' ${ }^{42}$ The policy set forth four broad principles, declaring that consumers were, among other

\footnotetext{
${ }^{40}$ Inquiry Concerning Deployment of Advanced Telecommunications Capability to All Americans in a Reasonable and Timely Fashion, Notice of Inquiry, GN Docket No 17-199, FCC No 17-109, 32 FCC Rcd 7029 (2017).

${ }^{41}$ See further Chapter 15, at Section 15.7.
}

42 Appropriate Framework for Broadband Access to the Internet over Wireline Facilities, Policy Statement, CC Docket Nos 02-33, 01-337, 95-20, 98-10, GN Docket No 00-185, CS Docket 02-52, FCC No 05-151, 20 FCC Rcd 14986 (2005). 
things, entitled to access content, run applications, and use services and devices of their choice, subject to law enforcement and technical network concerns.

The FCC promoted the policy in a number of ways. It accepted or required undertakings to comply with the policy before approving the mergers of SBC/AT\&T, Verizon/MCI, and AT\&T/Bell South. Moreover, all 12 licences, awarded in 2008, authorizing use of C block spectrum in the $700 \mathrm{MHz}$ band, technically suitable for wireless broadband services, included an obligation to treat lawful content, applications, and services in a nondiscriminatory manner. Similarly, the FCC sought to enforce the terms of the policy. In 2005, it entered into a consent decree ${ }^{43}$ with a telephone company providing DSL services, following complaints from a VoIP provider, that it was preventing its customers from using VoIP services. On 1 August 2008, the FCC found that Comcast, then the second largest provider of broadband internet access in the United States, breached the policy by deliberately interfering with the ability of Comcast customers to use BitTorrent and other peer-to-peer applications which allow the sharing of video and other large data files. ${ }^{44}$

As discussed in Section 5.2.5.2, the FCC's Comcast decision was overturned by the Court of Appeals. However, prior to the decision of the court, the FCC signaled its intention to codify the net neutrality policy. In December 2010, the FCC adopted three rules implementing and expanding upon the principles of the policy. The 'transparency rule' applied to all providers of 'mass market' broadband internet access services (other than dial-up), regardless of the type of network technology used. It required relevant providers to publicly disclose accurate information about their network management practices and the performance and commercial terms of their

${ }^{43}$ Madison River Communications, Order, File No EB-05-1H-0110, 20 FCC Rcd 4295 (2005).

44 Formal Complaint of Free Press and Public Knowledge Against Comcast Corporation for Secretly Degrading Peer-toPeer Applications, Memorandum Opinion and Order, File No EB-08-1H-1518, WC Docket No 07-52, FCC No 08183, 23 FCC Rcd 13028 (2008). 
broadband internet access services. The 'no blocking rule' stipulated that fixed and mobile broadband providers could not prevent customers from accessing, amongst other things, lawful content, applications and services, subject to 'reasonable network management'. The 'no unreasonable discrimination' rule prohibited fixed broadband providers from unreasonably discriminating in the transmission of lawful network traffic over a consumer's broadband internet access service. These provisions were overturned by the Court of Appeal in Verizon v FCC (740 F 3d 623) in 2014, although the FCC adopted similar provisions in $2015 .{ }^{45}$

As discussed in Section 5.2.5.2, the FCC concluded in December 2017 that the network neutrality framework adopted in 2015 was too onerous because it hindered ISP investment in broadband infrastructure. It therefore decided to abolish the no blocking rule and the 'no-unreasonable interference/disadvantage rule' (the Commission's revised 'no unreasonable discrimination' rule adopted in 2015). It decided that a revised transparency rule that stipulates broadband providers must also disclose information about their blocking, throttling and paid and affiliated prioritization practices to their customers, in conjunction with anti-trust and general consumer protection legislation, was better tailored to address identified regulatory harms.

Determining the appropriate regulatory framework for broadband services has been and remains one of the most controversial areas of US telecommunications regulation. The issue has generated a level of public awareness and interest that is uncharacteristic of most FCC regulatory matters. Moreover, participants in the debate continue to be split along party political lines.. The FCC commissioners appointed by President Obama who were members of the Democratic Party supported more robust network neutrality rules. The current chair of the FCC appointed by President Trump, Ajit Pai, and Commissioners Michael O'Rielly and Brendan Carr, also Republicans, staunchly oppose them, preferring less intervention in the market to address regulatory harms.

\footnotetext{
${ }^{45}$ See note 34 above.
} 


\subsubsection{VoIP and other IP-enabled services}

Early on, certain states asserted they had jurisdiction to regulate services enabling users to make or receive voice calls using IP technology. However, in 2004, the FCC concluded that it had exclusive jurisdiction over IP-enabled services. ${ }^{46}$ Despite its assertion of jurisdiction, the FCC has thus far declined to determine if VoIP should be classified as a 'telecommunications service' or an 'information service'. Instead, it has relied on its general ancillary powers under Title I of the 1934 Act and has, in a rather piecemeal fashion, imposed a series of obligations designed to promote public safety or advance the goal of universal service on what it has described as 'interconnected VoIP services' ${ }^{47}$ Many of these obligations are covered elsewhere in this chapter, and include compliance with the FCC's rules governing customer proprietary information ${ }^{48}$ and local number portability, ${ }^{49}$

46 Vonage Holdings Corporation Petition for Declaratory Ruling Concerning an Order of the Minnesota Public Utilities Commission, Memorandum Opinion and Order, WC Docket No 03-211, FCC No 04-267, 19 FCC Rcd 22404 (2004).

47 These are services that satisfy four criteria: firstly, they enable 'real-time, two-way voice communications'; secondly, they require 'a broadband connection from the user's location'; thirdly, they require 'Internet protocol-compatible customer premises equipment'; lastly, they allow 'users generally to receive calls that originate on the public switched telephone network and to terminate calls to the public switched telephone network'.

48 Implementation of the Telecommunications Act of 1996, Report and Order and Further Notice of Proposed Rulemaking, CC Docket No 96-115, WC Docket No 04-36, FCC No 07-22, 22 FCC Rcd 6927 (2007).

49 Telephone Number Requirements for IP-Enabled Service Providers, Report and Order, Declaratory Ruling, Order on Remand, and Notice of Proposed Rulemaking, WC Docket No 07-243, FCC No 07-188, 22 FCC Rcd 19531 (2007). 
and duties to enable users to contact emergency services, ${ }^{50}$ to ensure access by those with disabilities, ${ }^{51}$ and to contribute to the universal service fund. ${ }^{52}$ In 2012, the FCC required interconnected VoIP service providers to report network outages to the Commission. ${ }^{53}$

The FCC first began consideration of the complex legal and regulatory issues raised by IP-enabled networks and services in February 2004, but the development of a general framework for all IP-enabled networks and services has been slow to emerge. In recent years, however, the FCC has adopted a number of important regulatory measures to support the deployment of and transition to IP- enabled networks and services. In 2011, the Commission developed transitional intercarrier compensation arrangements for VoIP-PSTN traffic, which it has since clarified on several occasions. (see Section 5.10.4.1.) In 2015, it allowed interconnected VoIP providers to directly obtain telephone numbers from American numbering administrators (see Section 5.10.3). In addition,

50 IP-Enabled Services, First Report and Order and Notice of Proposed Rulemaking, WC Docket Nos 04-36, 05-196, FCC No 05-116, 20 FCC Rcd 10245 (2005).

51 IP-Enabled Services, Report and Order, WC Docket No 04-36, FCC No 07-110, 22 FCC Rcd 11275 (2007).

52 Universal Service Contribution Fund, Report and Order and Notice of Proposed Rulemaking, WC Docket Nos 06122 , 04-36, CC Docket Nos 96-45, 98-171, 90-571, 92-237, 99-200, 95-116, 98-170, NSD File No L-00-72, FCC No 06-94, 21 FCC Rcd 7518 (2006).

${ }^{53}$ The Proposed Extension of Part 4 of the Commission's Rules Regarding Outage Reporting to Interconnected Voice Over Internet Protocol Service Providers and Broadband Internet Service Providers, PS Docket No 11-82, FCC No 1222, 27 FCC Rcd 2650 (2012). 
there is an on-going inquiry into whether telephone numbers should no longer be associated with the geographic location of a user. ${ }^{54}$

\subsection{OVERVIEW OF KEY US REGULATORY BODIES}

\section{AND PROCEDURAL PRINCIPLES}

Telecommunications regulation occurs at both state and federal levels in the US and the number and different types of regulatory bodies reflect the diversity of the 50 states and the federal government, as well as the involvement of the executive and legislative branches of government in this area.

At the federal level the FCC is principally responsible for all interstate and foreign telecommunications issues, and, following the passage of the Telecommunications Act of 1996, for certain intrastate issues. It is the most well-known US regulatory body. The FCC's jurisdiction covers numerous sectors, including fixed, mobile, satellite, and broadcasting, as well as licensing, enforcement, and consumer outreach functions. The FCC's broad authority is similar in size and scope to that afforded to the UK's Office of Communications. The work of the FCC is complemented by that of other federal government entities, most notably the National Telecommunications and Information Administration of the Department of Commerce, the Department of Justice, and the Federal Trade Commission. Unlike other countries, the US has never attempted to combine telecommunications service and regulation into a single state-run postal telegraph and telephone entity. Telephony and radio broadcasting have always been run by private-sector entities, subject to separate government regulation.

\footnotetext{
${ }^{54}$ Numbering Policies for Modern Communications, Notice of Proposed Rulemaking, Order and Notice of Inquiry, WC Docket Nos 13-97, 04-36, 07-243, 10-90; CC Docket Nos 95-116, 01-92, 99-200, FCC No 13-51, 28 FCC Rcd 5842 (2013).
} 
At the state level, each of the 50 states and the District of Columbia has a public utility or public commission responsible for all telecommunications issues, including policy, licensing, and enforcement, arising within its jurisdiction. Having said that, state jurisdiction in certain areas has been reduced by the Telecommunications Act of 1996 and the use of the federal pre-emption doctrine (see Section 5.7). The work of the state regulators is also coordinated by the National Association of Regulatory Utility Commissioners (commonly known by its acronym, NARUC). The FCC is significant in that it wields a significant amount of policy-making authority. It has expansive jurisdiction over telecommunications issues, despite certain statutory limitations contained in the Communications Act of 1934. It exercises its authority via its rule-making and order functions, but like all federal government agencies, remains subject to certain restrictions and key procedural principles contained in the Administrative Procedure Act. ${ }^{55}$

\subsection{FEDERAL BODIES}

\subsubsection{The Federal Communications Commission}

\subsubsection{Role and jurisdiction}

The FCC has full jurisdiction over all issues surrounding interstate and foreign communications which originate and/or are received in the US, including all aspects of fixed, mobile, cable, satellite, broadcasting, and commercial radio spectrum, and, in particular, tariffs and the transfer of 1934 Act licences in the context of mergers and acquisitions of authorized communications providers. The FCC's jurisdiction covers both service

\footnotetext{
55 Administrative Procedure Act, ch 324, 60 Stat 237 (1946) (codified as amended at 5 USC).
} 
providers and facilities-based operators. Within its jurisdiction, the FCC has broad authority to ensure compliance with federal telecommunications law, subject to the requirement that any action taken is 'consistent with the public interest, convenience, and necessity', and is specifically granted the power to 'perform any and all actions, make such rules and regulation, and issue such orders ... as may be necessary in the execution of its functions' (referred to as ancillary jurisdiction). It is important to note that the regulatory power is conferred to the FCC as a whole rather than to an individual.

\subsubsection{Commissioners}

The FCC currently consists of five Commissioners, each of whom is appointed by the President and confirmed by the US Senate. Commissioners serve five-year terms, and Commissioners may be reappointed. Commissioners who are appointed to fill vacant positions must serve the remaining term (as opposed to starting a fiveyear term), and Commissioners who are not reappointed are limited in how long they may remain in office even if a replacement has yet to be confirmed. Accordingly, the Commission can and often will operate with fewer than five Commissioners if there are delays in the nomination and confirmation process. All Commissioners must be US citizens, and a maximum of three Commissioners may have the same political party affiliation. On a practical level, the Commissioners are responsible for formulating key policy initiatives, implementing new legislation, and adopting agency rules and regulations. However, the Commissioners delegate the dayto-day running of the FCC to its bureaux and offices.

One of the five Commissioners is designated by the President to serve as its chair, whose general duty is to coordinate the 'prompt and efficient disposition of all matters within the jurisdiction of the Commission'. In practice, the chair wields considerable power by setting the agency's agenda and directing the work of the Commission's bureaux. While the chair serves as the public face of the agency, all Commissioners are entitled to present their own non-binding views on any particular issue. 


\subsubsection{Bureaux and offices}

The 1934 Act confers on the FCC the general power to organize its staff in the integrated bureaux and/or other divisional organizations as it deems necessary. It may also (in the interests of efficiency and cost-effectiveness) delegate its powers to its employees. The Commissioners may not delegate certain functions, such as evaluating the lawfulness of tariffs and the resolution of complaints, but, effectively, the bureaux share with the Commissioners the duties of conducting the FCC's business. The FCC is staffed by approximately 1,700 employees (down from a high of more than 2,100 in 1995), the vast majority of whom work in the FCC's Washington, DC headquarters. The FCC also operates a technical laboratory in Maryland, a licensing office in Pennsylvania, and has a small network of enforcement field offices throughout the US.

As of 2017, the FCC is organized into seven operating bureaux, which collectively handle the majority of the FCC's workload. The FCC continues to maintain an organizational structure that is generally based on the different types of services the FCC regulates. For example, the Wireline Competition Bureau is concerned primarily with 'traditional' fixed and radio common carriers. It also oversees programmes that promote access to broadband and voice services (including rural and health care support mechanisms), as well as matters relating to access to poles and rights of way. The Wireless Telecommunications Bureau regulates all aspects of mobile communications, including cellular services, specialized mobile radio, microwave radio, and amateur and other personal radio services. It has developed an expertise in auction design that has been used beyond traditional mobile service licensing. Other major bureaux include: the Media Bureau, which is charged with regulating AM and FM radio stations, television broadcast stations, multichannel video programming distributors, such as cable television entities; the International Bureau, which is responsible for the FCC's international telecommunications and satellite programmes, implements international treaties concerning telecommunications, and licenses cable landings as well as satellite and earth stations; and the Public Safety and Homeland Security 
Bureau, which was created in 2006 to focus on public safety, network security and reliability, and anti-terrorism interests. Two additional bureaux - the Enforcement and Consumer Affairs bureaux - address matters that arise across different communications services (such as consumer complaints regarding television programming content and cellular service bills).

In addition to the work of its bureaux, the FCC is supported by eight offices. These offices, among other things, represent its legal interests, provide technology and economic advice, and offer general administrative support. Individual offices play a significant role in the FCC's policy-making activities. For example, the Office of General Counsel is involved in the review of all matters regarding the approval of mergers and acquisitions by FCC-regulated companies, and the Office of Engineering and Technology supports those rule-making proceedings that relate to the allocation of the electromagnetic spectrum to the different types of radio services (such as broadcasting, satellite, fixed, and mobile terrestrial operations, etc). In 2018, FCC chair Ajit Pai began the process to create a new Office of Economics and Analytics. ${ }^{56}$ This new office is intended to more thoroughly integrate economic analysis and data collection into the FCC's decision-making processes. It would house the vast majority of the Commission's economists, who are presently deployed throughout the FCC's organization, and would assume some functions, such as auction design and implementation, that are currently managed by other bureaux and offices.

The majority of the FCC's licensing and regulatory work continues to be conducted by service-specific bureaux even though many communications policy issues now affect communications services overseen by more than one bureau. To overcome this difficulty, one bureau (or office, when appropriate) will take the lead role and consult with other bureaux and offices when formulating proposals and drafting documents for Commission vote.

\footnotetext{
${ }^{56}$ Plan for Office of Economics and Analytics (OEA) Recommendations and Report to Chairman Ajit Pai Federal Communcaitions Commission, Jan 9, 2018 (https://transition.fcc.gov/Daily_Releases/Daily_Business/2018/db0109/DOC348640A1.pdf). [Replace with Rulemaking proceeding cite when available].
} 


\subsubsection{Enforcement powers}

Under the Communications Act of 1934, the FCC enjoys broad and powerful enforcement mechanisms. The FCC may enforce the provisions of the Act directly, or request the US federal district courts to initiate enforcement proceedings. Breach of the 1934 Act's provisions may result in monetary fines, revocation of the underlying authorization, or obligations to take the necessary steps to remedy the breach. The FCC and the district courts may also require authorized carriers to produce documentation relevant to investigations upon request.

\subsubsection{National Telecommunications and Information Administration}

The National Telecommunications and Information Administration (NTIA) was created by executive order of the President in 1978 and by statute in 1993 (Executive Order 12046 and statute codified at 47 USC $\S 901$ et seq). It is an agency of the Department of Commerce. While the FCC is generally well known to the American public, the NTIA has traditionally operated with little public recognition.

The NTIA advises the President on telecommunications policy and negotiates for greater market access in foreign countries for US companies and administers grant programmes related to telecommunications. Additionally, the NTIA administers spectrum for exclusive government use such as those radio frequencies used by the armed services (in contrast to the 'public' spectrum administered by the FCC).

Because the NTIA and FCC together control use of all electromagnetic spectrum in the US, both agencies have a strong incentive to work cooperatively to determine the most efficient way to allocate spectrum resources and how best to resolve competing proposals for its use. The NTIA and FCC divide the spectrum into that used for exclusive federal use, exclusive non-federal use, and shared use. The majority of spectrum is classified as shared use, and there are procedures in place by which the NTIA and FCC coordinate both individual authorizations within these frequencies and broader changes in overall band use policies. Also, the FCC and the NTIA can agree to redesignate spectrum from an existing type of use to another, and to change the rights 
of authorized users within particular bands. In recent years, the NTIA has worked to develop long-range national spectrum planning policies that account for the needs of federal users - such as the military - while identifying spectrum that can be transferred to or shared with commercial users who continue to covet the large quantities of federal-use spectrum under the NTIA's jurisdiction. Thus, while the NTIA has no official power over non-governmental interests, its decisions can have a substantial effect on the interests of private entities.

\subsubsection{Other federal agencies}

Federal anti-trust law has played a key role in the regulation of telephony and to a lesser extent in other areas such as broadcasting and television. The primary US anti-trust laws are the Federal Trade Commission Act, ${ }^{57}$ Clayton Act ${ }^{58}$ and the Sherman Anti-trust Act. All of the legislation is enforced by the Federal Trade Commission's Bureau of Competition and the Antitrust Division of the Department of Justice (DoJ). Technically, the jurisdiction of these two bodies overlaps, but the agencies have agreed that the DoJ has primary responsibility for the enforcement of US anti-trust law in the telecommunications sector. Both the DoJ and the Federal Trade Commission (FTC) have also been heavily involved in assessing the competitive effects of key industry mergers.

${ }^{57}$ Federal Trade Commission Act, ch 311, 38 Stat 711 (26 September 1914) (codified as amended at 15 USC $\S 41-58$ ).

58 Clayton Act, ch 323, 38 Stat 730 (15 October 1914) (codified as amended at 15 USC $\S 112-278$ and 29 USC $\S 52$, $53)$. 
The FTC has also traditionally worked to promote consumer rights. For example, it manages the Do-NotCall Registry, which places limitations on telemarketing phone calls, and investigates complaints against businesses that violate the rules, even though such jurisdiction is shared with the FCC and state and local authorities. It has also used its authority under $\S 5$ of the Federal Trade Commission Act to become the most active US agency in matters of consumer and online privacy. It is worth noting that the FTC lacks the jurisdiction to take action against unfair or deceptive acts or practices and unfair methods of competition by common carriers. This particular power, which is reserved to the FCC, took on added relevance within the context of net neutrality when the FCC's reclassification of fixed and mobile Internet providers as common carriers had the side effect of reducing the scope of the FTC's jurisdiction for the period of time when the 2015 network neutrality decision was in effect. Moreover the line between the FTC's and the FCC's authority is not always clear. While it was widely assumed that the FTC could regulate non-communication services that are provided by telecommunication companies, the US Court of Appeals for the Ninth Circuit found otherwise in $2016 .{ }^{59}$ At the time of writing, the full court was in the process of rehearing the case.

The Department of Homeland Security (DHS) was created in March 2003 in the wake of the September 2011 terrorist attacks against the US, and integrated all or part of 22 different federal departments and agencies into a single cabinet-level agency. DHS works with the FCC on matters relating to public safety and security and, in conjunction with the DoJ and Federal Bureau of Investigation, has taken an active role in matters relating to cybersecurity.

Other federal entities can become involved in telecommunications matters. The US Department of State coordinates treaty negotiations and preparation for international radiocommunication conferences, in coordination with the FCC's International Bureau. Both the US Patent and Trademark Office and the Copyright Office, part of the Library of Congress, are involved in issues relating to intellectual property and content rights. New

\footnotetext{
${ }^{59}$ FTC v AT\&T Mobility, 835 F 3d 993 (9th Cir 2016).
} 
technologies increasingly require the FCC to work with different specialised federal agencies. For example, the Department of Transportation has been involved in the development of policies related to unmanned aeronautical vehicles ('UAVs' or 'drones') and autonomous automobiles, while the Food and Drug Administration has an important role in the regulation of medical devices that incorporate radio transmitters.

\subsubsection{Courts}

The passage and implementation of the Telecommunications Act of 1996 triggered a flurry of legal challenges to the federal courts (and the DC Circuit Court in particular), resulting in several key decisions regarding federal pre-emption and unbundled network elements. Judicial intervention is not new in the telecommunications area, however. Where judicial authority has been exercised in the past, the courts have tended to adopt a more pro-competitive approach than the FCC.

\subsubsection{Congress and the President}

The FCC is an 'independent' agency established by Congress under the Communications Act of 1934. However, both Congress and the President exercise considerable influence over the agency.

The Congress consists of the Senate and the House of Representatives.

The Senate is composed of 100 members. Two are elected from each of the 50 states. Each member ('Senator') serves a term of six years. The House of Representatives, on the other hand, is composed of 435 representatives from all of the 50 states. The number of representatives for each state is determined by the population that resides there. Each state is entitled to at least one representative, who serves a term of two years. Broadly speaking, any proposed legislation must be approved by a majority of members in both the Senate and the House of Representatives before it is passed to the President, who will decide whether to sign the proposed 
legislation into law. The FCC's budget is authorized by Congress, although nearly all of this amount (approximately US \$388 million in 2017) comes directly from regulatory fees and other FCC-collected funds, such as a portion of proceeds from the auction of electromagnetic spectrum. The FCC must account for its annual spending and file an annual report to Congress containing information to facilitate Congressional review of its performance.

Much of the FCC's work is conducted under a broad legislative mandate by which the FCC has wide discretion to establish specific policies. Congress can also pass legislation directing the FCC to implement specific policy objectives, such as to auction a designated frequency block by a set date, or prohibiting the FCC from spending money to implement or enforce policies of which members of Congress disapprove. Congress is heavily lobbied by industry participants and consumer advocate groups, and the telecommunications sector is often listed among the top industries for both political lobbying activity and monetary contributions to Congressional interests. Members of Congress are not hesitant to criticize the FCC's actions publicly, call Commissioners to testify before Congressional committees, and threaten to enact legislation to modify or reform Commission procedures.

The President (and his Administration) also exert influence over the FCC. The President appoints FCC Commissioners, the majority of whom may represent his political party, subject to approval by the Senate. The President also names the FCC's chair. Because the chair has the power to set the FCC's agenda and oversees the workings of the staff, the President can utilize selection of the chair as a means to influence the tone and direction that a particular Commission is likely to take on matters of interest to the Administration and the political party it represents - a power recently and dramatically illustrated by the Commission's new approach to network neutrality, which reflects the views of the Trump Administration. Also, while independent from the President, the chair can and often will maintain contact with members of the Administration. 


\subsection{STATE BODIES}

\subsubsection{Public Utility Commissions}

The 1934 Act conferred extensive interstate jurisdiction on the FCC, while at the same time explicitly reserving jurisdiction over intrastate communication services to the 50 states as well as the District of Columbia. The state Public Utility Commissions (PUCs) are responsible for telecommunications regulation at this level. State jurisdiction over telecommunications has, in some areas, been reduced by the Telecommunications Act of 1996 and other legislation and the use of the federal pre-emption doctrine by the FCC (see Section 5.7). The PUCs approve tariffs and interconnection rates for intrastate telephony, handle customer complaints, and issue intrastate licences.

In addition to regulating telecommunications, PUCs oversee all other public utility functions. The structure and size of the PUCs and each of their telecommunications policies differ (significantly in some cases) from state to state, but generally all PUCs are state-created agencies with a division specializing in telecommunications regulation. Historically, some PUCs, in states such as Illinois, New York, and California, embraced competition within the local exchange markets; others thwarted competitive efforts by the FCC.

Although the Telecommunications Act of 1996 extends the FCC's authority to cover local competition, state regulators retain some jurisdiction over telephony issues. Their jurisdiction is limited, however, in many cases to ensuring compliance with federal regulations rather than developing policy. State regulators have the right to prohibit market entry of service providers if necessary to advance or preserve universal service, public safety, and telecommunications services. However, any regulation imposed by the states must be done so on a 'competitively neutral basis' and be consistent with the universal service obligations set forth in $§ 254$ of the 1934 Act. 


\subsubsection{National Association of Regulatory Utility Commissioners}

In addition to the PUCs, the National Association of Regulatory Utility Commissioners (NARUC) plays a role in the development of US telecommunications policy. The NARUC is comprised of federal and state utility regulators and strives to coordinate action by state regulators and to develop cooperation between federal and state regulators. Despite these aims, in practice the NARUC represents the interests of state regulators and becomes publicly involved with issues only when consensus already exists among the PUCs. It has a standing committee on telecommunications. 


\subsection{PROCEDURAL PRINCIPLES AND MECHANISMS: THE}

\section{ADMINISTRATIVE PROCEDURE ACT AND}

\section{ADMINISTRATIVE LAW PRINCIPLES}

Because the FCC is neither a judicial nor a legislative body, it operates under the general principles of administrative law. Administrative agencies such as the FCC are considered to have regulatory expertise in discrete subject areas. Under a theory of delegation, agencies exercise broad discretion to interpret and apply the laws passed by Congress and use their authority to enact their own specific rules and regulations that are legally enforceable. For example, §303(a) of the 1934 Act gives the FCC authority to classify radio stations, prescribe the nature of service to be provided in each class, and to determine the location and frequency bands of such stations. The FCC has used this broad authority to establish different types of radio services, such as the Microwave Radio Service and Television Broadcast Stations, and to establish rules and regulations regarding their operation. Each agency's rules are compiled in the Code of Federal Regulations (CFR). The FCC's rules are contained in Volume 47. The US government maintains an electronic version of the CFR at www.ecfr.gov that is updated each business day. It is worth remembering that the print edition of the CFR, published annually, may fail to include an agency's most recently adopted rules or will list rules that have been rescinded or modified.

\subsubsection{Administrative Procedure Act-rulemaking}

Although administrative agencies such as the FCC have wide discretion to interpret and apply laws, they must act within established procedural guidelines. The Administrative Procedure Act sets forth the basic 'notice and comment' framework that the FCC uses in promulgating rules, and ensures both publication of proposed rules 
and the opportunity for the public to comment before a rule is adopted. Either on its own motion, or in response to a 'Petition for Rulemaking', the FCC typically issues a 'Notice of Proposed Rulemaking' that announces proposed rules, describes the legislative authority on which the rules are based, and provides the public with an opportunity to file comments addressing the proposal. The FCC sets a specfic pleading cycle for each proceeding. It begins when the Notice (or a summary thereof) is published in the Federal Register, which is the US government's daily compilation of actions taken by the FCC and other agencies. Typical cycles allow from 30 to 90 days for interested parties to file comments and an additional 15 to 45 days for reply comments. The Commission may extend the filing dates, if circumstances warrant. The FCC may first issue a 'Notice of Inquiry' that contains no firm proposals to create public discussion of a subject that can aid the FCC in developing a proposed policy. A Notice of Inquiry is sometimes employed when the FCC seeks to introduce new and potentially controversial concepts which may or may not generate enough interest or consensus to support incorporation into the FCC's rules. In practice, this step is often omitted. As a consequence, Notices of Proposed Rulemaking issued by the FCC can read like broad inquiries into a subject area. These Notices ask many questions and propose different possible courses of action. Unlike with a Notice of Inquiry, however, the FCC may proceed to adopt binding rules once a Notice of Proposed Rulemaking has been issued.

For the FCC to adopt binding rules, it must issue a decisional document called a 'Report and Order'. The Report and Order must take into account the record generated by the Notice of Proposed Rulemaking and the FCC's original proposals. A large body of case law exists that interprets how closely an administrative agency's action must correspond to its proposals or the comments that parties have filed. Although considerable leeway exists for an agency to adopt final rules that differ from those that were proposed, the agency's action must be 'based on the record' of the proceeding. In addition, while the agency does not have to adopt proposals submitted by commenting parties, it cannot ignore them altogether. It must acknowledge those comments and explain why it has not adopted the parties' proposals. 
Rules adopted in a Report and Order typically do not take effect immediately upon release of the Commission's decision. After a Report and Order is adopted, a summary of the rules it contains and the date, designated by Commission, on which the rules will become effective have to be published in the Federal Register. Because it can take weeks (and sometimes even months) for this information to be published, a significant amount of time can elapse between the date the Commission makes it decision and when the rules it adopts come into force. In especially complex proceedings, the FCC may issue a document adopting rules while simultaneously proposing additional rules. Thus, a docket in a proceeding may remain 'open' for years and for the FCC to issue decisions with a title such as the 'Second Report and Order and Third Notice of Proposed Rulemaking'. The majority of Commissioners' votes is needed to adopt an item, and it is typical for individual Commissioners to attach statements explaining their decisions. Items require an affirmative vote of the majority of the sitting Commissioners to be adopted. Such decisions are made at the regular monthly meeting of the Commission that is open to the public; or through an internal circulation process. The FCC publishes announcements of upcoming meetings and associated agenda items, as well as a list of draft rulemaking documents that are 'on circulation' awaiting votes.

\subsubsection{Issuance of orders-adjudicatory action}

Much of the FCC's day-to-day work involves the issuance of adjudicatory orders addressing individual applications and petitions brought under the existing rules. Although these orders generally relate to a discrete matter, they are significant in that they provide insight as to how the FCC interprets its own rules and may be cited as precedent in subsequent actions before the FCC. Many of these orders are issued under delegated authority, either by a bureau chief or deputy, or by a division chief, although some orders are adopted by the FCC as a whole. FCC staff may also resolve matters by issuing a non-published letter, although this option is often used for routine processing matters, such as the dismissal of a defective application. 


\subsubsection{Review of FCC action}

Review of FCC action is generally accomplished by the filing of a 'Petition for Reconsideration', or, if the action was taken under delegated authority (such as by a chief of a bureau or office), by an 'Application for Review'. A party must file its application or petition within a set time period (generally 30 days) to preserve its right of review. In addition, the FCC may set aside an action on its own motion within 30 days. The Commission will respond to an application or petition by issuing a 'Memorandum Opinion and Order'. If the Commission makes new determinations and also modifies, clarifies, or upholds prior decisions in a particular proceeding, it may combine a further 'Report and Order' and a 'Memorandum Opinion and Order' into one document. The document will, however, always list the relevant docket and include both titles.

Both the Administrative Procedure Act and the FCC's rules contain provisions for formal hearings. However, the use of these procedures have become uncommon, most likely because the decision of an administrative law judge is still subject to review by the full Commission. Parties typically choose to bring maters to the Commissioners directly by filing a petition for reconsideration or they will appeal directly to federal courts, including the DC Circuit Court.

A party may seek court review of final FCC actions. In its review, a court will consider whether the FCC acted within its powers, both within the broad powers of the Communications Act of 1934 and under the specific legislation upon which the FCC based its rule or action. In addition, a court may, under the Administrative Procedure Act, set aside the FCC's decision if it is arbitrary, capricious, an abuse of discretion, or unsupported by evidence in the record. Courts often invoke the Administrative Procedure Act when the FCC has not explained the basis for its decision in the written order it adopted. In many cases, the court will send the matter back to the FCC (remand), with instructions to adequately explain all or a portion of the decision. 


\subsection{THE PRE-EMPTION DOCTRINE AND FCC JURISDICTION}

The 1934 Act created a two-tiered system of regulators: (i) the FCC, which is responsible for regulating interstate and foreign commerce in wire and radio communications; and (ii) state PUCs, with implicitly reserved powers to regulate intrastate communications. Under the Tenth Amendment of the US Constitution, all powers not expressly given to the Federal Government are reserved to the states. The creation of dual regulators reflected the need to balance the interests of state and federal governments in the US federal system and, in theory, states retain

complete control over common carriers providing telecommunication services within their borders.

The actual power states have to regulate intrastate commerce, however, has been reduced as a result of expansive interpretations of the Commerce Clause ${ }^{60}$ powers by the Supreme Court and the use of the pre-emption doctrine based on the Supremacy Clause. Broadly speaking, the Supremacy Clause enables Congress to pass law overriding state legislation. aIt also enables federal agencies, acting within the scope of their statutory authority, to pre-empt state law when, for example, state law frustrates or is in conflict with the federal purpose of legislation.

In the telecommunications sector, the Supreme Court has found that many seemingly intrastate activities directly and/or indirectly affect interstate commerce and thus fall within the ambit of the FCC.

The FCC began to to rely on the pre-emption doctrine in the 1960 s, when it sought to stimulate competition in the intrastate telephony market and tension between state regulators arose over the funding of universal service. North Carolina Utilities Commission v FCC, 537 F 2d 787 (4th Cir 1976), cert denied, 429 US 1027

${ }^{60}$ The Commerce Clause of the US Constitution gives the Federal Government the power to regulate commerce 'among the several states' and with foreign nations. 
(1976) (NCUC I) was the first in a series of cases that enlarged the jurisdiction of the FCC to include some power over intrastate communications via reliance on the pre-emption doctrine. NCUC I arose because several state regulators imposed conditions on the interconnection of non-AT\&T telephone hardware to the local system in an effort to limit the scope of the FCC's Carterfone decision (The Use of the Carterfone Device in Message Toll Service v AT\&T, 13 FCC 2d 420 (1968)), which permitted apparatus conforming to AT\&T's system specifications to be connected to the phone network. The Fourth Circuit reasoned that because the same handsets were used by customers to place interstate and intrastate calls, the state and federal regulations were incompatible with each other and that state regulation had to give way to federal law.

The case is significant as it attempted to define the ambiguous terms 'interstate' and 'intrastate' found in the 1934 Act. The court held that $\S 2($ b) of the 1934 Act only limits the FCC from regulating matters that 'in their nature and effect are separable from and do not substantially affect the conduct or development of interstate communications' (NCUC I at 793). Under this two-prong test, state regulators retain jurisdiction over issues that are separable from interstate communications and that have no impact on interstate telecommunications. If separation of interstate and intrastate communications is impossible, the FCC has or acquires jurisdiction.

The Supreme Court modified the NCUC I test in Louisiana Pub Serv Commission v FCC, 476 US 355, in 1986. In Louisiana, the court held that the FCC has jurisdiction only if the FCC can demonstrate that interstate and intrastate issues are inseparable and that the exercise of jurisdiction by the state frustrates the statutory authority of the FCC.

The scope of the FCC's jurisdiction over intrastate telephony matters was formally augmented in the Telecommunications Act of 1996. The 1996 Act required the FCC to introduce competition into the local loop. To that end, the Act expressly enables the FCC to pre-empt any state legislation that contravenes the purposes of 
local competition. ${ }^{61}$ In addition, the FCC may pre-empt any state regulation that may 'prohibit or have the effect of prohibiting the ability of any entity to provide interstate and intrastate telecommunications service'.

Attempts by the FCC to implement measures to introduce local competition were challenged by incumbent local exchange carriers (ILECs) and PUCs on the grounds that the FCC lacked the requisite authority to promulgate rules on such issues as pricing of local services and dialling parity. The Supreme Court in $A T \& T$ Corporation v Iowa Utilities Board, 525 US 366 (1999), however, affirmed that the FCC had general jurisdiction to implement the provisions of the 1996 Act, notwithstanding the provisions of the 1934 Act which reserve jurisdiction over intrastate matters to the states.

More recent examples of the FCC's reliance on the pre-emption doctrine include its decisions concerning VoIP, ${ }^{62}$ the deployment of wireless facilities ${ }^{63}$ and municipal broadband providers. ${ }^{64}$ In the municipal broadband providers decision, taken in 2015, the FCC attempted to pre-empt certain state law provisions restricting the ability of municipal providers to offer cable, video and Internet services outside of their service areas by arguing that the provisions conflicted with the federal policy, set out in $\$ 706$ of the 1996 Act, of ensuring 'reasonable and timely' deployment of broadband services. The Court of Appeals for the Sixth Circuit eventually overturned by the FCC's decision, ${ }^{65}$ holding that $\$ 706$ did not contain a sufficiently clear statement of preemption. However, the decision

\footnotetext{
${ }^{61} 47$ USC $§ 251(d)(3)(A)-(C)$.
}

${ }^{62}$ See footnote 46. The FCC's decision was upheld in Minnesota Public Utilities Commission v FCC, 483 F 3d 570 (8th Cir 2007).

${ }^{63}$ Acceleration of Broadband Deployment by Improving Wireless Facilities Siting Policies, Report and Order, WT Docket Nos 13-238, 13-32, WC Docket No 11-59, FCC No 14-153, 29 FCC Rcd 12865 (upheld in Montgomery County $v$ FCC, $811 \mathrm{~F} 3 \mathrm{~d} 121\left(4^{\text {th }}\right.$ Cir 2015)). See also Section 5.10.9.

${ }^{64}$ City of Wilson, North Carolina Petition for Preemption of North Carolina General Statutes Sections 160A-340 et seq, Memorandum Opinion and Order, WC Docket Nos 14-115, 14-116, FCC No 15-25, 30 FCC Rcd 2408 (2015).

${ }^{65}$ Tennessee v FCC, $832 \mathrm{~F} 3 \mathrm{~d} 597$ (6 ${ }^{\text {th }}$ Cir 2016). 
serves to illustrate the continuing importance of the pre-emption doctrine and the role of the courts in delineating the boundaries of federal and state jurisdiction over communications matters.

\subsection{LICENSING $^{66}$}

Subject to exemptions adopted by the FCC and limited statutory exceptions, Title II of the Communications Act of 1934 (1934 Act) requires operators and providers of interstate and overseas communications services who meet the definition of 'common carrier' to obtain the permission of the FCC before network operation and service provision. Common carriers must therefore ensure they hold and comply with the relevant authorization(s). Carriers that wish to use radio broadcasting, such as microwave links, must also obtain permission from the FCC to use the radio spectrum

(see Section 5.8.4). If carriers wish to provide intrastate services, they must obtain the requisite authorizations from the PUCs in each relevant state.

\subsubsection{Common carriers defined}

The 1934 Act unhelpfully defines a 'common carrier' as 'any person engaged as a common carrier for hire, in interstate or foreign communication by wire or radio or in interstate or foreign radio transmission of energy'. However, under common law, the term was interpreted to mean any carrier who holds itself out to the public for hire on general terms and who transmits communications signals at the request of a user without any

\footnotetext{
${ }^{66}$ See further Chapter 6.
} 
change to their form or content. ${ }^{67}$ The 1996 Act codified these requirements. It specifies that a 'telecommunications carrier' (or provider of 'telecommunications services') is treated as a common carrier 'only to the extent that it is engaged in providing telecommunications services'. The definition of 'telecommunications services' is explained in Section 5.2.5. Examples of common carriers include AT\&T and its subsidiary AT\&T Mobility, Verizon, Verizon Wireless, Sprint, and T-Mobile US.

Cable operators are not classified as common carriers. Instead they must obtain and comply with the licences granted by local municipalities and/or PUCs in the states in which they operate and any rules adopted by the FCC under Part VI of the 1934 Act.

The FCC has not decided if VoIP providers are common carriers. Consequently, they do not need an authorization from the FCC, but as discussed in Section 5.2.5.4, providers of 'interconnected VoIP' must nevertheless comply with certain Title II obligations.

\subsubsection{Common carrier authorization for provision of domestic fixed services}

Prior to 1999, the FCC required persons wishing to provide domestic or interstate communications services over wire, or to construct related facilities, to apply to the FCC for an individual authorization under $\$ 214$ of the 1934 Act. Authorizations were granted on a case-by-case basis and applicants had to be able to demonstrate that a grant would serve the public interest, convenience, and necessity. The FCC now gives 'blanket' authority for all carriers to provide domestic services, so there is no longer a need to obtain individual authorizations. However, carriers must register their details with the FCC. All carriers who provide services and operate networks pursuant to the FCC general authorization must comply with the FCC's rules applicable to them

\footnotetext{
${ }^{67}$ See further Chapter 15, at Section 15.7.1.
} 
or face revocation of the authorization. Carriers must also pay annual administrative fees levied by the FCC to recoup the costs of its regulatory activities. These regulatory fees (which are different from application processing fees and forfeitures that carriers may also have to pay) are calculated by reference to a carrier's revenue.

\subsubsection{Common carrier authorization for provision of international services}

Persons wishing to provide international services, or to construct facilities, must apply to the FCC for an individual authorization in accordance with $\S 214$ of the 1934 Act. Applicants must be able to demonstrate that the grant of the authorization will serve the public interest, convenience, and necessity. They must provide details of, among other things, their state of incorporation; all parties who directly or indirectly own at least 10 per cent of them; and the services to be provided. In addition, they must certify any affiliation with a foreign carrier; the countries to which services will be provided if the applicant is a foreign carrier or controls a foreign carrier in those countries; and the absence of any special concessions from foreign operators which have market power on a US international route.

As a result of its 1998 biennial regulatory review, the FCC streamlined the application process for granting §214 authorizations for the provision of international services. Provided an applicant is not (i) affiliated with a foreign carrier who possesses market power in the destination market; (ii) affiliated with a dominant US carrier whose international switched or private line services the applicant wishes to resell; or (iii) otherwise deemed to be ineligible for streamlined processing by the Commission, the FCC may grant the authorization 14 days after issuing a public notice. The applicant may provide services 15 days after the FCC's publication of a notice to the public. It can take 90 days or more for the FCC to process a filing made by an applicant 
caught by one of the above conditions or if the FCC otherwise deems an application ineligible for the streamlined procedure.

Pursuant to a $\S 214$ authorization, the applicant must file copies of all operating agreements with foreign operators. Carriers must also file tariffs in accordance with 47 CFR $\S \S 61.31$ to 61.59 if they have been classified as dominant on particular US international routes for reasons other than having an affiliation with a foreign carrier that possesses market power. In some cases, carriers must report the number of international circuits in operation.

\subsubsection{Spectrum licensing}

As has become common in Europe, the FCC awards spectrum licences for mobile services by auction. The spectrum is typically allocated to the highest bidder, although successful applicants must also be able to demonstrate their technical, financial, and legal ability to provide the underlying service. An auction winner does not acquire a property right in the underlying spectrum but can expect to hold and renew the licence without having to participate in subsequent auctions. Spectrum licences are for a set period (typically ten years) with an expectation of renewal, so long as the licensee has taken steps to meet the service requirements for its licence, such as building out facilities or meeting minimum service thresholds. Most services are licensed on a geographic basis - either nationwide, or in defined service areas. Licensees are permitted to partition (geographically split) their licence and/or disaggregate (divest a portion of the spectrum within their licensed area). They may also lease spectrum to third parties or enter into private common arrangements. Roll-out obligations vary, with nationwide licences typically requiring construction of base stations to cover a certain percentage of the population within a specified time period. In other cases, the FCC has required that the carrier provide 'substantial' service upon renewal. This service level is purposely unspecific, and is intended to take into account the nature and scope of communication services that have developed in the radio band without requiring 
the carrier to meet a certain benchmark (such as coverage to a fixed percentage of population). The FCC attempts to prevent companies from obtaining market dominance through a variety of means, including setting auction rules that exclude bidding by licensees of like services, and allocating multiple frequency channels within a given market. The FCC has also mandated spectrum caps, but this means of control has fallen out of favour. The FCC eliminated its fixed spectrum cap for commercial radio services effective from 1 January 2003, opting instead to evaluate the competitive effects of spectrum aggregation by these carriers on a case-bycase basis.

The FCC's auction authority dates to 1993, when Congress added §309(j) of the 1934 Act. Spectrum auctions are available for situations where there would be 'mutually exclusive' applications for the same licence, such as licensing an exclusive right to operate in a particular frequency band within a set geographic area. When multiple applications can be accommodated without conflict, such as narrow point-to-point microwave links, there is no mutual exclusivity and auctions are not appropriate. Although the billions of dollars in public revenue raised by spectrum auctions have attracted considerable attention, the 1934 Act (as amended) requires the FCC to consider efficient spectrum use and not the expectation of revenues as the dominant factor in designing and implementing auctions. The FCC is also mandated to ensure that licences are disseminated among a 'wide variety of licensees', including small businesses, rural telephone companies, and women- and minority-owned businesses. The FCC has addressed this requirement by establishing bidding credits for 'designated entities'. Other methods which have been employed (and generally without widespread success) include the offering of FCC-sponsored financing for winning designated entities and the setting aside of specific spectrum blocks that only designated entities may bid on.

The current auction process promotes both efficiency and participation by serious applicants. Whereas the very first auctions where chaotic affairs with a live auctioneer conducing proceedings in a large public function space, modern auctions are more akin to routine business transactions. Simultaneous bidding for multiple licences is conducted remotely by computer, and bidding rounds can last weeks if not months. In general, each 
interested bidder must file a 'short form' application prior to an auction that discloses its qualifications, and must submit an upfront deposit in relation to the licences it wishes to bid on. In each auction round, the bids may be increased only by a set increment. Once bidding activity drops below a set level, the auction closes and the FCC announces tentative winners for licences that have satisfied the auction's conditions (such as the 'reserve' - a minimum bid amount). Shortly thereafter, winning bidders must file a 'long form' application and submit payments. Bid withdrawal and default penalties are designed to ensure that only serious bidders participate. In addition, the FCC has adopted rules to prevent bidding collusion.

The spectrum auction policy is considered to be a success. Auctions can quickly allocate licences and promote the rapid deployment of service. In addition, the FCC has developed considerable expertise in designing and conducting auctions that have served as models for other countries considering their own spectrum auctions. The auction policy has not been without problems, however. Traditionally, the FCC faced the greatest difficulties in implementing its designated entity procedures. Constitutional challenges undermined the FCC's women and minority bidding preference programmes, and some designated entities either defaulted on instalment payments or declared bankruptcy. In addition to hindering the rapid deployment of service, these developments have pitted the FCC against federal bankruptcy courts and have weakened the FCC's control over its licensing process. More recent challenges have been policy related, focusing on matters of auction design. Decisions on how much spectrum to auction, the size of geographic areas covered by licences (eg, nationwide, regional or local), and even when to conduct auctions can affect how many bidders participate and how much revenue the auction will generate (which is popularly seen as a measure of its success). The FCC's decision to attach a special condition on the C-block in the $2008700 \mathrm{MHz}$ auction stating the licensee 'shall not deny, limit, or restrict the ability of their customers to use the devices and applications of their choice' remains controversial. Proponents assert that this condition furthered what was then considered the important public policy goal of network neutrality while critics claim that it skewed auction participation and lowered the final bid prices. 
Despite the challenges, auctions have become an entrenched part of the US licensing process. Congress has endorsed auctions by expanding the FCC's authority and mandating the use of auctions far beyond the original commercial mobile service auctions.

While auctions have become the predominant model for awarding licences for commercial wireless services, other licensing models exist. Another option used on a limited basis is to 'license by rule', in which an individual is considered to hold an FCC authorization and must abide by specific rules of operation for a radio service, but where the individual does not submit an application to the FCC to obtain a physical licence document. The Citizens Broadband Radio Service (formerly known as Citizens Band Radio) is the most wellknown radio service that is licensed by rule, although this model is increasingly used for a variety of applications where individual licences might be difficult to administer. Examples include implanted medical devices, medical telemetry, and automotive radars used for collision avoidance, lane departure warning, parking assist, and other safety and convenience features.

An additional authorization model that continues to gain prominence is unlicensed operation. So-called 'Part 15' devices (named for the part of the FCC rules under which they are administered) may be operated without a license. However, such devices must comply with technical standards that preclude high-power operations, as well as other conditions set forth in the rules, including equipment authorization requirements. Users have no exclusive rights to use the spectrum; must not cause interference to authorized (e.g. licensed) users; and must accept any interference received, including that caused by other unlicensed devices. While unlicensed operations are permitted in any frequency not expressly prohibited by the rules, most use has congregated in specific parts of the spectrum, including portions of the 2 and $5 \mathrm{GHz}$ bands. The minimal barriers to entry have made unlicensed operations an attractive proposition for entities that may not have the resources or business need to invest in exclusive spectrum licenses, and the unlicensed model has fostered innovations in wireless spectrum technologies and use. Originally characterised by cordless telephones, garage door openers, and baby monitors, unlicensed devices have now become a vital part of the communications landscape. WiFi 
and Bluetooth protocols are designed for unlicensed use, and the future 'Internet of Things' is expected to make extensive use of the unlicensed model. Wireless internet service providers (mostly small and rural in nature) have long operated on an unlicensed basis. Commercial mobile operators have increasingly come to rely on WiFi to provide backhaul support for their licensed networks and, in 2016, began deploying equipment designed to provide 4G LTE services under the unlicensed rules. This development has been controversial; while the technology promises to enhance mobile carriers' service and reliability by increasing data speeds over short distances, WiFi and cable providers expressed concerns over its compatibility with existing unlicensed devises and protocols that already crowd the spectrum available for unlicensed use.

The future of spectrum licensing is likely to be increasingly complex, and will include combinations of the licensing and authorization models discussed above. For example, the Commercial Spectrum Enhancement Act of $2004,{ }^{68}$ which established a mechanism for reimbursing federal agencies out of spectrum auction proceeds for the cost of relocating existing operations and was used in the auction of Advanced Wireless Services in 2006, represents an important milestone for the repurposing of federal spectrum for commercial use. The television incentive auction in 2016 provided evidence that incumbent licensees will voluntarily agree to give up some or all spectrum rights in exchange for a portion of the auction proceeds. The adoption of service rules for a new radio service, the Citizens Broadband Radio Service, in 2015 is particularly noteworthy because it introduced a mechanism by which different users holding different spectrum rights and authorized under different models will be permitted to operate in the same $3.5 \mathrm{GHz}$ band spectrum. Incumbent Access users, consisting of federal government users and grandfathered fixed satellite service operations, will receive protection

${ }^{68}$ Commercial Spectrum Enhancement Act, Pub L No 108-494, 118 Stat 3986, Title II (2004) (codified in various sections of 47 USC). 
from harmful interference from all other band users. Priority Access Licenses, awarded by auction, will be authorized to use a $10 \mathrm{MHz}$ channel in a specific geographic area for a mutiple-year period. General Authorized Access users will be permitted to use any portion of the band not assigned to Incumbent Access users and Priorty Access users and will be licensed-by-rule In addition, General Authorized Access users may operate in unused Priority Access channels by using advanced radios that consult with online databases to determine where and when such vacant channels exist. This idea - that users will be authorized to access spectrum opportunistically on an ad hoc basis as opposed to a pre-arranged assignment - draws on the work of the 'TV White Spaces' proceeding. There, the FCC permitted the operation of consumer devices that make use of locationsensing technologies to avoid interference with the signals of incumbent broadcasters, on an unlicensed basis in spectrum between licensed television channels. ${ }^{69}$

\subsubsection{Local entry licences}

Facilities-based operators and resellers who wish to provide telephone services, such as intra- and interLATA services, for a fee, must also apply for the requisite licences in each of the 50 states in which they operate. However, some states have exempted VoIP and broadband/internet access providers from their licensing rules. The application forms and specific requirements differ for each state and are too detailed to summarize here. Broadly speaking, each PUC requires basic information about the applicant (name and contact details), as well as information about the technical, administrative, and financial ability of the applicant to provide the service.

\subsubsection{Foreign ownership requirements}

${ }^{69}$ ET Docket 04-186. At the time of writing, the Commission was re-evaluating its rules for the $3.5 \mathrm{GHz}$ service, but was not expected to alter the fundamental three-tiered licencing approach. 
Until the adoption of the WTO's telecommunications 'Reference Paper', the FCC had a long-standing policy of protecting its domestic markets as well as US carriers abroad under the guise of promoting effective competition. For example, it required all foreign carrier applicants to satisfy the 'effective competitive opportunities' (ECO) test when applying for international $§ 214$ and cable landing licences. It also required all applicants seeking permission for ownership in excess of 25 per cent of US entities that directly or indirectly control broadcast, common carrier or aeronautical radio licensees to satisfy the ECO test when evaluating if such ownership was in the public interest in accordance with $\S 310(\mathrm{~b})(4)$ of the 1934 Act. This test required a showing that there were no legal or practical restrictions on US carriers' entry into the foreign carrier's domestic market.

On 15 February 1997, the US and 68 other countries adopted the WTO Basic Telecommunications Agreement in addition to specific market entry commitments contained in the telecommunications 'Reference Paper'. ${ }^{70}$ In light of the requirements of the Basic Telecommunications Agreement, the US substituted the ECO test with an 'open entry' standard for applicants from WTO countries. It now presumes that applications for international $§ 214$ and cable landing licences should be granted to foreign owners from WTO countries unless it can be shown that they pose a high risk to competition in the US. The Commission also applies this presumption when evaluating if petitions for ownership of more than 25 per cent in US entities that directly or indirectly control common carrier and certain aeronautical radio licensees are in the public interest. However, since 2013, it no longer distinguishes between WTO and non-WTO applicants seeking ownership of more than

\footnotetext{
70 See further Chapter 16, at Section 16.4.3.1.
} 
25 per cent in US entities that control directly or indirectly common carrier and certain aeronautical radio licensees. ${ }^{71}$ The presumption applies to all applicants, regardless of their WTO status. Applicants for international $\S 214$ and cable landing licences from non-WTO signatories must continue to satisfy the ECO test.

Over the last few years, the FCC has relaxed and sought to simplify its foreign ownership policies and procedures, especially in relation to $\S 310$ of the 1934 Act, which imposes various restrictions on the foreign ownership of broadcast, common carrier or aeronautical radio licences. All modifications have been prompted by a desire to facilitate increased foreign investment in US wireless networks. In addition to adopting a unified approach for WTO and non-WTO applicants for ownership in excess of 25 per cent of US entities that directly or indirectly control common carrier and certain aeronautical radio licensees (discussed above), the Commission in 2012 elected to forbear from applying $\S 310$ (b)(3) of the 1934 Act to foreigners seeking to own more than 20 per cent of a US entity that has shares in but does not control a common carrier licensee, provided such ownership is consistent with the public interest. ${ }^{72}$ Section 310(b)(3) prohibits foreigners from owning more than 20 per cent of the shares of a US entity that has shares in but does not control a broadcast, common carrier or aeronautical radio licensee. In 2013, the Commission adopted the same open entry standard for applicants from WTO and non-WTO countries when filing petitions under s $310(\mathrm{~b})(3) \cdot{ }^{73}$ Since 2016 , it has permitted foreign applicants to file petitions for approval to own 100 per cent of shares in US entities that control broadcast radio licensees. ${ }^{74}$

\footnotetext{
${ }^{71}$ Review of Foreign Ownership Policies for Common Carrier and Aeronautical Radio Licensees under Section 310(b)(4) of the Communications Act of 1934, as Amended, Second Report and Order, IB Docket No 11-133, FCC No 13-50, 28 FCC Rcd 5741 (2013).

${ }^{72}$ Review of Foreign Ownership Policies for Common Carrier and Aeronautical Radio Licensees under Section 310(b)(4) of the Communications Act of 1934, as Amended, First Report and Order, IB Docket No 11-133, FCC No 1293, 27 FCC Rcd TBA 9832 (2012).

${ }^{73}$ See footnote 71 .

${ }^{74}$ Review of Foreign Ownership Policies for Broadcast, Common Carrier and Aeronautical Radio Licensees under Section 310(b)(4) of the Communications Act of 1934, as Amended, Report and Order, GN Docket No 15-236, FCC No 16128, 31 FCC Rcd 11272 (2016).
} 


\subsection{SPECTRUM MANAGEMENT ${ }^{75}$}

The portion of the electromagnetic spectrum that is suitable for radiocommunications represents a vital resource, particularly with the increasing demand for mobile communications. First used for distress communications and, later, to provide over-the-air broadcasting of audio and video programming, radio frequencies are now an integral part of nearly all communications systems.

Spectrum management in the US has been based on the idea that spectrum is a scarce resource, and this scarcity rationale has served as one justification for government intrusion into areas of content and speech that would otherwise be constitutionally protected (as in matters relating to broadcast indecency). It is important to remember, however, that radio frequencies can be used to provide services that fall into any number of regulatory schemes, including common carrier, subscription, and mass media broadcasting models. Although technological innovation continues to expand the portion of the electromagnetic spectrum that is suitable for radio propagation and to reduce the amount of bandwidth necessary to transmit vast quantities of information, the increasing demand for radio services and the deployment of new bandwidth-intensive applications continue to make spectrum a valuable resource. The radio bands consist of the portion of the electromagnetic spectrum between $3 \mathrm{kHz}$ to $3000 \mathrm{GHz}$. At the time of writing, the US had only allocated the frequencies between 8.3 $\mathrm{kHz}$ and $275 \mathrm{GHz}$, although limited scientific, amateur and experimental operations exist above $275 \mathrm{GHz}$.

Although the US has sovereignty to regulate the use of the electromagnetic spectrum within its borders, its spectrum management is heavily influenced by the decisions of the International Telecommunication Union

\footnotetext{
75 See further Chapter 7.
} 
(ITU), an international organization within the United Nations System where governments and the private sector coordinate global telecommunication networks and services. ${ }^{76}$ The majority of the US lies within Region 2 , although certain Pacific territories are part of Region 3. By following the international allocation for a particular band, the US can promote economies of scale in the development and manufacture of equipment and, in the case of non-geostationary satellite systems or terrestrial systems located near international borders, avoid harmful interference from the use of incompatible types of services. The US follows the same terms to designate categories of services and allocations as does the ITU in the international Radio Regulations. ${ }^{77}$

The FCC publishes a table of frequency allocations at 47 CFR $\$ 2.106$ that lists the international allocation for each region, the US table of frequency allocations for both federal government and non-federal government use, and a list of the relevant FCC rules for each band. As discussed in Section 5.4.2, a separate body, NTIA, administers spectrum used by federal government entities. Accordingly, while the FCC lists federal government allocations in the US table of frequency allocations, it does not control that use. A spectrum band may have both primary and secondary allocations. Within a band, secondary services must not cause harmful interference to stations of primary services, nor may secondary services claim protection from stations of a primary service. Generally, however, a station operating on a secondary basis may claim protection from a secondary station that begins operation at a later date.

This allocation model serves as the basic framework for organizing the electromagnetic spectrum. Once spectrum has been allocated for a particular purpose (eg fixed or mobile services, broadcasting, Earth-to-space satellite operations), the FCC may then designate a particular type of radio service to use that spectrum band

${ }^{76}$ See further Chapter 16, at Section 16.3.2.

77 See further Chapter 16, at Section 16.3.4. 
and set forth appropriate licensing and operational rules for that service. Spectrum licensing is discussed in greater detail in Section 5.8.4. It is important to keep in mind that spectrum use under an unlicensed authorization model, as discussed in that section, falls outside of the allocation framework. There are no allocations for unlicensed services. Instead, unlicensed devices operate on a sufferance basis and must accept any interference from and not cause interference to any and all licensed services.

\subsection{ACCESS, INTERCONNECTION, AND RELATED}

\section{MEASURES ${ }^{78}$}

This section reviews some of the important access, interconnection, and related measures imposed by Congress, the FCC and other bodies. Where possible, it highlights the tensions which have arisen between established operators and new entrants, both of whose revenue streams are significantly affected by the underlying policy.

\subsubsection{Unbundled network elements}

To break the monopolies that ILECs had in the local access market for narrowband services, Congress enacted the Telecommunications Act of 1996. The Act imposed a broad duty on ILECs to provide any requesting telecommunications carrier 'non-discriminatory access to network elements on an unbundled basis at any technically feasible point on rates, terms and conditions that are just, reasonable and non-discriminatory'. ${ }^{79}$ The Act

78 See further Chapter 8 .

${ }^{79}$ See 47 USC $§ 251(c)(3)$. 
also required ILECs to provide unbundled network elements (UNEs) so that requesting carriers are able to combine UNEs to provide telecommunications services. Under the Act, all carriers (including resellers, facilities-based operators, and wireless providers) are entitled to UNEs.

The FCC had the responsibility of implementing the Act's unbundling provisions, and, under the FCC's current unbundling rules, ${ }^{80}$ ILECs must provide access to 'proprietary' network elements—elements in which an ILEC can demonstrate that it has invested resources to develop information or functionalities that are protected by patent, copyright, or trade secret law—where access is 'necessary'. Access is deemed to be necessary if, taking into consideration the availability of elements outside the incumbent's network (eg self-provisioning and alternative suppliers), access to that propriety network element would, as a practical, economic, and operational matter, preclude the requesting carrier from providing the services it intends to offer. ${ }^{81}$ In certain limited cases, the FCC will mandate the unbundling of proprietary network elements even if access is not necessary, where, for example, lack of access may frustrate the purposes of the 1996 Act. $^{82}$

Access to non-proprietary network elements is determined by reference to an 'impairment' standard. If a carrier can demonstrate that an inability to access a non-proprietary network element 'impairs' its capacity to provide a telecommunications service, then the relevant ILEC must make that element available to the requesting carrier. Impairment occurs when 'lack of access to that element poses a barrier or barriers to entry, including operational and economic barriers that are likely to make entry into a market by a reasonably efficient

8047 CFR $\S \S 51.307-51.321$.

8147 CFR $§ 51.317(a)(1)$.

8247 CFR §51.317(a)(2)(iii). 
competitor uneconomic'. ${ }^{83}$ As occurs under the 'necessary' standard, when making this assessment the availability of elements outside the incumbent's network (eg self-provisioning and alternative suppliers) must be taken into account. The scope of the term 'telecommunications services' as used in the Act is broad; however, the FCC has stipulated that a carrier cannot use UNEs to provide wireless and long-distance services. ${ }^{84}$ As these markets are competitive, no impairment arises. ${ }^{85}$ The current FCC rules mandate that ILECs provide local loops, subloops, network interface devices, dedicated transport, 911 and Enhanced 911 databases which enable calls to emergency services and operations support systems (OSS), although certain restrictions apply. ${ }^{86}$ Access to these network elements is designed to facilitate competition in narrowband and broadband services. When carriers are unable to agree the prices of UNEs, PUCs determine them in accordance with a forward long-run incremental methodology adopted by the FCC; or a series of proxy ceilings and ranges, also set by the FCC. ${ }^{87}$

It is an understatement to say that, for the FCC, formulating the necessary and impair tests and determining the specific network elements to be unbundled was a fraught process. Implementation of the unbundling

8347 CFR $§ 51.317(b)$.

8447 CFR $§ 51.309(b)$.

${ }^{85}$ Unbundled Access to Network Elements, Order on Remand, WC Docket No 04-313, CC Docket No 01-338, FCC No 04-290, 20 FCC Rcd 2533 (2005).

8647 CFR $§ 51.319$.

8747 USC $\S 252(d)(1) ; 47$ CFR $\S \S 51.501-51.515$. See also Review of the Commission's Rules Regarding the Pricing of Unbundled Network Elements, Notice of Proposed Rulemaking, WC Docket No 03-173, FCC No 03-224, 18 FCC Rcd 18945 (2003). 
provisions finally ended in 2006, a decade after the 1996 Act was adopted. The FCC's difficulty was in part due to the lack of guidance given in the Act about the factors it should take into account when determining which network elements should be unbundled. The Act stated only that the FCC had to consider 'at a minimum' if access to proprietary network elements was 'necessary' and if denial of access to non-proprietary network elements would 'impair' the ability of a carrier seeking UNEs to provide telecommunications services. ${ }^{88}$, In addition, the FCC had significant difficulty developing rules that passed judicial scrutiny. The courts overturned the FCC's unbundling rules in whole or in part on three occasions. In 1999, the Supreme Court rejected the FCC's first formulations ${ }^{89}$ of the necessary and impair standards. ${ }^{90}$ In 2002, the US Court of Appeals-DC Circuit ${ }^{91}$ upheld the FCC's revised necessary standard ${ }^{92}$ but overturned its new impairment test. In 2004, the court ${ }^{93}$ was again critical of the FCC's third formulation ${ }^{94}$ of the impairment standard. However, in 2006, the

${ }^{88}$ See 47 USC 251(d)(2).

${ }^{89}$ Implementation of the Local Competition Provisions in the Telecommunications Act 1996, First Report and Order, CC Docket Nos 96-98, 95-185, FCC No 9-325, 11 FCC Rcd 15499 (1996). This report and order is also known as the Local Competition Order.

${ }^{90}$ FCC v Iowa Utilities Bd, 525 US 1133 (1999).

91 United States Telecom Association v FCC, 290 F 3d 415 (DC Cir 2001) (USTA 1).

92 Implementation of the Local Competition Provisions of the Telecommunications Act of 1996, Third Report and Order and Fourth Further Notice of Proposed Rulemaking, CC Docket No 96-98, FCC No 99-238, 15 FCC Rcd 3696 (1999). This report and order is also known as the UNE Remand Order.

93 United States Telecom Association v FCC, 359 F 3d 554 (DC Cir 2004) (USTA II).

${ }^{94}$ Review of the Section 251 Unbundling Obligations of Incumbent Local Exchange Carriers, Report and Order and Order on Remand and Further Notice of Proposed Rulemaking, CC Docket Nos 01-338, 96-98, 98-147, FCC No 0306, 18 FCC Red 16978 (2003). This report and order is also known as the Triennial Review Order. 
court ${ }^{95}$ upheld the FCC's new definition of impair developed in light of the 2004 ruling. ${ }^{96}$ As the court stated, 'the Commission's fourth try [was] a charm'. ${ }^{97}$ One of the consequences of the extensive litigation has been a shift to a higher threshold for unbundling than the FCC had originally envisaged and CLECs had wished. The revised standards implicitly adopt an 'essential-facilities' type focus which favours ILECs. ${ }^{98}$

\subsubsection{Co-location within ILEC premises}

An issue closely related to UNEs is co-location, which also proved to be highly contentious. As a result of the 1996 Act, ILECs are required to provide physical co-location of equipment necessary for interconnection or access to UNEs at their premises. Where subject to technical and space limitations, ILECs must provide virtual co-location. ${ }^{99}$ The FCC's Local Competition First Report and Order specified where CLECs could locate equipment, the types of equipment they could co-locate, and the allocation of space if insufficient physical colocation space existed. For example, space within an exchange was allotted on a first-come, first-served basis.

Covad Communications Co and DIECA Communications, Inc v FCC, 450 F 3d 528 (DC Cir 2006).

${ }^{96}$ Unbundled Access to Network Elements, Order on Remand, WC Docket No 04-313, CC Docket No 01-338, FCC No 04-290, 20 FCC Rcd 2533 (2005).

${ }^{97}$ Covad, $450 \mathrm{~F} 3 \mathrm{~d}$ at 531.

${ }^{98}$ For further information on the saga of the FCC's unbundling rules, see Karen Lee and Jamison Prime, 'Overview of US Telecommunications Law', Telecommunications Law and Regulation (2nd edn, OUP, 2005) 531-538.

${ }^{99}$ See 47 USC §251(c)(6). 
ILECs were not obliged to construct or lease additional space to facilitate co-location but had to take into account projected demand for co-location of equipment when planning construction work. In addition, ILECs who rejected co-location applications citing space constraints had to permit applicants to 'walk through' the relevant space so that they could confirm that no space was available.

Three years later, the FCC modified its rules in its Advanced Services Order ${ }^{100}$ to enable CLECs to share co-location space at an ILEC's premises and to co-locate equipment without the need for a cage surrounding their equipment. In addition, if there were insufficient co-location space, ILECs had to permit co-location in adjacent controlled 'environmental vaults' or similar structures where technically feasible. The FCC's order was challenged before the DC Circuit Court in GTE v FCC (205 F 3d 416 (DC Cir 2000)). Some of the order's provisions were upheld but the DC Circuit Court directed the FCC to reconsider rules requiring ILECs to permit the co-location of equipment which performs functions in addition to those strictly needed to interconnect or access UNEs and the cross-connection of CLEC equipment co-located at different ILEC premises. The right of CLECs to select the physical co-location space at an ILEC's premises and the prohibitions on ILECs requiring CLECs to use separate rooms for co-location were also overturned.

The FCC published its revised rules in $2001 .{ }^{101}$ It determined that ILECs had to permit CLECs to co-locate switching and routing equipment. Other multifunction equipment could be co-located only if its primary purpose was for interconnection and/or access. ILECs also had to provide cross-connection to CLECs co-located within the same premises as ILECs. The FCC's current co-location rules are set out in 47 CFR §51.323.

100 Deployment of Wireline Services Offering Advanced Telecommunications Capability, Third Report and Order in CC Docket No 98-147 and Fourth Report and Order in CC Docket No 96-98, FCC No 99-355, 14 FCC Rcd 20912 (1999).

101 Deployment of Wireline Services Offering Advanced Telecommunications Capacity, Fourth Report and Order, CC Docket No 98-147, FCC No 01-204, 16 FCC Rcd 15435 (2001). 


\subsubsection{Interconnection}

The 1996 Act, at 47 USC §251(a), imposes a duty on all telecommunications carriers to interconnect 'directly or indirectly' with the facilities and equipment of other carriers. ILECs must permit other carriers to interconnect to the PSTN at any technically feasible point in their networks to enable the transmission and routing of telephone exchange and exchange access services. ${ }^{102}$ The rates ILECs charge must be 'just, reasonable and

non-discriminatory, ${ }^{103}$ and any service provided by an ILEC must be equal in quality to the service it supplies to itself or any affiliate.

The responsibility for day-to-day interconnection issues, including determinations of whether or not rates are 'just and reasonable', falls to PUCs. However, in the Local Competition First Report and Order, the FCC mandated that the states had to apply the same long-run incremental cost methodology (LRIC) pricing standard it adopted for UNEs. PUCs challenged the FCC's decision but in FCC v Iowa Utilities Bd (525 US 1133 (1999)), the Supreme Court held that the FCC had the authority to direct states to adopt a uniform pricing methodology. The adoption of a LRIC standard was also attacked by ILECs but was ultimately upheld by the Supreme Court in Verizon v FCC (535 US 467 (2002)). The FCC may also directly intervene in interconnection disputes where a PUC fails to carry out its responsibilities under the Telecommunications Act of 1996 codified at 47 USC $\S 252$.

10247 USC $\$ 252(\mathrm{c})(2)(\mathrm{A})-(\mathrm{B})$.

10347 USC $\S 252(\mathrm{c})(2)(\mathrm{D})$. 
In an important ruling for VoIP providers in March 2007, ${ }^{104}$ the FCC affirmed that CLECs providing wholesale telecommunications services to VoIP service providers are entitled to interconnect with ILECs under $\$ 251(a)$ and (b) of the Act. Certain PUCs had denied CLECs rights of access to ILEC interconnection services in 2005 on the ground that CLECs were not telecommunications carriers when providing wholesale services to VoIP service providers - they were not offering 'telecommunications for a fee directly to the public'. The FCC's ruling enables the exchange of voice calls between broadband networks and the PSTN when VoIP service providers procure interconnection services through CLECs. The FCC has yet to determine if VoIP providers are 'telecommunications carriers' and consequently permitted in their own right to rely on $\$ 251$ of the Act to interconnect directly with ILECs.

There remain no FCC rules specific to the interconnection of IP networks, even though the Commission has recognised for many years that the rights and obligations of providers need to be clarified. However, it has adopted a number of measures designed to facilitate IP-to-IP interconnection. One example is its 2015 decision to permit interconnected VoIP providers to directly access telephone numbers from American numbering administrators. Previously, they had to obtain them from a telecommunications carrier. ${ }^{105}$ The FCC also continues to reiterate its expectation that carriers will negotiate IP-to-IP interconnection requests in good faith.

\subsubsection{Origination, transportation, and termination of calls}

\footnotetext{
104 Time Warner Cable Request for Declaratory Ruling that Competitive Local Exchange Carriers May Obtain Interconnection Under Section 251 of the Communications Act of 1934, as Amended, to Provide Wholesale Telecommunications Services to VoIP Providers, Memorandum Opinion and Order, WC Docket No 06-55, DA 07-709, 22 FCC Rcd 3513 (2007).
}

${ }^{105}$ Numbering Policies for Modern Communications, Report and Order, WC Docket Nos 13-97, 04-36, 07-243, 10-90; CC Docket Nos 95-116, 01-92, 99-200, FCC No 15-70, 30 FCC Rcd 6839 (2015). 


\subsubsection{Intercarrier compensation}

Currently, the rates carriers pay one another for origination, transportation, and termination of calls are determined by two different arrangements. Access charges - the fees interexchange carriers (IXCs) and 'commercial mobile radio services' carriers pay to LECs for originating, terminating, and transporting long-distance calls - are governed by determinations of the FCC. The FCC sets the rates for interstate access charges in accordance with $\S 201$ of the 1934 Act and a series of FCC rules contained in 47 CFR Part 69. Intrastate access charges are set by PUCs. Reciprocal compensation — the fees for terminating and transporting local calls—are set by PUCs with reference to a framework adopted by the FCC. ${ }^{106}$ PUCs can determine rates using LRIC methodology. In the event that a PUC lacks access to adequate cost information, it can determine a default rate. As a general rule, the rates for CLECs and ILECs have to be symmetrical, although asymmetrical rates can be used if certain conditions are met. PUCs can also select a 'bill and keep' arrangement, whereby neither carrier charges the other carrier for termination services, provided a roughly equivalent amount of traffic is exchanged between the two carriers. The 1996 Act, at 47 USC § 251(b)(5), imposes a general requirement on all LECs to establish reciprocal compensation arrangements.

Since the FCC's Declaratory Ruling in $1999^{107}$ when it first asserted jurisdiction over ISP-bound traffic, there has been growing recognition that the intercarrier compensation arrangements, which are based on perminute charges and were designed before the development of the internet, are in need of reform. It has been

10647 CFR $\S 51.701-51.717$.

107 Implementation of the Local Competition Provisions in the Telecommunications Act of 1996, Declaratory Ruling and Notice of Proposed Rulemaking, CC Docket Nos 96-98, 99-68, FCC No 99-38, 14 FCC Rcd 3689 (1999). The jurisdiction of the FCC to regulate ISP-bound traffic was upheld in Bell Atlantic Telephone Companies v FCC, $206 \mathrm{~F}$ 3d 1 (2000), although other aspects of the Declaratory Ruling were overturned. 
argued that, because termination rates are not uniform and are above cost, the current arrangements create opportunities for regulatory arbitrage and disincentives for carriers, particularly ILECs, to invest in broadband and IP technology. How to reform the current system, however, has been the subject of much dispute due to the amount of money involved, the entrenched positions of 'winners' under the existing regime, the effect reform will have on the funding for universal service, and the likelihood of price increases for consumers.

In April 2001, ${ }^{108}$ the FCC proposed a 'bill and keep' arrangement for all types of interconnection whereby carriers were not permitted to charge each other for call termination, although they could recover the carriage costs involved from their respective customers. Pending adoption of this arrangement, the FCC adopted an 'interim' arrangement for ISP-bound traffic. ${ }^{109}$ In 2005, the FCC consulted on a number of alternatives proposed by industry ${ }^{110}$ to the 'bill and keep' arrangement and, in 2006, sought comment ${ }^{111}$ on the 'Missoula Plan' 112 proposed by the National Association of Regulatory Utility Commissioners' Task Force on Intercarrier Compensation and supported by many in industry. In 2008, there was hope that the FCC would finally resolve the

108 Developing a Unified Intercarrier Compensation Regime, Notice of Proposed Rulemaking, CC Docket No 01-92, FCC No 01-132, 16 FCC Rcd 9610 (2001).

109 See ibid paras 77-88 for a description of the interim regime. The FCC argued that ISP-bound traffic was not subject to the reciprocal compensation requirements of $\$ 251(\mathrm{~b})(5)$. Nevertheless, it had authority to regulate ISP-bound traffic pursuant to $\S 251(\mathrm{~g})$ of the 1934 Act.

110 Developing a Unified Intercarrier Compensation Regime, Notice of Proposed Rulemaking, CC Docket No 01-92, FCC No 05-33, 20 FCC Rcd 4685 (2005).

111 Federal Communications Commission, Public Notice, Comment Sought on Missoula Intercarrier Compensation Reform Plan, DA 06-1510 (25 July 2006).

112 A copy of the plan is available at $<$ http://www.fcc.gov/wcb/ppd/IntercarrierCompensation/history.html $>$. 
intercarrier compensation issue, as a result of a decision of the Court of Appeals ${ }^{113}$ in 2008 which held that the interim arrangement for ISP-bound traffic would cease to have effect unless the FCC could identify a legal basis on which the FCC could exclude ISP-bound traffic from its reciprocal compensation rules. The decision was prompted by the FCC's failure to articulate a legal basis for the interim arrangement following the decision of the Court of Appeals in $2002^{114}$ not to vacate the FCC's decision adopting the interim rules even though it held the FCC could not base the interim regime on 47 USC $§ 251(\mathrm{~g})$ added by the 1996 Act. The unusual action of the Court of Appeals was a result of the court's belief that there was a strong likelihood that the FCC had statutory power to regulate ISP-bound

traffic. The FCC's response to the 2008 decision of the Court of Appeals disappointed many, however. Rather than announce sweeping reforms, the FCC, internally divided on the issue, adopted a narrow order ${ }^{115}$ to ad- $^{-}$ dress the specific concerns of the court, ${ }^{116}$ enabling the FCC to keep the interim arrangements in place, and solicited comment on yet another three proposals for reform. One proposed option involved doing nothing.

Unsurprisingly, the FCC task force responsible for development of the National Broadband Plan identified reform of the intercarrier compensation regime as a priority. It called for a three-stage reform process which

113 In re Core Communications, Inc, 531 F $3 \mathrm{~d} 849$ (2008).

114 WorldCom v FCC, 288 F 3d 429 (2002).

115 High-Cost Universal Service Support, Order on Remand and Report and Order and Further Notice of Proposed Rulemaking, WC Docket Nos 05-337, 03-109, 06-122, 04-36, CC Docket Nos 96-45, 06-122, 99-200, 96-98, 01-92, 99-68, FCC No 08-262, 24 FCC Rcd 6475 (2008).

116 The FCC determined that ISP-bound traffic was subject to the statutory requirements of reciprocal compensation. Nevertheless, it asserted it could regulate ISP-bound traffic in accordance with the interim arrangements as a result of $\S 201$ of the 1934 Act. 
included the rebalancing of intrastate and interstate termination rates and the abolition of per-minute charges phased in over time with corresponding incremental increases in subscriber line charges to offset revenue losses. Implementation of these broad objectives began in 2011 with the publication of a Report and Order and Further Notice of Proposed Rulemaking. ${ }^{117}$ In the Report and Order, the FCC adopted amendments to its interstate access rules to address the problems of 'access stimulation' ${ }^{118}$ and made changes to its call-signalling rules to stop the problem of 'phantom traffic'. ${ }^{119}$ Further, it stated the current per-minute system would eventually be replaced with a bill and keep framework as the default methodology for all intercarrier compensation traffic. Carriers remain free to negotiate alternative arrangements. In order to reach the goal of bill and keep, the FCC adopted a series of transitional arrangements which included capping rates for all forms of interstate access and intrastate termination. Carriers had to bring interstate and intrastate termination rates to parity by July 2013 and to gradually reduce their rates to bill and keep over a period of six to nine years, depending on the type of carrier involved. To help offset termination revenue lost during the period of transition, ILECs and other carriers may recoup some costs from their customers in accordance with FCC rules developed for this purpose and, in some instances, from the Connect America Fund (see Section 5.11). The FCC also adopted interim arrangements for VoIP-PSTN traffic but has yet to determine the appropriate transitional measures for

117 Connect America Fund, Report and Order and Further Notice of Proposed Rulemaking, WC Docket Nos 10-90, 07135, 05-337, 03-109, GN Docket No 09-51, CC Docket Nos 01-92, 03-109, WT Docket No 10-208, FCC No 11161, 26 FCC Rcd 17663 (2011).

118 Access stimulation occurs when LECs seek to generate revenue by increasing the volume of traffic terminated to their networks by entering into access revenue sharing agreements with high volume customers such as chat line and adult entertainment providers.

119 Phantom traffic is the practice of carriers and providers disguising the origin of calls in an effort to avoid or minimize termination payments. 
origination and transportation rates. The FCC has had to clarify the complex rules implementing its 2011 Report and Order on numerous occasions, ${ }^{120}$ but it remains committed to the adoption of a bill and keep framework.

\subsubsection{Calls to mobile}

The termination of calls to US mobile networks is not regulated. This is unlike the UK and Europe where a significant amount of regulatory resource has been directed to the prices mobile operators charge for terminating calls to their networks. In the US, the charges for calls to and from mobile phones are paid for by the mobile subscriber. There has been a lack of interest in 'calling party pays' (CPP) offerings, in the US, even though the FCC concluded in $2001^{121}$ that carriers were not precluded from offering CPP. Given the ongoing shift from voice to data services and the low cost of wireless calls (which many plans offer on an unlimited basis), CPP is not likely to become an issue in the future..

The FCC has not tried to regulate the termination rates for calls to overseas mobile networks, despite initiating a Notice of Inquiry to gather information on foreign mobile termination rates, action by overseas regulators, and the effect foreign termination rates were having on US consumers in October $2004 .{ }^{122}$

\footnotetext{
${ }^{120}$ See, eg, Connect America Fund, WC Docket No 10-90, CC Docket No 01-92, FCC No 15-14, 30 FCC Rcd 1587 (2015).

121 Calling Party Pays Service Offering in the Commercial Mobile Radio Services, Memorandum Opinion and Order on Reconsideration and Order Terminating Proceeding, WT Docket No 97-207, FCC No 01-125, 16 FCC Rcd 8297 (2001).
}

122 The Effect of Foreign Mobile Termination Rates on US Customers, Notice of Inquiry, IB Docket No 04-398, FCC No 04-247, 19 FCC Rcd 21395 (2004). 


\subsubsection{Re-sale}

47 USC §251(b)(1), added by the 1996 Act, requires all LECs to make their telecommunications services available for re-sale on reasonable and non-discriminatory terms. All resale services must be of equal quality and provided within the same period of time as LECs provide to others. ${ }^{123}$ The wholesale rates that incumbent LECs may charge are determined by PUCs, subject to directions from the FCC, and are calculated by reference to the retail rate for the relevant telecommunications service less 'the portion thereof attributable to any marketing, billing, collection and other costs ${ }^{124}$ avoided by the ILEC by not providing its services to retail customers. In its Local Competition First Report and Order, the FCC adopted a 'reasonably avoidable standard' to determine avoidable costs. However, the Commission's ILEC re-sale pricing rules were overturned by the Eighth Circuit Court of Appeals in Iowa Utilities Bd v FCC (219 F 3d 744 (2000)). The Court held that the FCC's interpretation was inconsistent with the plain meaning of the statute. The appropriate standard for determining avoided costs was those costs that the ILEC will actually avoid incurring in the future, because of its wholesale efforts, not costs that 'can be avoided'. The Court also stated that PUCs must assume that ILECs are acting as both a wholesale and retail provider when they determine costs whereas previously the FCC's rules had treated ILECs as only wholesalers. No modifications to the resale rules were made following the Court's decision, although the FCC sought comment on the need to adopt new rules implementing the relevant statutory provision in $2003 .{ }^{125}$

12347 CFR $\$ 51.603$.

12447 USC §252(d)(3).

${ }^{125}$ Review of the Commission's Rules Regarding the Pricing of Unbundled Network Elements and the Resale of Service by Incumbent Local Exchange Carriers, Notice of Proposed Rulemaking, WC Docket No 03-173, FCC No 03224, 18 FCC Rcd 20265 (2003). 


\subsubsection{Poles, ducts, conduits, and rights of way}

Section 224(f)(1) of the 1934 Act requires 'utilities'-ILECs and electric, gas, water, and other public utilities - to provide cable operators and 'telecommunications carriers' (a term interpreted by the FCC to include wireless providers ${ }^{126}$ ) with non-discriminatory access to any pole, duct, conduit, or right of way owned or controlled by them. Under the Act, a state may elect (but is not compelled) to regulate the rates, terms, and conditions of access by way of a process of FCC 'certification'. Absent certification, the FCC retains jurisdiction and access is governed by a series of rules set out in $\S \S 1.1401$ to 1.1424 of the CFR. Under these provisions, all requests for access must be in writing; utilities must either grant or reject the request within 45 days and provide evidence why a request cannot be granted. In the event of a dispute, the parties may refer the matter to the FCC for resolution.

The National Broadband Plan, which the FCC was required to submit to Congress in $2010,{ }^{127}$ highlighted a number of weaknesses in the FCC's rules dealing with pole attachments, including significant disparities between the rates cable and telecommunications carriers paid for access to poles (cable rates were lower) and inefficiencies in access procedures, all of which it was argued increased the cost of broadband deployment for both wireless and wired carriers. The FCC subsequently amended its rules in April $2011^{128}$ to establish a fourstage process for pole attachments, each with prescribed deadlines. Among other measures, it modified its cost

126 The FCC's interpretation received the backing of the Supreme Court in National Cable \& Telecommunications, Inc $v$ Gulf Power Co, 534 US 327 (2002).

${ }^{127}$ See further Section 5.11.1.

128 Implementation of Section 224 of the Act and a National Broadband Plan for Our Future, Report and Order and Order on Reconsideration, WC Docket No 07-245, GN Docket No 09-51, FCC No 11-50, 26 FCC Rcd 5240 (2011). 
formulae to ensure that the rates paid by telecommunications carriers were on par with those of cable operators and imposed obligations on parties to escalate disputes to their respective corporate executives prior to filing complaints with the FCC. In an Order on Reconsideration issued more than four years later, ${ }^{129}$ the FCC addressed concerns that its 2011 Order, as written, allowed pole owners to apply the cost formulae in a way that still allowed for disparities between the rates charged to cable and telecommunications carriers. The decision was intended to foster a more harmonised cost model to bring the cost of pole attachments for telecommunications carriers in line was the traditionally lower cable rate. This FCC's action was especially important in light of its decision to reclassify broadband services as telecommunications services. ${ }^{130}$ That decision led to the worry that pole owners would begin imposing higher telecommunications carrier rates on cable companies. Although a consortium of electric utilities challenged the FCC's decision, it was upheld in 2017 by the US Circuit Court of Appeals for the Eighth Circuit. ${ }^{131}$

The FCC continues to recognise that access to poles, conduits, ducts, and rights of way are keys to improved infrastructure use and broadband deployment, especially with the advent of 5G and the consequential need for additional mobile network infrastructure. Popular ideas being discussed by policymakers include mandating 'one touch' access in which a single construction crew would be permitted to complete all of the work necessary to make a pole ready for a new attachment, including making necessary modifications to existing equipment installed by attachers, and 'dig once' requirements in which in-street conduits must be built to accommodate future users so the streetscape is not re-disturbed. In 2017, the Commission formed a new federal advisory committee, the Broadband Deployment Advisory Committee, which will examine pole attachment and other infrastructure issues as it identifies ways to accelerate the deployment of broadband services.

\footnotetext{
${ }^{129}$ Implementation of Section 224 of the Act and a National Broadband Plan for Our Future, Order on Reconsideration, WC Docket No 07-245, GN Docket No 09-51, FCC No 15-151, 30 FCC Rcd 13731 (2015).

${ }^{130}$ See further Section 5.2.5.2.

${ }^{131}$ Ameren Corporation v FCC, 865 F 3d 1009 ( $8^{\text {th }}$ Cir 2017).
} 


\subsection{7 'Dialling parity'}

LECs are required to provide 'dialling parity' (or carrier pre-selection, as it is known in Europe) for all originating telecommunications services. LECs must not cause unreasonable dialling delay and must provide customers with the option of using different carriers for local calls as well as inter- and intraLATA services.

'Anti-slamming' measures prohibit carriers from changing a customer's designated carrier(s) without consent. In 2005, the FCC adopted rules governing the exchange of customer billing data between carriers to facilitate dialling parity. ${ }^{132}$

\subsubsection{Number portability}

The 1996 Act amended the 1934 Act to require LECs to provide number portability for fixed line numbers to the extent 'technically feasible' in accordance with requirements prescribed by the FCC. The FCC permits carriers to recover certain costs associated with number portability from other providers which use a carrier's number portability facilities to process their own calls and from end-users. Charges incurred by end-users are included in their monthly telephone bills. In 2003, the FCC clarified that wireline carriers must port numbers to wireless carriers where the coverage area of the wireless carrier overlaps with the geographic location in which a wireline number is provided. ${ }^{133}$ In 2007 , it extended the obligations of local number portability to providers offering interconnected VoIP services which

132 Rules and Regulations Implementing Minimum Customer Account Record Exchange Obligations on All Local and Interexchange Carriers, Report and Order and Further Notice of Proposed Rulemaking, CG Docket No 02-386, FCC No 05-29, 20 FCC Rcd 4560 (2005).

133 Telephone Number Portability, Memorandum Opinion and Order and Further Notice of Proposed Rulemaking, CC Docket No 95-116, FCC No 03-284, 18 FCC Rcd 23697 (2003). 
enable customers using a broadband connection to receive calls from and terminate calls to the PSTN. ${ }^{134}$ In 2015, following its decision to allow interconnected VoIP providers to obtain telephone numbers directly from numbering administrators, the Commission imposed a rule clarifying that all telecommunications carriers must facilitate a valid customer's request to port a telephone number to or from an interconnected VoIP provider. ${ }^{135}$

Relying on other powers in the 1934 Act, the FCC mandated in 1996 that all cellular, broadband PCS, and specialized mobile radio (SMR) providers (collectively referred to as commercial mobile radio service (CMRS)) had to enable their subscribers to port their wireless telephone numbers to other wireless carriers. Phased in over a number of years, wireless number portability has been available in all areas of the US since 24 May 2004. Wireless-to-wireline porting is also required in some cases, although the vast majority of porting has been away from wireline services.

\subsubsection{Siting of wireless towers and antenna}

Until adoption of the Telecommunications Act of 1996, the construction of antenna towers and other physical facilities had traditionally been regulated at the local level where it was subject to local zoning and land-use regulations. However, the 1996 Act's addition of \$332(c)(7) to the Communications Act of 1934, limited state and local authority over zoning and land use decisions for personal wireless service facilities. Under that provision, a state or local government may not unreasonably discriminate among providers of functionally equivalent wireless services and must not regulate in a manner that prohibits or has the effect of prohibiting the provision of personal wireless services. In addition, the Act requires state and local entities to act on applications

\footnotetext{
134 Telephone Number Requirements for IP-Enabled Service Providers, Report and Order, Declaratory Ruling, Order on Remand and Notice of Proposed Rulemaking, WC Docket Nos 07-243, 07-244, 04-36, CC Docket Nos 95-116, 99200, FCC No 07-188, 22 FCC Rcd 19531 (2007).
}

${ }^{135}$ See footnote 105. 
within a 'reasonable period of time'. These entities must also make any denial of an application in writing supported by substantial evidence in a written record. Furthermore, the Act expressly pre-empts decisions that are premised (either directly or indirectly) on the environmental effects of radio frequency (RF) emissions, so long as the provider complies with the FCC's RF rules.

Allegations that a state or local government has acted inconsistently with $\S 332(c)(7)$ are to be resolved exclusively by the courts. The extensive record of court decisions developed in this area generally has found in favour of wireless carriers seeking access to site towers, although municipalities have prevailed when they have accompanied their denials with a clear, written record, and when the courts have been convinced that they are not acting to effectively deny all new facilities. In AT\&T Wireless PCS v Virginia Beach, $155 \mathrm{~F} 3 \mathrm{~d}$ 423 (4th Cir 1998), the Court of Appeals for the Fourth Circuit found that the city of Virginia Beach did not violate the Act when it denied an application for approval to erect a communications tower on a church's roof despite the fact that the denial effectively precluded the provision of service to a part of the community. Subsequently, courts distinguished or explicitly rejected the Virginia Beach decision as not adequately recognizing the extent of pre-emption provided in the Telecommunications Act of 1996.

The FCC has frequently taken actions to try to reduce the regulatory barriers faced by providers who need to deploy additional towers and antenna to fulfil consumer demand. For example, in 2009 it defined the meaning of 'reasonable period of time' for the purposes of $\S 332(\mathrm{c})(7)$ as 90 days for co-location applications and 150 days for all other siting applications. ${ }^{136}$ Prior to its decision, there were reports of applications pending for up to three years. The National Broadband Plan the FCC submitted to Congress in 2010 emphasised the need for federal, state, and local governments to further minimize barriers to infrastructure roll-out, calling for,

136 Petition for Declaratory Ruling to Clarify Provisions of Section 332(c)(7)(B) to Ensure Timely Siting Review and to Preempt Under Section 253 State and Local Ordinances that Classify All Wireless Siting Proposals as Requiring a Variance, Declaratory Ruling, WT Docket No 08-165, FCC 09-99, 24 FCC Rcd 13994 (2009). 
among other things, the development of a standard form master contract for the placement of wireless towers on all federal land. The agency has also regularly turned to advisory committees to investigate this issue. The Technology Advisory Council has periodically examined wireless antenna requirements, recommendeding such measures as the adoption of an Executive Order to expedite the approval process for antenna sitings on federal land and the elimination of redundant requirements in state and local planning practices. The Broadband Deployment Advisory Committee, discussed in Section 5.10.6, is expected to identify barriers to wireless siting, particularly at the state and local levels. .

When making decisions in this area, the FCC has to consider the requirements imposed on it by the National Historic Preservation Act (NHPA), ${ }^{137}$ the Endangered Species Act (ESA), ${ }^{138}$ and the National Environmental Policy Act (NEPA). ${ }^{139}$ NEPA is a 'cross-cutting law' in that it applies broadly to federal undertakings and requires them to implement procedures which consider the potential environmental effects within the agency's decision-making process. FCC licensees and applicants are required to review whether or not their proposed actions will have environmental consequences and, if applicable, prepare an environmental assessment that leads to a series of steps designed to evaluate the environmental effect of the proposed action and, if

137 National Historic Preservation Act of 1966, Pub L No 89-665, 80 Stat 915 (1966) (codified as amended at 16 USC $\S 470$ et seq).

138 Endangered Species Act of 1973, Pub L No 93-205, 87 Stat 884 (1973) (codified as amended at 16 USC $\S 1531$ et seq).

139 National Environmental Policy Act of 1969, Pub L No 91-190, 83 Stat 852 (1970) (codified as amended at 42 USC $\S \S 4321-4347)$. 
the impact is significant, to seek alternatives or mitigations. The filing of an environmental assessment is required, among other times, when a proposed facility may have a significant effect on historic properties, could threaten endangered species or critical habitats, or may affect Native American religious sites.

One particular challenge has been the issue of migratory birds. Many parties, including the US Fish and Wildlife Service (FWS), have estimated that communications towers kill between four and five million birds per year, and have a potentially significant impact on migratory birds - including some 350 species of nightmigrating birds that may be affected by tower lights. Moreover, FWS has suggested that provisions of the Migratory Bird Treaty Act ${ }^{140}$ that allow for prosecution of individuals who kill migratory birds would apply when birds are struck and killed by flying into communications towers. In February 2008, the US Court of Appeals for the DC Circuit ${ }^{141}$ struck down a 2005 FCC decision denying a petition of the American Bird Conservancy and the Forest Conservation Council which requested, among other things, that the FCC prepare an environmental impact assessment of communications towers on migratory birds in the Gulf Coast region of the US. The 2008 decision of the Court of Appeals also triggered an ongoing nationwide environmental assessment of the FCC's antenna structure registration procedures. Since that time, federal agencies have worked to better harmonize their interests in this area, and to unify the guidance they give regarding tower siting issues. For example, the Federal Aviation Administration (FAA) has revised its procedures to make it easier to discontinue the use of steady burning lights on towers (which are more likely to attract birds); the FCC provides more detailed guidance for when tower construction might trigger the need to conduct an environmental assessment;

140 Migratory Bird Treaty Act of 1918 (3 July 1918; ch 128, 40 Stat 755) (codified as amended at 16 USC §703 et seq).

141 American Bird Conservancy, Inc and Forest Conservation Council v FCC, 516 F 3d 1027 (DC Cir 2008). 
and FWS has issued a set of recommended best practices for the design, siting, construction, operation, maintenance, and decommissioning of communications towers.

Wireless siting issues have taken on a newfound importance with the advent of $5 \mathrm{G}$ networks. The deployment of dense networks of small cells threaten to overwhelm existing site approval processes, and the Commission has indicated that it intends to play an active role in this area. A Notice of Proposed Rulemaking and Notice of Inquiry issued in April $2017^{142}$ critically reviewed, among other things, the FCC's existing rules and procedures for NHPA and NEPA review; asked about the use and impact of state and local moratoria; and proposed to 'deem granted' applications where there has been an unreasonable delay in the local review process. In announcing the proceeding, the Commission cited 'evidence that despite Commission action to reduce delays and costs of infrastructure review, providers continue to face significant costs and delays and reform may be needed.' At the time of writing, the outcome of the FCC's proposals were unknown. As with its past efforts in this area, the Commission will have to find ways to balance its obligation to promote the widespread availability of telecommunications with the interests of state, local and tribal communities, historical preservationists and environmental groups, as well as the limits imposed by NEPA and other laws.

\subsubsection{Roaming}

Since 2007, all Commercial Mobile Radio Service (CMRS) carriers offering text messaging, push-to-talk, and mobile voice and data services that interconnect to the PSTN must permit subscribers of other CMRS networks to 'roam' onto their networks on a non-discriminatory basis (with an exception for when the networks

\footnotetext{
${ }^{142}$ Accelerating Wireless Broadband Deployment by Removing Barriers to Infrastructure Investment, Notice of Proposed Rulemaking and Notice of Inquiry, WT Docket No 17-79, FCC No 17-38, 32 FCC Rcd 3330 (2017).
} 
are not technologically compatible). ${ }^{143}$ Following submission of the National Broadband Plan to Congress, the FCC moved swiftly to impose an obligation to roam on all facilities-based providers of commercial mobile data services, including those that do not interconnect with the PSTN. ${ }^{144}$ Subject to certain exceptions, facilities-based providers must enter into roaming arrangements with other providers on commercially reasonable terms and conditions. It provided further guidance on the commercially reasonable standard in a December, 2014 declaratory ruling. ${ }^{145}$ Within the US, roaming is no longer a significant consumer issue. Most carriers have implemented 'nationwide' plans and no longer charge for domestic roaming, although off-network access often does not provide the full breadth of services available on the user's home network and some carriers will limit or even cap excessive data use while roaming. Moreover, the prevalence of WiFi access offers an acceptable substitute in many cases. The experience is markedly different for travelers who leave the US, who remain subject to high international roaming charges for voice and data use.

\subsubsection{Network neutrality}

As already mentioned, the FCC's network neutrality framework was significantly altered in December 2017.

Prior to then, the framework was made up of the transparency and no blocking rules referred to Section

5.2.5.3, although the transparency rule was broadened in 2015 to require broadband providers to disclose

143 Reexamination of Roaming Obligations of Commercial Mobile Radio Service Providers, Report and Order and Further Notice of Proposed Rulemaking, WT Docket No 05-265, FCC No 07-143, 22 FCC Rcd 15817 (2007). The obligation arises from the FCC's interpretation of $\S \S 201$ and 202 of the 1934 Act.

144 Reexamination of Roaming Obligations of Commercial Mobile Radio Service Providers and Other Providers of Mobile Data Services, Second Report and Order, WT Docket No 05-265, FCC No 11-52, 26 FCC Rcd 5411 (2011).

${ }^{145}$ Reexamination of Roaming Obligations of Commercial Mobile Radio Service Providers and Other Providers of Mobile Data Services, Declaratory Ruling, WT Docket No 05-265, DA 14-1865, 29 FCC Rcd 15483 (2014). 
monthly service charges, other fees and data caps (if any) and information about the loss of information packets. However, small businesses, defined as providers with 100,000 or fewer subscriber lines, were exempt from these modifications. In addition, fixed and mobile broadband providers had to comply with the 'no-throttling', 'no-paid prioritization' and 'no-unreasonable interference/disadvantage' rules. The no-throttling rule prohibited the impairment or degradation of lawful Internet traffic on the basis of Internet content, application, or service, or use of a non-harmful device, subject to reasonable network management. The 'no-paid prioritization' rule prevented broadband providers from managing their networks in a manner that gave preference to some traffic over other traffic for consideration from a third party or to benefit an affiliated entity. Subject to reasonable network management, the no-unreasonable interference rule banned broadband providers from unreasonably interfering with or disadvantaging the ability of end users to select, access and use broadband internet access services or the lawful internet content, applications, services and devices of their choice. It also prohibited broadband providers from unreasonably interfering with or disadvantaging the ability of 'edge providers' providers of content, applications or services over the internet and providers of devices used for accessing content, applications or services over the internet - to make lawful content, applications, services or devices available to end users. As a result of the Commission's December 2017 decision, the network neutrality framework consists of only a transparency rule, although the FCC also mandates that broadband providers must inform their customers about their blocking, throttling, paid prioritization and affiliated prioritization practices.

\subsection{UNIVERSAL SERVICE OBLIGATIONS (USOS)}

\subsubsection{Policy and legislative background}


The concept of 'universal service' was coined by Theodore Vail, then Chairman of AT\&T, in $1907 .{ }^{146}$ Vail first conceived the term to promote a public policy whereby a telephone company would provide all who wanted service in an area in return for continued regulation as the sole service provider in a given area. Later, as universal service came to represent the policy that all Americans should have basic telephone access at a reasonable rate, the primary issues related to the subsidy of high-cost users (such as rural and residential customers) by low-cost users (such as urban and business customers).

Some 80 years after the concept was first adopted, Congress finally wrote the principle of universal service into law by enacting the Telecommunications Act 1996 which added $\S 254$ to the 1934 Act. However, Congress declined specifically to define universal service, instead recognizing it as an 'evolving level of telecommunications services'. When determining the services that should be provided universally under $\S 254$, the FCC is required to take into account 'advances in telecommunications and information technologies and services' and consider four factors, including, for example, whether a particular service is essential to education, public health, or public safety and a 'substantial majority' of residential customers have subscribed to the service. Universal service policy must also be informed by seven broad principles, such as that quality service should be available at just, reasonable, and affordable rates; that access to advanced telecommunications and information services should be provided in all regions of the US; and that low-income consumers and consumers in rural and other high-cost areas should have access to telecommunications services of the same quality and at the same rates as those provided to consumers in urban areas. The 1996 Act also expanded the concept of universal service to include the principle that health care providers in rural areas, schools, and libraries

\footnotetext{
146 Stated by Garnham, N, 'Universal Service', in Telecom Reform (ed Melody) (Technical University of Denmark, 1997) at 207. See also Chapter 4, at Section 4.8.
} 
should have access to advanced telecommunications services, such as the internet and other broadband services.

Following the adoption of the Act, the FCC developed four universal service programmes to implement §254: (1) a programme for low-income users; (2) the high-cost fund for rural communities; (3) the schools and libraries programme; and (4) a programme for public and non-profit rural health care providers. All four schemes were developed with the assistance of the Federal-State Joint Board, a body comprised of FCC commissioners, PUCs, and a state-appointed utility consumer advocate. The function of the Joint Board is to keep universal service policy and related mechanisms under review and make recommendations from time to time to the FCC.

Until the adoption of the American Recovery and Reinvestment Act of 2009 (the Recovery Act), the principal focus of the FCC's four universal service programmes was to ensure access to voice services. The schools and libraries programme (also known as the 'e-rate' programme) and the rural health care programme supported access to the Internet, but most universal service funding was spent on supporting voice services. Following the adoption of the Recovery Act, however, the focus of all four universal service programmes has shifted to ensuring access to broadband services. The Recovery Act required the FCC to develop a National Broadband Plan (NBP) that sought to 'ensure that all people of the United States have access to broadband capability'. The term broadband was not defined in the Recovery Act, but the plan the FCC submitted to Congress in March 2010 set a target of ensuring all households and business had affordable broadband access with an actual download speed of at least 4 Mbps and actual upload speed of at least 1 Mbps by 2020. The NBP also included a number of recommendations to ensure that schools, libraries and health care facilities had the high-speed broadband services and facilities needed for the $21^{\text {st }}$ century. 
Since submission of the NBP, the FCC has adopted 'support for advanced services' as a universal service principle which it must take into account when formulating universal service policy. ${ }^{147}$ Moreover, the FCC continues to revise its definition of advanced services. In 2016, for example, the Commission made universal service funding from the high-cost programme available to certain carriers on the condition they offer broadband services with a minimum download speed of $25 \mathrm{Mbps}$ and a minimum upload speed of $3 \mathrm{Mbps} .{ }^{148}$ The Commission has also adopted numerous measures to reform its universal service programmes, but many of the programmes are still in a state of transition. For the time being, they support voice; broadband services; and bundled voice and broadband services, but the FCC intends to eliminate support for voice services in the future. The current programmes, each of which is administered by the Universal Service Administrative Company (USAC), an independent, not-for-profit corporation appointed by the FCC, in accordance with Part 54 of the Commission's rules, are discussed below. ${ }^{149}$

\title{
5.11.2 Existing programmes and proposed reforms
}

\author{
5.11.2.1 The low-income scheme
}

147 See Connect America Fund, Report and Order and Further Notice of Proposed Rulemaking, WC Docket Nos 10-90,
$07-135,05-337,03-109$, GN Docket No 09-51, CC Docket No 01-92, 96-45, WT Docket No 10-208, FCC No 11-161, 26
FCC Rcd 17663 (2011). Under $\S 254($ b)(7), the FCC may adopt other universal service principles to protect 'the public,
convenience and necessity'.
${ }^{148}$ See Connect America Fund, Report and Order, Order and Order on Reconsideration, and Further Notice of Proposed
Rulemaking, WC Docket Nos 10-90, 14-58; CC Docket No 01-92, FCC No 16-33, 31 FCC Rcd 3086 (2016).

${ }^{149}$ For a summary of the programmes prior to the adoption of the NBP and the reforms needed to them as a result of the NBP, see chapter 5 in the previous edition of this book. 
Lifeline is the principal programme to assist low-income subscribers. Eligible subscribers are entitled to discounts on communications services specified by the FCC. Until 2012, these services were limited to switched telephony, but they now comprise all voice telephony services (fixed and mobile) and, since 2016, broadband services (fixed and mobile) and bundled voice and broadband services. Current rules dictate that from 2021, Lifeline services will consist only of broadband services (fixed and mobile) and bundled voice and broadband services that meet minimum service standards. ${ }^{150}$ It appears that these rules will be unaffected by the FCC's decision to reclassify broadband services as information services. The FCC has stated that it will continue (and has the legal authority under $\$ 254(\mathrm{e})$ of the $1934 \mathrm{Act}^{151}$ ) to maintain support for broadband services in the Lifeline programme. ${ }^{152}$

All Lifeline services are supplied by 'eligible telecommunications carriers' (ETCs). Voice providers are designated as ETCs by PUCs. At the time of writing, broadband providers are designated as ETCs by the FCC, but it is intended that they will be designated by PUCs in the future. ${ }^{153}$ ETCs must provide the specified services in accordance with standards set by the FCC. At the time of writing, fixed broadband services must have a minimum download speed of $10 \mathrm{Mbps}$ and a minimum upload speed of $1 \mathrm{Mps}$; mobile broadband services must have speeds of $3 \mathrm{G}$ mobile technology or better. The minimum data usage for fixed broadband services is 150 GB per month. For mobile broadband services, it is $500 \mathrm{MB}$ per month, but it will rise to 2 GB per month by December 2018.

\footnotetext{
${ }^{150}$ Lifeline and Link Up Reform and Modernization, Third Report and Order, Further Report and Order, and Order on Reconsideration, WC Docket Nos 11-42, 09-197, 10-90, FCC No 16-38, 31FCC Rcd 3962 (2016).

${ }^{151}$ Section 254(e) states, '[a] carrier that receives such [universal service] support shall use that support only for the provision, maintenance, and upgrading of facilities and services for which the support is intended.'

${ }^{152}$ See Restoring Internet Freedom, above n 39, para 193.

${ }^{153}$ Bridging the Digital Divide for Low-Income Consumers, WC Docket Nos 17-287, 11-42, 09-197, FCC No 17-155, 32 FCC Rcd 10475 (2017).
} 
In addition to the Lifeline programme, there is the Link Up programme. It provides eligible low-income subscribers living on Native American land with discounts on the installation costs associated with Lifeline services and allows them to defer payment on any remaining charges.

Over the last few years, the FCC has been particularly concerned with stopping waste, fraud and abuse of the low-income scheme. To that end, it has required USAC to develop a National Lifeline Accountability Database. The database contains subscriber information provided by ETCs and is used to identify subscribers receiving Lifeline services from more than one ETC. ${ }^{154}$ The FCC has also adopted national eligibility criteria for subscribers. Until 2012, PUCs were permitted to adopt their own eligibility criteria. In 2016, the FCC directed USAC to establish a National Lifeline Eligibility Verifier, whose function is to determine if subscribers meet eligibility criteria. Previously, ETCs assessed the eligibility of Lifeline applicants. These measures were taken following reports critical of previous versions of the Lifeline and Link Up schemes by the Government Accountability Office in 2008 and 2010.

\subsubsection{Connect America Fund}

The Connect America Fund (CAF), also known as the high-cost program, is intended to ensure the provision of affordable voice and broadband services, fixed and mobile, to areas in the US where the cost of those services, absent subsidies, would be much higher than the national average. Funds are allocated to ETCs to help offset, for example, the cost of providing and maintaining local loops and deploying fixed and mobile broadband infrastructure in rural and other underserved areas. CAF is the most complex and costly of the four universal service programmes. Its annual budget is $\$ 4.5$ billion.

\footnotetext{
${ }^{154}$ Lifeline and Link Up Reform and Modernization, Report and Order and Further Notice of Proposed Rulemaking, WC Docket Nos 11-42, 03-109, 12-23, CC Docket No 96-45, FCC No 12-11, 27 FCC Rcd 6656 (2012).
} 
CAF consists of three components: the support programs for price cap and rate-of-return carriers that support voice and broadband services, and the Mobility Fund (MF), which supports the provision of mobile broadband services in high-cost areas. Price cap carriers are dominant LECs, such as BOCs and other large and medium-sized carriers, subject to price cap regulation. Rate-of-return carriers are ILECs subject to rate of return regulation. In 2011 when the FCC began the process of reforming the high-cost program by issuing its USF/ICC Transformation Order, ${ }^{155} 83$ per cent of the people that had no broadband were living in high-cost areas served by price cap carriers. Rate-of-return carriers served less than five per cent of all access lines in the US.

Following submission of the NBP, a great deal of the FCC's attention in this area has been directed toward ensuring broadband deployment. In 2012, the FCC awarded \$115 million to price cap carriers to support the roll out of broadband infrastructure, as part of a program called CAF Phase I, and \$300 million to wireless carriers to support the deployment of $3 \mathrm{G}$ services in high-cost areas, as part of a program called MF Phase I. In 2015, as part of a program called CAF Phase II, ten price cap carriers accepted \$9 billion from the FCC. In exchange, they agreed to provide broadband services with a minimum download speed of $10 \mathrm{Mbps}$ and a minimum upload speed of 1 Mbps to 85 per cent of the high-cost areas served within three years and 100 per cent of the high-cost areas served within five years. ${ }^{156}$ The support each carrier received was calculated by reference to a forward-looking cost model known as the Connect America Cost Model (CAM) ${ }^{157}$ and will be paid annually over six years. In 2016, the FCC announced a similar scheme for rate-of-return carriers, although they will be funded for 10 years and their roll-out obligations will differ. ${ }^{158}$ In 2017 , the Commission launched MF Phase II

\footnotetext{
${ }^{155}$ See footnote 147 above. The order was challenged but was eventually upheld by the Court of Appeals. See Direct Communications Cedar Valley v FCC, 753 F 3d 1015 (2014).

${ }^{156}$ Connect America Fund, Report and Order, WC Dockets Nos 10-90, 14-58, 14-192, FCC No 14-190, 29 FCC Rcd 15644 (2014).

${ }^{157}$ Connect America Fund, Report and Order, WC Dockets Nos 10-90, 05-337, DA No 14-534, 29 FCC Rcd 3964 (2014).
}

${ }^{158}$ See footnote 148 above. 
during which the FCC will offer wireless carriers $\$ 453$ million in financial support annually over a period of 10 years. In exchange, wireless carriers must deploy 4G LTE services. ${ }^{159}$

The FCC continues to support price cap carriers who provide voice services in high-cost areas, although the amount of money received by price cap carriers has been frozen since 2011 and will continue to be reduced over time. Rate-of-return carriers also remain eligible for CAF Broadband Loop Support (BLS) (formerly known as Interstate Common Line Support), provided there is no other unsubsidized competitor in the area served, and High Cost Loop Support (HCLS), which supports voice services. However, the FCC plans to abolish BLS and HCLS and develop a single CAF programme for rate-of-return carriers.

A notable development across the high-cost programmes has been the FCC's use of reverse auctions to award available funding. In a reverse auction, carriers bid for the subsidy they need to provide services in specified areas. The winning bidder is the carrier that needs the smallest subsidy. Reverse auctions were first used in MF Phase I and will be used in MF Phase II. Moreover, the FCC is already planning the first CAF Phase II auction ${ }^{160}$ and intends that all available funds will be awarded by a competitive bidding process.

\subsubsection{E-rate}

With a budget of $\$ 3.9$ billion, the 'e-rate' programme provides discounts of between 20 to 90 per cent on communications services specified by the FCC to schools and libraries. The precise discount a school or library receives depends on the household income levels of students in the community and whether the school or library is in an urban or rural area. The services that currently attract a discount include voice services, data transmission

\footnotetext{
${ }^{159}$ Connect America Fund, Report and Order and Further Notice of Proposed Rulemaking, WC Docket No 10-90, WT Docket No 10-208, FCC No 17-11, 32 FCC Rcd 2152 (2017).

${ }^{160}$ Connect America Fund, Report and Order and Further Notice of Proposed Rulemaking, WC Dockets Nos 10-90, 1458, 14-259, FCC No 16-64, 31 FCC Red 5949 (2016); Connect America Fund, Report and Order and Order on Reconsideration, WC Dockets Nos 10-90, 14-5, FCC No 17-12, 32 FCC Rcd 1624 (2017).
} 
services, Internet access, internal connection services and equipment necessary for high-speed broadband connectivity, related maintenance and managed internal broadband services, such as WiFi. However, the FCC plans to eliminate all support for voice services in the near future, so that all funding can be directed to achieving the programme's principal goal: ensuring 'affordable access to high-speed broadband sufficient to support digital learning in schools and robust connectivity for libraries' ${ }^{161}$

The FCC continues to work toward the high-speed Internet access and WAN connectivity targets it set for schools and libraries in July 2014. The Commission has, for example, amended its rules to permit schools and libraries to build their own broadband facilities in certain circumstances and has required recipients of highcost program funding to offer high-speed broadband services to schools and libraries. ${ }^{162}$ For schools, the highspeed Internet access target is $1 \mathrm{Gbps}$ per 1,000 students and staff. Libraries serving less than 50,000 people must have Internet access with speeds of at last $100 \mathrm{Mbps}$. For libraries serving more than 50,000 people, the Internet access target is $1 \mathrm{Gbps}$. The WAN connectivity target for schools is $10 \mathrm{Gbps}$ per 1,000 students and staff.

\subsubsection{Rural health care programme}

\footnotetext{
${ }^{161}$ Modernizing the E-rate Program for Schools and Libraries, Report and Order and Further Notice of Proposed Rulemaking, WC Docket No 13-184, FCC No 14-99, 29 FCC Rcd 8870 (2014).

${ }^{162}$ Modernizing the E-rate Program for Schools and Libraries, Second Report and Order and Order on Reconsideration, WC Docket Nos 13-184, 10-90; FCC No 14-189, 29 FCC Rcd 15538 (2014).
} 
The rural health care programme consists of two principal components: the Healthcare Connect Fund (HCF), established in 2012, ${ }^{163}$ and the Telecommunications Program. ${ }^{164}$ HCF subsidises the provision of high-speed broadband services and related equipment to individual public and non-profit rural health care providers and to consortia of these providers; and the construction of high-speed broadband networks by consortia of rural and non-rural health care providers. Health care providers include hospitals, community health centres, mobile clinics, local health departments and, following the passage of the Rural Health Care Connectivity Act in 2016, 'skilled nursing facilities'. HCF was modelled on the FCC's Rural Health Care Pilot Program, a program designed in 2006 to increase use of the rural health care programme. The Telecommunications Program subsidises the provision of telecommunications services. HCF and the Telecommunications Program are administered in a similar fashion as the schools and libraries programme. The annual budget for rural health care programme has been capped at US\$400 million.

\subsubsection{Funding}

Prior to the 1996 Act, universal service was paid for predominantly by AT\&T and other large long-distance providers. Under the 1996 Act, all telecommunications carriers providing interstate and international telecommunications services to the public and other designated providers must pay towards the cost of universal service unless their contribution is less than US $\$ 10,000 .{ }^{165}$ The meaning of interstate and international services is

\footnotetext{
${ }^{163}$ Rural Health Care Support Mechanism, Report and Order, WC Docket No 02-60, FCC No 12-150,27 FCC Rcd 16678 (2012).

16447 CFR §54, Subpart G

16547 CFR $§ 54.706(a)$.
} 
broad and encompasses satellite, mobile, and payphone services. Telecommunications carriers and interconnected VoIP providers ${ }^{166}$ pay quarterly charges toward universal service provision to USAC, which in turn makes payments in support of the universal service fund programmes.

Contributions are calculated by multiplying the projected revenues for interstate and international telecommunications services of a provider (less its projected universal service contribution) by a 'contribution factor' ${ }^{167}$ Quarterly, the FCC determines the contribution factor, which is the ratio of the total projected costs of the four universal service programmes for that period and the total projected revenue for all interstate and international telecommunications services offered by all providers who must contribute to the scheme less their total estimated universal service contributions. ${ }^{168}$ Providers are permitted to pass on some of these charges to their customers. ${ }^{169}$ Revenue from interstate and international telecommunications services has, however, been falling for years due to rigorous competition for long-distance services and the use of IP-enabled technologies. The bundling of interstate and intrastate services and other products and the availability of wireless packages that enable users to make long-distance calls at no additional cost have also made it difficult to determine if all interstate revenue is being fully counted.

166 Universal Service Contribution Methodology, Report and Order and Notice of Proposed Rulemaking, WC Docket No 06-122, CC Docket Nos 96-45, 98-171, 90-571, 92-237, 99-200, 95-116, 98-170, WC Docket Nos 06-122, 0436, FCC No 06-94, 21 FCC Rcd 7518 (2006) (upheld in Vonage Holdings Corp v FCC, 489 F 3d 1232 (DC Cir 2007)).

16747 CFR $§ 54.709$ (a) and (a)(1).

16847 CFR §54.709(a)(2).

16947 CFR §54.712(a). 
As early as 2001 and 2002, the FCC considered alternatives to its current approach in an attempt to increase available funding and to ensure that telecommunications carriers contribute to the fund equally. ${ }^{170}$ All involved the imposition of a flat-rate fee on providers. However, the criterion on which the flat-rate fee would be imposed differed. Under the first approach, the fee would be imposed for each residential, single-line business, payphone, mobile wireless, and pager connection. Contributions in the second approach were determined by the maximum capacity of a customer's connection. The third approach imposed a fee for each telephone number assigned to a customer and the capacity of any connection for customers not allocated any numbers. In 2008, the FCC sought comment on two variations of these methods. ${ }^{171}$ In the first option, subject to certain exceptions, any provider (other than a wireless prepaid provider) who assigned a telephone number to a residential customer would pay a US\$1 per month for each number. Fees for wireless prepaid providers would be determined by an alternative formula which took into account the number of monthly minutes generated by the provider. All providers of business services would be required to pay a fee based on the number of businesses connected to the public network. In the second option, arrangements similar to those in the first option would apply for residential customers, although the amount contributed per number would be US\$.85 per month. The contribution for providers of business services would be determined by the number and capacity of the dedicated access connections used by their business customers. Each connection with a capacity of up to 64 kbps would incur a charge of US\$5; each connection in excess of $64 \mathrm{kbps}$ would incur a charge of US\$35.

170 Federal-State Joint Board on Universal Service, Notice of Proposed Rulemaking, CC Docket Nos 96-45, 98-71, 90571, 92-237, 99-200, 95-116, 98-170, FCC No 01-145, 16 FCC Rcd 9892 (2001); Further Notice of Proposed Rulemaking and Report and Order, CC Docket Nos 96-45, 98-71, 90-571, 92-237, 99-200, 95-116, 98-170, FCC No 02-43, 17 FCC Rcd 3752 (2002); and Report and Order and Second Further Notice of Proposed Rulemaking, CC Docket Nos 96-45, 98-71, 90-571, 92-237, 99-200, 95-116, 98-170, FCC No 02-329, 17 FCC Rcd 24952 (2002).

171 High-Cost Universal Service Support, n 94, Appendix A paras 92-156; Appendix B paras 39-104; Appendix C paras 88-151. Appendix A and Appendix $\mathrm{C}$ are in all material respects the same. 
The NBP recommended that the contribution base for universal service be broadened. In response, the FCC again sought comment on who should contribute to the universal service fund and how contributions should be assessed. ${ }^{172}$ It asked if providers of certain specified services, such as text messaging and broadband Internet access services, should contribute; or if all providers of interstate information and telecommunications services, subject to some exclusions, should contribute. It also asked if contributions of providers should be assessed by reference to their revenue; the number of connections to communications networks they provide to customers; the amount of telephone numbers assigned to them; or by either of the two approaches on which it consulted in 2008. However, no changes to the FCC's rules were made. In 2014, the FCC asked the Federal State Joint Board to make recommendations as to how it should modify its universal service contribution methodology by 7 April 2015. ${ }^{173}$ Shortly before the Joint Board's report was due, broadband services were reclassified as telecommunications services. Consequently, broadband providers could have been required pursuant to Title II to contribute to the universal service fund. However, the FCC decided it would forebear from enforcing the contribution obligations and indicated it would revisit its decision following receipt of the Joint Board's report. At of the time of writing, the Joint Board has still not produced a report; the FCC is considering reclassifying broadband services as information services; and the complex issues surrounding how best to secure funding for the universal service programmes remain unresolved. In the meantime, the quarterly contribution factor continues to rise. In the first quarter of 2017, it was 16.7 per cent.

\subsection{COMPETITION LAW}

\footnotetext{
${ }^{172}$ Universal Service Contribution Methodology, Further Notice of Proposed Rulemaking, WC Docket No 06-122, GN Docket 09-51, FCC No 12-46, 27 FCC Rcd 5357 (2012).

${ }^{173}$ Federal State Joint Board on Universal Service, Order, WC Docket Nos 96-45, 06-122 and GN Docket No 09-51, FCC No 14-116, 29 FCC Rcd 9784 (2014).
} 
As discussed in Section 5.4.3, the Department of Justice (Telecommunications and Media Enforcement Section) (DoJ) is the federal body primarily responsible for the enforcement of US anti-trust law in the telecommunications sector. The Federal Trade Commission (FTC) looks after the cable and ISP sectors. The two key pieces of legislation they enforce are the Sherman Anti-trust Act and the Clayton Act, both of which have been interpreted extensively by the courts. These Acts contain

provisions which prohibit anti-competitive agreements, market abuse by monopolists, and other restrictive practices. The Clayton Act (as amended by the Hart-Scott-Rodino Antitrust Improvements Act of $1976^{174}$ ) and related regulations also require parties to mergers and other acquisitions to notify such transactions to the DoJ and the FTC and to obtain clearance from the relevant organization before their consummation. As a result, the DoJ and FTC have significant oversight of the structural changes occurring across the communications sector. Third parties damaged by anti-competitive conduct also have rights to bring private actions against operators and others for alleged violations of anti-trust legislation, and a number of claims have been made against them.

\subsubsection{Anti-competitive agreements/monopolies}

Section 1 of the Sherman Anti-trust Act mirrors the prohibitions of Article 101 of the EC Treaty. ${ }^{175}$ Section 1 declares all contracts, combinations, and conspiracies that restrain trade between the 50 states of the US and foreign countries to be illegal. The Supreme Court has ruled that there are two types of conduct caught by $\S 1$ : conduct that is 'per se illegal' and conduct which violates the so-called 'rule of reason'.

An example of conduct which is 'per se illegal' is price fixing. Conduct is contrary to the rule of reason when

${ }^{174}$ Pub L No 94-435, 90 Stat 1390 (codified at 15 USC §18a).

175 See further Chapter 10. 
it is otherwise lawful but unreasonably restrains trade. Such conduct is reviewed on a case-by-case basis and in light of its pro- and anti-competitive effects on relevant market(s).

In 2000, the DoJ and the FTC issued 'Antitrust Guidelines for Collaborations among Competitors' which sets out the general principles that both agencies will use when reviewing agreements between competitors and the potential competition concerns likely to arise from collaboration. Section 1 of the Sherman Anti-trust Act does not expressly permit either the DoJ or the FTC to exempt anti-competitive behaviour from the Act where it 'contributes to improving the production or distribution of goods or to promoting technical or economic progress, while allowing consumers a fair share of the resulting benefit . ..'; nevertheless, in practice, the procompetitive effects of agreements will be taken into account by the courts, the DoJ, and the FTC when assessing whether or not an agreement unreasonably restrains trade.

Section 2 of the Sherman Anti-trust Act makes it unlawful for natural persons and legal entities to monopolize any part of trade or commerce between the 50 states and foreign countries. Monopolies are not per se illegal but where a party has acquired or intends to acquire market power through anti-competitive means then a violation of $\S 2$ of the Sherman Anti-trust Act will occur. Where trade with foreign countries is involved, $\S \S 1$ and 2 of the Sherman Anti-trust Act are not violated unless the conduct has a direct, substantial, and reasonably foreseeable effect on domestic trade or commerce, or on export trade or commerce of a person engaged in such trade or commerce in the US.

Of the two provisions, it is the application of $\S 2$ of the Sherman Act by the DoJ which has had greater effect on the telecommunications industry due to AT\&T's historical monopoly and the degree of market power ILECs hold in local access markets.

\subsubsection{Price discrimination and other practices}


The provisions of the Sherman Anti-trust Act are supplemented by $\S \S 2$ and 3 of the Clayton Act. These provisions make it unlawful for persons involved in commerce to discriminate in price between similarly situated purchasers of like products where the effect of such discrimination may be 'substantially to lessen competition or tend to create a monopoly'. Discrimination is permissible, however, where price differences arise due to the cost of manufacture, sale, or delivery. Other provisions

prohibit the payment or acceptance of bribes, discrimination in rebates, discounts or advertising services, and sales conditional on the non-use of goods or services of a competitor.

\subsubsection{Penalties for non-compliance}

A breach of $\S 1$ of the Sherman Anti-trust Act renders the underlying agreement void. Both the DoJ and FTC may bring civil prosecutions in a federal court against offenders. Only the DoJ can prosecute criminal action. Persons who participate in unlawful restraints of trade face severe fines and/or criminal penalties if convicted. Individuals may be fined up to US\$1 million and be imprisoned for up to ten years. Corporations may be fined up to US\$100 million for each offence. Similar penalties may be imposed by a court if $\S 2$ of the Sherman Anti-trust Act is violated. Violations of $\S \S 2$ and 3 of the Clayton Act may result in fines but they carry no criminal penalties.

The DoJ has adopted 'leniency' policies for corporations ${ }^{176}$ and individuals ${ }^{177}$ who report anti-trust violations previously unknown to the DoJ. Corporations and individuals who confess their involvement, fully cooperate with the DoJ, and agree to other conditions will not be charged with criminal law violations.

176 Department of Justice, Corporate Leniency Policy, available at $<$ http://www.usdoj.gov/atr/public/guidelines/0091.htm>.

177 Department of Justice, Leniency Policy for Individuals, available at $<$ http://www.usdoj.gov/atr/public/guidelines/0092.htm>. 
Individuals who are injured as the result of conduct in contravention of anti-trust law may also sue the offender(s) in a federal district court. If successful, they may recover three times the damages they suffered plus reasonable attorney's fees. ${ }^{178}$ The possibility of treble damages provides a powerful incentive for private parties to enforce anti-trust legislation, and a number of competitors to and consumers of leading communications operators and providers in the US have sought to enforce anti-trust law directly through the courts. Over the years, individuals have filed suits alleging breaches of $\S \S 1$ and 2 of the Sherman Anti-trust Act in a number of markets. Most lawsuits were unsuccessful. Nevertheless, the option remains available for those who believe that a competitor or a supplier has acted in contravention of anti-trust law.

\subsubsection{Investigations}

The DoJ and FTC may initiate investigations into alleged anti-competitive practices following internal reviews by in-house economists and lawyers and complaints from industry participants, concerned citizens, informants, and other government agencies. Both may compel legal and natural persons to produce information and other documentation relevant to a civil investigation by serving a Civil Investigative Demand (CID). They may request in a CID for a witness to give oral testimony or to answer questions in writing. Evidence in relation to criminal investigations is gathered by the DoJ pursuant to subpoenas issued by a grand jury. Assistance from the Federal Bureau of Investigation and other federal agencies may also be requested during investigations. ${ }^{179}$

178 Clayton Act, $\S 4(a), 15$ USC $\S 15$.

179 For further information about the procedural matters surrounding a DoJ investigation, see the DoJ's Antitrust Division Manual available at <http://www.justice.gov/atr/public/divisionmanual>. For a copy of the FTC's manual, see $<$ http://www.ftc.gov/foia/ch03investigations.pdf $>$. 


\subsubsection{Regulatory double jeopardy?}

The behaviour of operators and service providers in the US is subject to anti-trust law as well as the regulatory requirements set out in the Communications Act of 1934 and enforced by the FCC. In theory, certain conduct could violate both anti-trust law and regulatory rules. However, in Verizon Communications Inc v Law Offices of Curtis V Trinko, LLP (540 US 398 (2004)), a case where a violation of $\S 2$ of the Sherman Anti-trust Act was not sustained in part because the FCC had adopted rules pertaining to unbundled network elements and taken enforcement action against Verizon, the Supreme Court stated that where a regulatory structure is designed to deter and remedy anti-competitive harm, it is less likely that anti-trust law requires any additional scrutiny. In other words, no anti-trust liability is likely to arise where regulation exists to prevent or remedy anti-competitive harm. By implication, alleged behavior that may violate anti-trust law and regulatory requirements is more expeditiously assessed and evaluated in accordance with regulatory law. Although more than a decade old, the case remains good law and continues to be cited and followed by federal courts.

\subsubsection{Mergers}

Section 7 of the Clayton Act prohibits the acquisition of shares or capital in a natural or legal entity engaged in commerce or related activities affecting commerce where such acquisition may be 'substantially to lessen competition, or to tend to create a monopoly'. This provision covers mergers, asset and share purchases, joint ventures, and other acquisitions. The DoJ is responsible for ensuring that mergers in the telecommunications sector comply with $\S 7$. Reviewing mergers of cable operators and ISPs is the duty of the FTC.

The DoJ and the FTC have issued a number of guidelines relating to horizontal and non-horizontal mergers. The Horizontal Merger Guidelines were first issued in 1992 and were revised in 1997 and 2010. The Guidelines focus on market definition and concentration, the potential adverse competitive effects of mergers, the ability of new participants to enter the relevant market(s), efficiencies resulting from the merger, and the 
likelihood of either party to the merger failing if the merger does not take place. The Non-Horizontal Merger Guidelines were issued in 1984. Non-horizontal or vertical mergers are less likely to give rise to competition concerns but the guidelines set out the principal theories under which either the DoJ or FTC would challenge non-horizontal mergers. These include the elimination of actual or potential competition, the creation of barriers to entry, and the ability of vertical mergers to facilitate collusion at retail levels and in downstream markets.

Since 1978, unless exempted by $§ 7 A(c)$ of the Clayton Act, mergers which meet specified criteria must be notified prior to the consummation of the transaction to both the DoJ and the FTC. ${ }^{180}$ As a general rule, the purchaser and the target of the acquisition must notify the DoJ and the FTC if the following conditions ${ }^{181}$ are satisfied:

1. if one person has sales or assets of at least US\$100 million; the other person has sales or assets of at least US\$10 million; and as a result of the transaction the acquiring person will hold an aggregate amount of stock and assets valued at more than US\$50 million of the acquired person but less than US\$200 million; or

2. as a result of the transaction, the acquiring person will hold an aggregate amount of stock or assets of the acquired person valued at more than US\$200 million regardless of the sales or assets of the acquiring and acquired person.

Failure to notify may result in civil penalties or a court order requiring the parties to divest any assets acquired in violation of the Clayton Act if the transaction is already consummated.

180 See the Clayton Act $§ 7 A(a)$ and the Premerger Notification Rules found at 16 CFR Parts 801, 802, and 803.

181 Note the monetary thresholds are adjusted annually. 
Notifying parties must complete and have certified a Notification and Report Form, which requires the notifying parties to provide details about the transaction and information about acquisitions made in the last five years. The notifying parties must inform the DoJ and FTC if the acquiring person and acquired entity earn revenue from businesses that fall within any of the same industry and product codes in accordance with the North American Industry Classification System and, if so, the geographic areas in which they operate. They must also pay the appropriate filing fee which is determined by reference to the value of the transaction. Notifying parties may voluntarily submit additional information to facilitate review of the transaction.

After a Notification and Report Form is submitted, both the DoJ and the FTC review the Form. The notifying parties must usually wait a minimum of 30 days ( 15 days in the case of a cash tender sale or bankruptcy sale) before they may consummate a transaction. Parties may request early termination of the waiting period; however, requests for early termination are granted only where the DoJ and the FTC have completed their preliminary reviews and have concluded they will not take any enforcement action against the parties. Complex mergers which raise substantial anti-trust concerns will usually not be eligible for early termination.

If either agency believes or both agencies believe that a transaction involving the communications sector requires further analysis, then the body with responsibility for the relevant segment of the market affected by the merger becomes responsible for further investigation. If further information is necessary, additional information from the notifying parties may be requested. Such a request usually extends the waiting period for another 30 days (ten days in the case of a cash tender offer or a bankruptcy sale) from the date the parties comply with the request. Interested third parties may submit written comments or make a presentation about the effects of the proposed transaction to the DoJ or the FTC at any stage of the review process.

If, at the end of its review, the responsible body concludes that the transaction does not substantially lessen competition, or does not tend to create a monopoly, then it recommends that no further action is taken. If it believes a transaction does raise concerns then it may discuss terms of settlement, such as divestiture of certain assets or businesses, with the notifying parties. Details of any negotiated settlements must be published 
in the Federal Register and third parties must be given time to comment on their proposed terms. Additional procedures apply if the DoJ negotiates the settlement. Alternatively, the DoJ and FTC may elect to commence injunction proceedings in a US district court to stop the acquisition.

The DoJ has agreed the terms on which a number of mergers could proceed in the telecommunications sector, including, for example: Cingular Wireless's acquisition of AT\&T Wireless proposed in 2004; SBC Communications' acquisition of AT\&T in 2005; and Verizon's acquisition of MCI in the same year. The DoJ has rarely sought to injunct an acquisition in the telecommunications sector but it did seek to enjoin MCI Worldcom's acquisition of Sprint in 2000 and AT\&T's merger with T-Mobile USA in August 2011. Examples of mergers settled by the FTC include AOL/Time Warner (2000), TCI/Cablevision (1998), and TimeWarner/Turner Broadcasting (1996). When it becomes clear an agency will oppose a transaction, the notifying parties usually abandon it.

\subsubsection{Mergers and the FCC}

The FCC also has a significant amount of oversight of structural changes occurring in the telecommunications sector brought about by mergers, corporate reorganizations, and other ownership transactions that result in the 
transfer of control or assignment of a 1934 Act licence. Under the 1934 Act, prior approval of the FCC is required before authorizations and licences relating to common carriers, ${ }^{182}$ radio (both public and private), ${ }^{183}$ satellite earth stations, ${ }^{184}$ and submarine cable landings ${ }^{185}$ may be transferred.

Failure to obtain the FCC's prior permission may result in fines and other enforcement action. In some cases, however, pro forma transactions (transactions that do not result in a change of ultimate ownership) are permitted without prior FCC approval. Licensees must notify the FCC within 30 days of completion of the transaction. In 2003, the FCC further streamlined its assignment and transfer of control procedures-particularly with respect to spectrum leasing schemes — as part of a comprehensive initiative to encourage the development of secondary markets in spectrum usage rights. ${ }^{186}$

In all cases where prior approval is required, the FCC must be satisfied that the 'public interest, convenience and necessity' are served by the transfer of the relevant FCC authorization. The impact of the proposed licence transfer on competition in relevant markets is closely analysed by the FCC, although other factors, such as the potential effects of a transfer on universal service provision, national security, spectrum efficiency,

$18247 \mathrm{CFR} \S \S 63.03,63.04$, and 63.24.

18347 USC $\S 310(d)$.

18447 CFR $\$ 25.119$.

18547 CFR $§ 1.767$.

186 Promoting Efficient Use of Spectrum Through Elimination of Barriers to the Development of Secondary Markets, Second Report and Order, Order on Reconsideration, and Second Further Notice of Proposed Rulemaking, WT Docket No 00-230, FCC No 04-167, 19 FCC Rcd 17503 (2004). 
and technical innovation, are also typically considered. Each licence transfer is assessed on a case-by-case basis, and the procedures followed vary depending on the specific licence. In all cases, the parties to a transaction are encouraged to discuss the merger with FCC staff in advance of submitting an application. The FCC tries to complete its review of major transactions within 180 days of the publication of the FCC's notice about the transaction; however, the 180-day timetable may be extended in light of the complexity of the transaction. Interested third parties are normally given 30 days in which to file comments. The FCC issues its decision in writing. Unsuccessful applicants may challenge an FCC decision by way of judicial review. Because FCC approval requires a majority vote of its commissioners, controversial and large-scale mergers have often been approved with conditions that are either developed by the commissioners in order to reach consensus or proposed by the applicant in response to public opposition that might jeopardize the likelihood of receiving a majority vote. However, such practices have come under sharp criticism from some Republican members of the FCC, including now Chair Ajit Pai. They claim that these conditions do not relate to the merits of the transaction, but instead are designed to impose regulations that further the majority members' policy goals.

The FCC also has powers under $\S \S 7$ and 11 of the Clayton Act to block acquisitions of common carriers engaged in fixed and radio communications where the effect of the acquisition would be to substantially lessen competition or create a monopoly. In practice, these powers are rarely used and any action taken by the FCC is based on its powers set out in the Communications Act of 1934.

\subsection{CONSUMER PRIVACY MEASURES ${ }^{187}$}

187 See further Chapter 13. 
Federal communications privacy law seeks to protect individuals against unsolicited communications from business entities and telemarketers. It also imposes restrictions on the use of customer data acquired by telecommunications carriers. The law does not confer an absolute right of privacy on individuals. Rather, it seeks to balance the interests of individuals and the interests of commercial entities and telecommunications carriers, which enjoy constitutional protections of commercial speech. Communications privacy matters in the US are complicated by the distinction between telecommunications services and information services, because different regulatory bodies may become involved depending the type of service at issue.

\subsubsection{Legal constraints on regulation of telemarketers}

In the US, solicitation by telemarketers is a type of commercial speech, protected by the First Amendment of the Constitution. Congress may regulate commercial speech, however, provided such regulation meets the four-part test set out in Central Hudson Gas \& Elec Corp v Public Service Commission (447 US 557 (1980)). If the commercial speech concerns illegal activity or is misleading, then the government may freely regulate the speech. If, however, the speech is not illegal or misleading, then the government must be able to demonstrate that it has a substantial interest in regulating the speech, the regulation it seeks to impose directly and materially advances the government's interest, and is narrowly tailored. In Cincinnati v Discovery Network, Inc (507 US 410 (1993)), the Supreme Court held that a regulation is 'narrowly tailored' if it involves a careful calculation of the costs and benefits associated with the regulation and the burden on commercial speech it imposes.

\subsubsection{Unsolicited calls and texts}


Congress first addressed the problem of unsolicited calls by adopting the Telephone Consumer Protection Act of 1991 (TCPA). ${ }^{188}$ The TCPA gave the FCC authority to adopt regulations to stop unwanted telephone solicitations in order to protect the privacy rights of residential telephone subscribers. The TCPA also imposed restrictions, subject to certain exceptions adopted by the FCC, on the use of automated telephone equipment.

When adopting regulations to implement the TCPA in $1992,{ }^{189}$ the FCC mandated the use of company-specific do-not-call lists (as opposed to a national do-not-call list) that allowed subscribers to indicate whether or not they wished to receive pre-recorded telemarketing calls to their fixed home numbers from solicitors on a company-by-company basis. Companies were expected to comply with subscriber requests, although companies that had established business relationships with subscribers on the list and tax-exempt non-profit organisations were exempt from the rules. Companies engaged in telemarketing were permitted to ring subscribers not on their do-not-call lists no earlier than 8 am and no later than $9 \mathrm{pm}$; and had to identify themselves to subscribers. Certain prohibitions against autodialed calls were also imposed.

By 2002, it was the clear the FCC's approach was not effectively balancing legitimate business interests and privacy concerns. The Commission had received thousands of complaints about an ever increasing amount of unsolicited calls, the use of new technologies, and practices by telemarketers to circumvent the requirements of the TCPA. In the absence of any action by the FCC, the Federal Trade Commission (FTC), which has powers to regulate some telemarketers under the Telemarketing Consumer Fraud and Abuse Prevention Act, ${ }^{190}$ adopted an order establishing a federal do-not-call list. Several state legislatures also established or were in the

188 Pub L No 102-243, 105 Stat 2394 (1991) (codified at 47 USC §227).

${ }^{189}$ Rules and Regulations Implementing the Telephone Consumer Protection Act of 1991, Report and Order, CC Docket No 92-90, FCC No 03-153, 7 FCC Rcd 8752 (1992).

19015 USC $\S \S 6101-08$. See also the FTC’s Telemarketing Sales Rules. 16 CFR $\S 310.1-310.9$. 
process of establishing statewide do-not-call lists. Faced with this situation, Congress enacted new legislation, the Do-Not-Call Implementation Act, ${ }^{191}$ in March 2003, that gave the FTC the authority to collect the funds necessary to implement its do-not-call list, required the FCC to finalize its Telephone Consumer Protection Act rulemaking proceeding maximising consistency with the FTC's rules, and called for annual reports from both the FTC and FCC.

The FCC's Report and Order of 26 June 2003 set out rules that supplemented the FTC's own telemarketing rules. Collectively, the FCC and FTC rules established a single national database of fixed and mobile telephone numbers of subscribers who object to receiving telephone solicitations. The FCC's 26 June 2003 Report and Order also adopted more stringent measures to combat the increased use of predictive dialers and required callers to display caller identification; and concluded that the TCPA protects wireless subscribers from receiving unwanted voice calls as well as text messages. ${ }^{192}$ It is worth noting that the FCC's jurisdiction over telemarketers is broader than the FTC's jurisdiction. The FTC has no oversight of common carriers, ${ }^{193}$ banks, credit unions, savings and loans, insurance providers, airlines and intrastate telemarketing calls. ${ }^{194}$ The FCC rules apply to all of these entities as well as interstate and intrastate telemarketing calls. The FTC has effectively become the lead agency for administration and promotion of the registry, as well as the key source of public outreach and consumer

191 Pub L No 108-10, 117 Stat 557 (2003).

${ }^{192}$ On the issue of unwanted text messages, see also Satterfield $v$ Simon \& Schuster, 569 F 3d 946 ( $9^{\text {th }}$ Cir 2009) and Rules and Regulations Implementing the Telephone Consumer Protection Act of 1991, Declaratory Ruling and Order, CG Docket Nos 02-278, WC Docket No 07-135, FCC No 15-72, 30 FCC Rcd 7961 (2015).

${ }^{193}$ See further Section 5.4.3. above.

19415 USC $\S 45(a)(2)$. 
support in this area. Because of the FCC's more extensive jurisdiction in this area, however, the FCC, which has the power to impose fines on rule violators, has taken a strong enforcement role.

As a result of the scheme, fixed and wireless subscribers now have three options to preserve their privacy by:

1. adding their numbers to the national do-not-call registry;

2. continuing to make do-not-call requests of companies on a case-by-case basis; or

3. registering on the national list and providing specific companies with permission to ring them.

If telemarketers do not respect the wishes of subscribers, subscribers may complain to the FCC or sue the offending party in state court.

The FCC has clarified and/or modified its rules implementing the federal do-not-call-list and related TCPA provisions over time, ${ }^{195}$ although several modifications were adopted in response to changes made by the FTC to its own telemarketing rules. For example, the 26 June 2003 Report and Order exempted companies that had established business relationships with customers from respecting the do-not-call list. However, this exemption was abolished in 2012 and replaced with a requirement that the express written consent of the called party has to be obtained prior to making a call. Moreover, since 2012, the FCC requires callers to provide called parties with an automated, interactive mechanism whereby they can opt out of receiving pre-recorded messages. Similarly, telemarketers cannot abandon more than 3 per cent of calls answered by customers for the duration of any calling campaign. ${ }^{196}$

\footnotetext{
${ }^{195}$ See, eg, Rules and Regulations Implementing the Telephone Consumer Protection Act of 1991, above n 192.

${ }^{196}$ See Rules and Regulations Implementing the Telephone Consumer Protection Act of 1991, Report and Order, CG Docket No 02-278, FCC No 12-21,27 FCC Rcd 1830 (2012).
} 
Federal legislation has also resulted in modifications to the do-not-call list and related TCPA provisions. When the Do Not Call Implementation Act was adopted, numbers could be kept on the list for only a limited period of time. However, in 2008, Congress decided numbers could be kept on the list indefinitely. ${ }^{197}$ In 2009 , Congress passed the Truth in Caller ID Act. This legislation responded to concerns that it had become increasingly easy for parties to alter the phone number displayed with a call (the 'Caller ID') to make it appear that the call was coming from any number, and that such spoofing activity was being used to trick and defraud consumers. In implementing this legislation, the FCC prohibited persons from causing the display of inaccurate caller identification information for the purposes of defrauding, harming, or otherwise obtaining anything of value, and applied the rule to calls made using any telecommunications or interconnected VoIP service. ${ }^{198}$ Under these rules, callers may continue to choose to block their call information, although telemarketers must transmit and display a valid number in conjunction with their calls. In November 2017, the FCC adopted additional rules to combat the continuing problems of spoofing and unwanted telemarketing calls. ${ }^{199}$ In particular, it now expressly permits providers of voice services to block calls originating from any number at the request of a subscriber and calls originating from certain numbers specified by the FCC. The new rules follow requests for legal clarification from the 'Robocall Strike Force,' ${ }^{200}$ a body established by and comprised of industry representatives to address the problems of spoofing and unwanted telemarketing calls.

\footnotetext{
${ }^{197}$ Do Not Call Improvement Act of 2007, Pub L No 110-187, 122 Stat 633 (2008).

198 Rules and Regulations Implementing the Truth in Caller ID Act of 2009, Report and Order, WC Docket No 11-39, FCC No 11-100, 26 FCC Rcd 9114 (2011).
}

\footnotetext{
${ }^{199}$ Advanced Methods to Target and Eliminate Unlawful Robocalls, Report and Order and Further Notice of Proposed Rulemaking, CG Docket No 17-59, FCC No 17-151, 32 FCC Rcd 9706 (2017).

${ }^{200}$ See, eg, Robocall Strike Force Report (26 October 2016) (available at https://transition.fcc.gov/cgb/Robocall-StrikeForce-Final-Report.pdf).
} 


\subsubsection{Unsolicited faxes}

The TCPA, as amended by the Junk Fax Prevention Act ${ }^{201}$ enacted in 2005, makes it unlawful for any person within the US, or any person outside the US if the recipient is within the US, to use a fax machine, computer or other device to send unsolicited advertisements to a fax machine. The prohibition on sending unsolicited fax advertisements does not apply where recipients have given senders permission; or senders have an established business relationship and recipients voluntarily provide them with their fax numbers or have otherwise made their fax numbers publicly available in a directory, advertisement or website. The Act requires any person sending an unsolicted fax advertisement under an exemption to include a notice that complies with any applicable rules mandated by the FCC. Current rules require senders to inform recipients of their ability to and the means by which they can avoid unsolicited faxes. ${ }^{202}$ In 2006, the FCC imposed similar opt-out requirements for persons sending solicited fax advertisements, a decision it confirmed in $2014,{ }^{203}$ but the requirements were found to be unlawful in March 2017. ${ }^{204}$ As is the case for unsolicited calls and texts, failure to comply with the relevant provisions of the TCPA may result in fines by the FCC. Violations of the fax rules also give subscribers a right to sue the offending party in state court. Public dissatisfaction with junk faxes, additional Congressional oversight, and continued FCC interest in this area have resulted in a steady stream of FCC enforcement actions against violators. While forfeitures are often in the thousands of dollars, large-scale violations have resulted in forfeitures as high as US\$5 million against a single company.

\footnotetext{
${ }^{201}$ Pub L No 109-21, 119 Stat 359 (2005).

${ }^{202}$ See Rules and Regulations Implementing the Telephone Consumer Protection Act of 1991, Report and Order and Third Order on Reconsideration, CG Docket Nos 02-278, 05-338, FCC No 06-42, 21 FCC Rcd 3787 (2006); 47 CFR $\S 64.1200(\mathrm{a})(4)$.
}

${ }^{203}$ Rules and Regulations Implementing the Telephone Consumer Protection Act of 1991, Order, CG Docket Nos 02278, 05-338, FCC No 14-164, 29 FCC Rcd 13998 (2014).

${ }^{204}$ See Bais Yaakov of Spring Valley v FCC, No. 14-1234 (DC Cir Mar 31, 2017). 


\subsection{Unsolicited email}

The provisions of the TCPA do not apply to unsolicited email that advertises or promotes commercial products and services. To address the loopholes in the legislation and consumer concerns about 'spam', Congress enacted the Controlling the Assault of Non-Solicited Pornography and Marketing Act of 2003 or the CANSPAM Act of $2003 .{ }^{205}$ The Act came into force on 1 January 2004 and makes it unlawful to send to a computer commercial email that contains deceptive or misleading subject headings or false information about the origin of an email. It requires senders of commercial emails to notify recipients that such emails are advertisements, to provide the sender's physical postal address, and to give recipients an opportunity to 'opt-out' of receiving commercial emails in the future. The opt-out notice must contain a return email address or other internet-based mechanism by which email recipients can indicate they do not wish to receive future emails. The opt-out mechanism selected by a sender must remain active for 30 days. In addition, the Act prohibits senders and anyone acting on their behalf from sending commercial emails to a recipient who requests not to receive subsequent emails. The prohibition begins ten business days from the date of the recipient's request. Violation of the civil provisions of the Act may lead to injunctive relief and/or statutory fines. Breaches of criminal law may lead to imprisonment and fines up to US\$6 million. The FTC has primary responsibility for implementing and enforcing the legislation.

In addition, the FCC adopted rules that took effect in 2005 that prohibit the sending of unwanted commercial email messages to wireless devices without the prior permission of subscribers. ${ }^{206}$ To facilitate compliance with the rules, it also established a list of domain names typically used to send messages to wireless

205 Pub L No 108-187, 117 Stat 2699 (2003).

${ }^{206}$ Rules and Regulations Implementing the Controlling the Assault of Non-Solicited Pornography and Marketing Act of 2002, Order, CG Docket Nos 04-53, C02-278, FCC 04-194, 19 FCC Rcd 15927 (2004). 
devices. The CAN-SPAM Act of 2003 directed the FCC to issue regulations protecting consumers from 'unwanted mobile service commercial messages'.

\subsubsection{Customer proprietary information}

Federal legislation imposes duties on telecommunications carriers to respect the confidentiality of the "proprietary information' of their customers. Section 222(c) of the 1934 Act, added by the Telecommunications Act of 1996 and amended by the Wireless Communications and Public Safety Act of $1999,{ }^{207}$ also sets forth a framework regulating the use of 'customer proprietary network information' (CPNI) by telecommunications carriers. The term 'telecommunications carrier' means any provider of a telecommunications service. CPNI is defined in $\S 222(\mathrm{~h})(1)$ of the 1934 Act and includes any information, made available to a carrier by a customer by virtue of the carrier-customer relationship, that relates to the quantity, technical configuration, type, destination, location, and amount of use of a telecommunications service subscribed to by any customer; and information contained in a customer's bill. CPNI expressly excludes, however, 'subscriber list information'—information identifying the names of subscribers, their telephone numbers, or addresses that are published in a directory. Under the Act, a telecommunications carrier may use, disclose, or permit access to 'individually identifiable' CPNI only as required by law or with the approval of their customers. In addition, §222(c)(1) of the 1934 Act permits a carrier to use, disclose, or permit access to individually identifiable CPNI to provide the telecommunications service from which such information is derived; or to provide services necessary to, or used in, the provision of that telecommunications service.

There are, however, a number of exceptions to the confidentiality obligations of telecommunications carriers. Use, disclosure, and access to CPNI is permissible by a carrier, either directly or indirectly through its agents,

207 Pub L No 106-81, 113 Stat 1286 (1999). 
for such purposes as billing and debt collection, the protection of a carrier's rights and property, the provision of telemarketing and referral services requested by subscribers, and the provision of call location information concerning the users of commercial mobile services in specified emergency situations. Disclosure of CPNI upon the affirmative written request by a customer is permitted. CPNI that is 'aggregated' and does not contain individually identifiable CPNI may be disclosed to any party. ${ }^{208}$ Moreover, telecommunications carriers that provide telephone exchange services must disclose subscriber list information to any person for the purpose of publishing telephone directories. ${ }^{209}$

The FCC has adopted and revised rules implementing these substantive confidentiality provisions on numerous occasions since 1996 to reflect changes in technology and market practices. In 2007, for example, the FCC extended its customer proprietary information rules to providers of interconnected VoIP services. ${ }^{210}$ The FCC also revisited the rules in 2016 following its decision to reclassify broadband services as telecommunications services. ${ }^{211}$ When broadband services were treated as information services, the FCC had no authority to regulate providers of these services under $\S 222$ of the 1934 Act, because its jurisdiction is limited to telecommunications carriers (as defined). The privacy practices of information service providers and other entities providing broadband services were instead regulated by the FTC. The FTC is responsible for enforcing $\S 5$ of the Federal Trade

\footnotetext{
20847 USC $\S 222(d)$.

${ }^{209} 47$ USC $\$ 222(e)$.

${ }^{210}$ Implementation of the Telecommunications Act of 1996, Report and Order and Further Notice of Proposed Rulemaking, CC Docket No 96-115, WC Docket No 04-36, FCC No 07-22, 22 FCC Rcd 6927 (2007).

${ }^{211}$ See Section 5.2.5.2.
} 
Commission Act, a provision that prohibits unfair and deceptive trade practices, and one that the FTC has actively used to promote online privacy as part of its broader mandate to protect consumer interests. ${ }^{212}$ When the FCC reclassified broadband services as telecommunications services, providers of broadband services became telecommunications carriers and the FTC lost its authority to regulate the privacy practices of these entities. The FTC has no jurisdiction over common carriers or entities providing telecommunications services. ${ }^{213}$

The rules the Commission adopted in 2016, shortly before President Obama left office, harmonised the privacy rules applicable to all telecommunications carriers. They imposed notice, customer approval, data security and data breach notification obligations on broadband providers. They also provided for protection of precise geo-location information belonging to customers. ${ }^{214}$ However, the rules are no longer in effect. On 1 March 2017, following the inauguration of President Trump and the receipt of numerous petitions for reconsideration of the rules from industry, the Commission, operating with only three Commissioners, issued a temporary stay of the data security obligation, which required telecommunications carriers to take reasonable measures to protect customer proprietary information from unauthorized use, disclosure and access. ${ }^{215}$ The stay was to remain in place until the Commission was able to reconsider the FCC's rules in full, but on 3 April 2017, the Republican-controlled House of Representatives and Senate adopted a joint resolution of disapproval under the Congressional Review Act that President Trump signed the same day. The resolution prevented the 2016 rules from taking effect. ${ }^{216}$

\footnotetext{
${ }^{212}$ For more information, see, eg, Daniel J Solove and Woodrow Hartzog, 'The FTC and the New Common Law of Privacy' (2014) 114 Columbia Law Review 583.

${ }^{213}$ See also Section 5.4.3.

${ }^{214}$ Protecting the Privacy of Customers of Broadband and Other Telecommunications Services, Report and Order, WC Docket No 16-106, FCC 16-148, 32 FCC Rcd 13911 (2016).

${ }^{215}$ Protecting the Privacy of Customers of Broadband and Other Telecommunications Services, Order Granting Stay Petition in Part, WC Docket No 16-106, FCC No 17-19, 32 FCC Red 1793 (2017).

${ }^{216}$ The resolution also prevents the FCC from reissuing the rules in substantially the same form unless specifically authorised by a law enacted after the date of the joint resolution.
} 
Adoption of the 2016 rules was so controversial because they were more onerous than the approach applied by the FTC to information service providers such as Google, Skype and other so-called 'edge providers', providers of websites, web-based email, applications and search engines, even though it had been argued that these entities pose a greater threat to consumer privacy than broadband providers. In addition, the FTC, led by its acting chair Maureen K Ohlausen, appointed to that role by President Trump, had argued that the FCC's rules resulted in two different privacy frameworks, which was likely to generate confusion for consumers.

As a result of the Commission's decision to reclassify broadband services as information services in December 2017, broadband service providers will again be subject to the jurisdiction of the FTC and must therefore comply with $\S 5$ of the Federal Trade Commission Act and related case law. Telecommunications carriers providing telecommunications services remain subject to the jurisdiction of the FCC and must comply with the customer proprietary information rules adopted by the FCC prior to 2016 and codified in 47 CFR $\S \S 64.2001$ 64.2012. However, there remains some concern that the FTC's privacy framework is sufficiently robust to protect consumer data because it is not specifically tailored to the practices of broadband service providers.

\subsection{CONCLUDING REMARKS}

It is difficult to predict how the US communications regulatory framework will evolve over the next few years. It is clear that the FCC has an important role in ensuring that robust communications services are made available throughout the US, and will face numerous regulatory challenges raised by the on-going transition from a PSTN to a wholly IP environment; as well as other market developments that have been highlighted in this chapter. The rapid evolution of technology and changes to how communciations services are used will undoubtedly present additional policy challenges that cannot be readily forseen. It is also becoming increasingly clear that as a result of Ajit Pai's appointment as chair of the Commission in January 2017 and the Republican 
commissioners' acquisition of majority control of the FCC, there has been a move away from the more consumer-oriented approach that characterised the Commission during the presidency of President Obama. The Commission has shifted its emphasis to the free-market, calling for evidence-based decision-making and more rigorous economic analysis before regulatory obligations are imposed. However, it is far too soon to determine the precise effect (positive or negative) this new approach is likely to have over the long term. In addition, the possibility of Congress intervening and rewriting the legislative framework that governs the US communications sector cannot be discounted. It has been more than 20 years since the last comprehensive communications-related legislation, the 1996 Act, was enacted, and many aspects of the communications environment have changed dramatically in the intervening time. At the time of writing, Republicans, by virtue of their control of both the House and Senate, have the power to alter the regulatory mandate of the FCC and other communications-related agencies if they so desire. 